\title{
RESÍDUOS DE BROMOPROPILATO E CLOROBENZILATO EM CASCAS E POLPAS DE LARANJAS 'VALÊNCIA' DETERMINADOS POR CROMATOGRAFIA EM FASE GASOSA
}

MARCOS APARECIDO PIZANO

Engenheiro Agrōnomo

Orientador: Prof. Dr. GILBERTO CASADEI DE BATISTA

Dissertação apresentada à Escola Superior de Agricultura "Luiz de Queiroz", da Universidade de São Paulo, para obtenção do título de Mestre em Ciẻncias Biológicas, Área de Concentração: Entomologia.

\author{
$P$ I R A C I C A B A \\ Estado de São Paulo - Brasil \\ Outubro - 1988
}


Pizano, Marcos Aparecido

P695r Residuos de bromopropilato e clorobenzilato em cascas e polpas de laranjas "valência" determinados por cromotografia em fase gasosa. Piracicaba, 1988 .

$101 \mathrm{p}$. ilus.

Diss.(Mestre) - ESALQ

Bibliografia.

1. Cromatografia gasosa 2. Laranja valência Praga - Controle 3. Pesticida em laranja valência Resíduo - Análise I. Escola Superior de Agricultura Luiz de Queiroz, Piracicaba

$\operatorname{CDD} 634.31$ 


\section{RESÍDUOS DE BROMOPROPILATO E CLOROBENZILATO EM CASCAS \\ E POLPAS DE LARANJAS 'VALÊNCIA' DETERMINADOS POR. CROMATOGRAFIA EM FASE GASOSA}

MARCOS APARECIDO PIZANO

Aprovada em: 10.04 .1989

Comissão julgadora:

Prof. Dr. Gilberto Casadei de Batista

ESALQ/USP

Prof. Dr. Renê Luis de O. Regitano

ESAL

Dr. Joaquim Teófilo Sobrinho

IAC

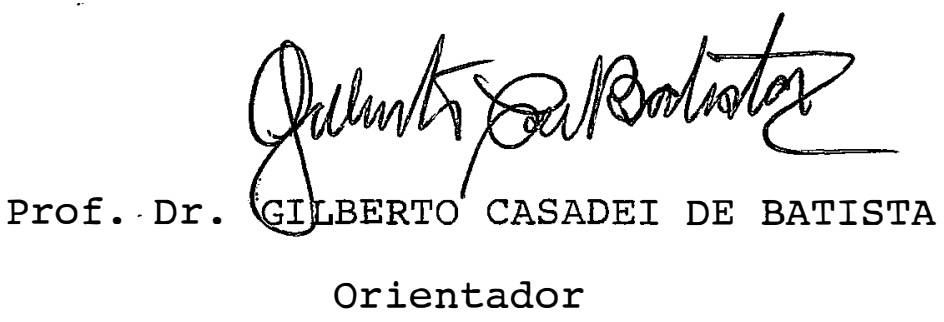


A minha esposa VERA LUCTA $e$ à minha filha JULIANA

\section{DEDICO.}

AOs meus pais FRANCISCO $e$ IRENE $e$ aos meus irmãos DORIVAL e OSVALDO que me incentivaram a todo momento 


\section{AGRADECIMENTOS}

- Ao Prof. Dr. Gilberto Casadei de Batista, pela segura e valiosa orientação, apoio e revisão dos originais ;

- $\bar{A}$ Fundação de Amparo à Pesquisa do Estado de são Paulo (FAPESP), pela concessão de bolsa de estudo durante a realização do curso;

- Ao Dr. Joaquim Teófilo Sobrinho, chefe da Estação Experimental de Citricultura do Instituto Agronōmico de Campinas, pelas condições proporcionadas no desenvolvimento deste trabalho;

- Ao Programa Nacional de Melhoramento da Cana-de-agúcar (PLANALSUCAR), COSUL, nas pessoas do Dr. Antonio Hermínio Pinazza e Dr. José Carlos Casagrande, pelas condições oferecidas na redação deste trabalho;

- Ao Sr. Luís Roberto Boscariol pela colaboração prestada na execução das anālises;

- Aos Professores do Departamento de Entomologia da Escola Superior de Agricultura "Luiz de "Queiroz", da Universidade de São Paulo, pelos ensinamentos e consideração; 
- Aos colegas do setor de Entomologia do PLANALSUCAR, COSUL, pelo incentivo e amizade;

- Ao Dr. Renê Luis de Oliveira Rigitano, professor adjunto do Departamento de Fitossanidade da Escola Superior de Agricultura de Lavras-MG, pelo apoio e estímulo;

- À Srta. Sonia Aparecida Fachini, pelos serviços datilográficos e amizade. 


\section{SUMÁRIO}

Página

IISTA DE FIGURAS .................... vii

IISTA DE TABELAS $\ldots \ldots \ldots \ldots \ldots \ldots \ldots \ldots \ldots \ldots \ldots \ldots \ldots$

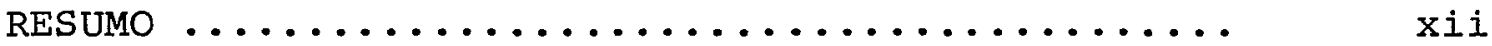

SUMMARY $\ldots \ldots \ldots \ldots \ldots \ldots \ldots \ldots \ldots \ldots \ldots \ldots \ldots \ldots \ldots \ldots$

1. INTRODUÇÃO $\ldots \ldots \ldots \ldots \ldots \ldots \ldots \ldots \ldots \ldots \ldots \ldots \ldots$

2. REVISÃo DE LITERATURA ............................ 5

2.1. Aspectos básicos no estudo de residuo de defensivos agrícolas ............ 5

2.2. Determinação dos residuos de defensivos agricolas em frutas citricas .........

2.3. Residuos de defensivos agrícolas em produtos citricos ................

2.3.1. Sucos de frutas citricas ......

2.3.2. Rações para gado ........... 36

2.4. Bromopropilato ................ 38

2.4.1. Residuos de bromopropilato em

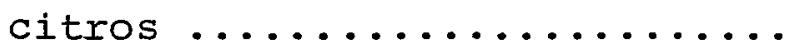

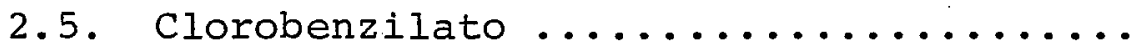

2.5.1. Residuos de clorobenzilato em citros ................

3. MATERIAIS E MÉTODOS ..................... 52

3.1. Experimento de campo ............. 52 
3.1.1. Experimento 1-Bromopropilato..

3.1.2. Experimento 2-Clorobenzilato..

3.2. Limites de detecção, porcentagens de recuperação e descrição do método de anáIise de resíduos de bromopropilato e clorobenzilato em casca e polpa de la-

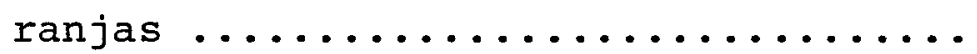

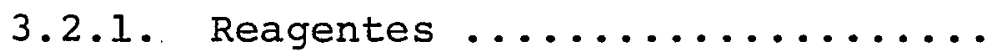

3.2.2. Aparelhos, vidraria e outros ma-

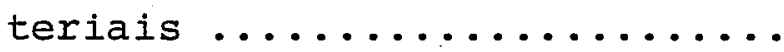

3.2.3. Descrição do método de análise de residuos de bromopropilato e de clorobenzilato em casca e polpa de laranjas............

4. RESULTADOS E DISCUSSÃO .............

4.1. Limites de deteção e porcentagens de recuperação do método .............

4.2. Residuos de bromopropilato em cascas e polpas de laranjas 'Valência' ........

4.3. Resíduos de clorobenzilato em cascas e polpas dè laranjas 'Valência' ........

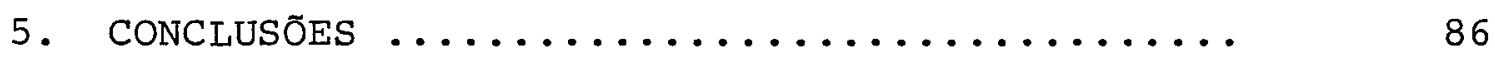

REFERENCIAS BIBLIOGRĀFICAS $\ldots \ldots \ldots \ldots \ldots \ldots \ldots$ 
vii.

\section{LISTA DE FIGURAS}

Figura

Pāgina

1 Residuos de dieldrin e chlorfenson em frutas citricas (GUNTHER \& BLINN, 1956) ...

2 Curvas de degradação (A e B) e persistência (C) de inseticidas em folhas e frutos de laranjeiras. A, DDT em folhas; B e C, p-clorofenil-p-clorobenzenesulfonato em frutos. (GUNTHER \& BLINN, 1955) ......

3 Curvas de degradação (B) e persistência (C) do Malation (1,4 kg PM 25/380 litros) sobre e no interior de cascas de laranjas 'Valência' (GUNTHER \& WESTLAKE, 1968 citado por GUNTHER, 1969) .............

4 Desenvolvimento esquemático de fruto de citros em três estägios de crescimento (DUPUIS, 1975) $\ldots \ldots \ldots \ldots \ldots \ldots \ldots \ldots \ldots \ldots$

5 Esquema simplificado do processamento de frutos de citros (KESTERSON \& BRADDOCK,

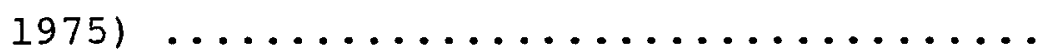


viii.

Figura

Pāgina

6 Curvas de persistēncia dos residuos de clorobenzilato, determinados pelos métodos colorimétrico e ultravioleta, em cascas de limões Eureka, apōs a aplicação de uma formulação pó molhāvel a 25\% na dosagem de $1,8 \mathrm{~kg} / 380$ litros (GUNTHER, 1969)

7 Descascador de frutos de citros, construído com alumínio. Escala 1:1 ......

8 Cromatogramas do padrão e da amostra de casca fortificada com 0,01 ppm de bromo-

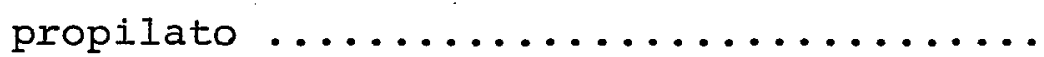

9 Cromatogramas do padrão e da amostra de polpa fortificada com 0,01 ppm de bromo-

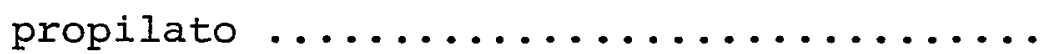

10 Cromatogramas de amostras testemunhas de cascas e polpas (215\%C - "bromopropilato")

11 Cromatogramas do padrão e da amostra de casca fortificada com 0,5 ppm de cloro-

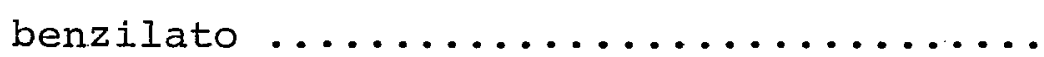

12 Cromatogramas do padrão e da amostra de polpa fortificada com 0,5 ppm de cloro-

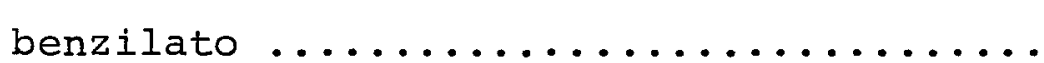


Figura

13 Cromatogramas de amostras testemunhas de cascas e polpas (1909C - "clorobenzilato")

14. Curvas de degradação e persistência de residuos de bromopropilato sobre e no interior de cascas de laranjas 'valēncia', provenientes de plantas pulverizadas com

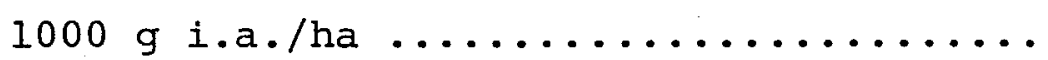

15 Curvas de degradação e persistência de residuos de bromopropilato sobre e no interior de cascas de laranjas 'Valência', provenientes de plantas pulverizadas com

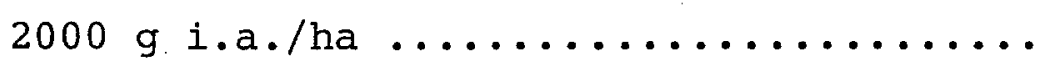

16 Curva de persistência de resíduos de clorobenzilato sobre e no interior de cascas de laranjas 'Valência', provenientes de plantas pulverizadas com $500 \mathrm{~g} \mathrm{i.a./ha} \mathrm{..}$

17 Curva de persistência de residuos de clorobenzilato sobre e no interior de cascas de laranjas 'Valência', provenientes de plantas pulverizadas com $1000 \mathrm{~g} \mathrm{i.a./ha.}$ 


\section{LISTA DE TABELAS}

Tabela

Página

1 Valores de meia-vida de persistēncia (dias) de alguns defensivos agrícolas sobre e no interior de cascas de frutas cítricas tratadas no campo ............

2 Exemplos de tolerâncias nacionais (expressas em ppm na fruta toda) e período de carência (em dias). (DUPUIS, 1975) ..

3 Residuos de defensivos agrícolas em ração para gado proveniente de frutas tratadas no campo $\ldots \ldots \ldots \ldots \ldots \ldots \ldots \ldots \ldots . . . \ldots$

4 Dados de residuos de bromopropilato em diferentes culturas, considerando diversos intervalos entre aplicação e amostragem $\ldots \ldots \ldots \ldots \ldots \ldots \ldots \ldots \ldots \ldots \ldots$

5 Porcentagens de recuperação de bromopropilato e clorobenzilato, pelo método de RIBAS (1974) em casca e polpa de laranjas fortificadas ..................

6 Residuos de bromopropilato em cascas e polpas de laranjas 'Valência' provenientes de plantas pulverizadas com $1000 \mathrm{gi.a./ha}$ (tratamento A) e $2000 \mathrm{~g}$ i.a./ha (tratamento в) $\ldots \ldots \ldots \ldots \ldots \ldots \ldots \ldots \ldots \ldots$ 
xi.

Tabela

Pāgina

7 Residuos de clorobenzilato em cascas e polpas de laranjas 'Valência' provenientes de plantas pulverizadas com $500 \mathrm{~g}$ i.a./ha (tratamento A) e $1000 \mathrm{~g} \mathrm{i.a./ha} \mathrm{(trata-}$ mento B) $\ldots \ldots \ldots \ldots \ldots \ldots \ldots \ldots \ldots$ 
xii.

\title{
RESÍDUOS DE BROMOPROPILATO E CLOROBENZILATO EM CASCAS E POLPAS DE LARANJAS 'VALÊNCIA' DETERMINADOS POR CROMATOGRAFIA EM FASE GASOSA
}

\author{
Autor: MARCOS APARECIDO PIZANO \\ Orientador: PROF. DR. GILBERTO CASADEI DE BATISTA
}

\section{RESUMO}

No presente trabalho, procurou-se estudar a degradação e persistência dos resíduos de bromopropilato (Neoron $50 \mathrm{CE}$ ) e clorobenzilato (Akar 500 EC) em cascas e polpas de laranjas.

o experimento foi instalado em pomar de laranjeiras da variedade 'Valência', com doze anos de idade, localizado na Estação Experimental de Citricultura do Instituto Agronômico de Campinas, em Cordeirópolis-sp.

Os produtos foram aplicados no início do período de maturação dos frutos, nas dosagens de 1000 e 2000 g i.a./ha de bromopropilato, correspondendo a 250 e $500 \mathrm{ml}$ de Neoron $50 \mathrm{CE}$, respectivamente, por 100 litros de água e 500 e $1000 \mathrm{~g}$ i.a./ha de clorobenzilato, o que foi representado por 84 e $168 \mathrm{ml}$ de Akar 500 EC, respectivamente, por 100 litros de água. A aplicação realizou-se com o auxílio de um pulverizador costal motorizado. os frutos foram 
amostrados aos 3, 7, 15, 24, 38, 59 e 100 dias após o tratamento para o bromopropilato e aos $3,7,15,25,42,60$ e 100 dias para o dlorobenzilato, sendo as cascas e polpas analisadas separadamente.

o método empregado nas anālises foi basicamente aquele de RIBAS (1974) e constou de extração com acetonitrilo e purificação através de partição em éter de petróleo. Para limpeza do extrato, utilizou-se coluna de florisil, sendo a eluição efetuada com uma mistura de éter de petróleo e éter etílico. Esse extrato purificado foi concentrado e injetado em cromatógrafo de gás, marca CG, modelo 3700 , equipado com detector de captura de elétrons (Niquel-Ni ${ }^{63}$ ) e coluna cromatogrä́fica de vidro $(1,2 \mathrm{~m}$ de comprimento e 1/8" de diâmetro) empacotada com 2,5\% de SE-30/ Chromosorb WHP.

Os limites de detecção obtidos para o método foram de 0,005 ppm para bromopropilato em casca e polpa e 0,1 ppm para clorobenzilato nos dois substratos. As porcentagens de recuperação em amostras fortificadas com diferentes concentrações variaram de 79 a 113\% para bromopropilato e de 71 a $98 \%$ para clorobenzilato.

Os valores de meia-vida de persistência dos compostos nas cascas foram 83 e 89 dias para bromopropilato e 63 e 59 dias para clorobenzilato, respectivamente para a menor e maior dosagens empregadas, indicando que os residuos de bromopropilato são mais lentamente degradados que 
aqueles de clorobenzilato.

Nas análises de polpas foram detectados residuos de bromopropilato em todas as coletas, indicando niveis variáveis de 0,027 a $0,120 \mathrm{ppm}$ e de 0,058 a $0,430 \mathrm{ppm}$ nas amostras que receberam 1000 e $2000 \mathrm{~g} \mathrm{i.a./ha} \mathrm{de} \mathrm{bromo-}$ propilato, respectivamente. No caso do clorobenzilato não foram detectados resíduos acima do limite de deteç̧ão, mostrando ocorrer uma insignificante, ou talvez nula, penetracão dos resíduos desse produto nas partes comestiveis dos frutos.

Considerando que os limites de tolerância para defensivos agrícolas em frutas citricas são estabelecidos com base na fruta toda (caso de bromopropilato e clorobenzilatol e que a Secretaria Nacional de Vigilāncia Sanitária do Ministério da Saúde estabeleceu tolerâncias de 5 e 1 ppm e períodos de carência de 21 e 5 dias, respectivamente para bromopropilato e clorobenzilato, os residuos dos dois compostos não foram superiores aos limites de tolerâncias desde a primeira amostragem ( 3 dias após a aplicação). 
$\mathrm{xV}$.

\section{BROMOPROPYLATE AND CHLOROBENZILATE RESIDUES IN 'VALENCIA' ORANGE PEEL AND PULP DETERMINED BY GAS CHROMATOGRAPHY}

Author: MARCOS APARECIDO PIZANO

Adviser: PROF. DR. GILBERTO CASADEI DE BATISTA

\section{SUMMARY}

The objective of this study was to know the degradation and persistence of bromopropylate (Neoron $50 \mathrm{EC}$ ) and chlorobenzilate (Akar 500 EC) residues in peel and pulp of citrus fruits. The experiment was carried out in an orchard of orange 'Valēncia' variety, ten years old, locatted at Citrus Experimental Station "Instituto Agronômico de Campinas", Cordeirópolis-sP. Dosages of 1000 and $2000 \mathrm{~g}$ a.i./ha of bromopropylate, corresponding to 250 and $500 \mathrm{ml}$ of Neoron 50 EC per 100 liter of water respectively, and 500 and $1000 \mathrm{~g} \mathrm{a.i./ha} \mathrm{of} \mathrm{chlorobenzilate} \mathrm{corresponding} \mathrm{to}$ 84 and $168 \mathrm{ml}$ of Akar 500 EC respectively, were applied at the beginning of the ripening period of the fruits. At 3 , $7,15,24,38,59$ and 100 days after bromopropylate application and $3,7,15,25,42,60$ and 100 days after chlorobenzilate application, fruits were sampled for analysis of peel and pulp. The method used was adapted from that des- 
xvi.

cribed by RIBAS (1974). The residues were extracted with acetonitrile and, after partition with petroleum ether, the extracts were cleaned up using a florisil column, being the elution made with a mixture of petroleum ether and diethyl ether. This purified extract was concentrated and injected in a gas chromatograph. The limits of detection obtained were $0.005 \mathrm{ppm}$ of bromopropylate in peel and pulp and $0.1 \mathrm{ppm}$ of chlorobenzilate in both substrates. The percentages of recovery in fortified samples with different concentrations ranged from 79 to $113 \%$ for bromopropylate and from 71 to $98 \%$ for chlorobenzilate. The half-life values of persistence in peels showed that the bromopropylate residues (83 and 89 days, for 1000 and $2000 \mathrm{~g} \mathrm{a.i./ha} \mathrm{doses} \mathrm{respec-}$ tively) are more persistent than chlorobenzilate residues 163 and 59 days, for 500 and $1000 \mathrm{~g} \mathrm{a.i./ha} \mathrm{doses} \mathrm{respecti-}$ vely). In pulp samples, bromopropylate residues throught out the sampling period ranged from 0.027 to $0.120 \mathrm{ppm}$ and from 0.058 to $0.430 \mathrm{ppm}$, after one single application of 1000 and $2000 \mathrm{~g} \mathrm{a.i./ha} \mathrm{respectively.} \mathrm{For} \mathrm{chlorobenzilate,}$ residues higher than detection limits were not detected, indicating no significant or no penetration of these residues inside the edible parts of the fruits. The residues of both compounds were not higher than the tolerance limits since the first sampling ( 3 days after application). 


\section{INTRODUCÄO}

A necessidade de aumento na produção de alimentos, torna-se cada vez mais evidente em função do crescimento da população mundial, além de que o contingente rural tem diminuido consideravelmente nos ültimos anos. Neste sentido, os insetos que contribuem para diminuir a produtividade das culturas, podem ser combatidos através da utilização isolada ou associada dos diversos métodos de controle. Assim, os defensivos agrícolas têm sido considerados como um dos principais recursos de que os lavradores de todo o mundo dispōem, para manter, ou até aumentar, o rendimento de suas lavouras.

os defensivos agrícolas são, indubitavelmente, necessārios para uma agricultura moderna, e as autoridades mundiais estão convencidas de que o método de controle químico continuará a desempenhar um papel preponderante nos programas de controle de pragas e doenças nas próximas décadas. Ainda que necessários, os defensivos agrícolas são também tóxicos e podem deixar resíduos persistentes nos alimentos e no meio ambiente, que podem causar problemas à saủde püblica e/ou aos demais seres vivos do ecos- 
sistema, constituindo em um grande e controvertido problema. Este fato trouxe preocupação às entidades governamentais, e ao público em geral, sobre o futuro do controle de pragas e doenças de plantas.

A cultura dos citros apresenta alguns problemas fitossanitārios críticos, principalmente, àcaros (falsa ferrugem, leprose), mosca das frutas e cochonilhas, a lém das doenças, que requerem um programa anual de controle que inclui o uso de inseticidas e acaricidas. Assim, além do problema de saúde pública, um sério incoveniente causado pelos resíduos tóxicos é ao nível de comércio externo, pois a presença destes nos produtos agrícolas, acima de tolerāncias internacionalmente aceitas, representam um risco à balança comercial do País. Segundo este raciocínio, e considerando que as exportações brasileiras no ano de 1987 atingiram um valor aproximado de US\$ 26 bilhões, dos quais, grande parte foi devida a produtos agricolas, torna-se necessário garantir a credibilidade junto aos importadores, expandindo consequentemente o mercado externo. Neste mesmo ano, segundo VIACAVA (1987) a receita cambial, com a exportação de produtos cîtricos atingiu US\$752.000.

- Brasil assume a posição de primeiro produtor e exportador mundial de citros, sendo que na região sudeste do Brasil as lavouras têm aumentado de importância a cada ano. De acordo com FUNDAÇÃo GETÚLIO VARGAS (1988) em 1987 o país possuia uma área de 724.766 ha cultivados com 
plantas cítricas, dos quais, 563.487 ha no Estado de são Paulo, onde a maior parte da produção destina-se a fabricação de suco concentrado.

Na obtenção do suco concentrado de frutas cítricas, o processamento industrial tem como principais produtos a casca, bagaço e óleos essenciais, sendo que para cada tonelada de frutas processadas, obtem-se cerca de 500 a $600 \mathrm{~kg}$ de material residual. Este tem sido utilizado principalmente para a conversão em farelo de polpa cítrica (pellets), que é usado na fabricação de ração para gado. Por este motivo, torna-se urgente levantar dados sobre o comportamento de residuos de defensivos agrícolas, que devem ser analisados tanto na polpa como na casca.

Considerando a utilização generalizada de defensivos agrícolas na cultura dos citros, principalmente acaricidas, e a carência de dados referentes ao comportamento dos residuos desses produtos nas condições brasileiras, estudos dessa natureza são de suma importāncia.

Assim, a presente pesquisa teve por objeti-

vos:

a. Estudar a degradação e persistência de residuos de bromopropilato e clorobenzilato em cascas e polpas de laranjas;

b. Determinar os valores de meia-vida. de degradação e de persistência desses dois produtos nos referidos substratos; 
4 .

c. Correlacionar os niveis de residuos encontrados com os limites de tolerância e os períodos de carência estabelecida pela legislação. 


\section{REVISÃO DE LITERATURA}

\subsection{ASPECTOS BÁSICOS NO ESTUdO DE RESÍdUO DE DEFENSI- VOS AGRÍCOLAS}

A decisão do emprego de determinado defensivo deve ser acompanhada do prévio conhecimento de seu comportamento no ambiente e no material tratado. Por outro lado, é inevitāvel a ocorrência de resíduos nas superfícies que receberam aplicação desse produto, mesmo que em quantidades pequenas. Deste modo, ROUCHAUD \& MEYER (1982) citam que os pesticidas geralmente penetram nos tecidos da planta, mesmo que fracamente. Tambëm comentam, que os produtos que não penetram nos tecidos, permanecem na superfície da planta, sendo fotodecompostos e perdendo-se por volatiliza€̣ão: e lavagem pelas chuvas.

Depósitos e resíduos não são termos sinōni-

mos e sim duas fases complementares por que passam os defensivos ao serem aplicados.

Segundo GUNTHER (1969), "depósito" è a quantidade do produto químico inicialmente colocada na superficie da planta pelo tratamento, enquanto "residuo" refere-se 
ao material sobre ou no interior do substrato após o início da atuação dos processos de penetração e degradação do composto. Assim, GALLO et alii (1978), citam que um "depósito" torna-se um "resíduo" tão logo ele seja afetado por lavagem, conversões metabólicas ou outros processos de alteração que causam diminuição na quantidade do composto.

A grandeza dos depósitos iniciais e consequentemente os níveis de resíduos finais são influenciados por muitos fatores. DUPUIS (1975) cita que a presença de residuos em uma determinada amostra depende do tipo de produto utilizado, da estrutura e propriedades físico-quimicas de cada produto, do tipo de aplicação, incluindo época, número de aplicações, tempo entre ültima aplicação e colheita, formulação usada, condições climáticas, morfologia e fisiologia da planta, sendo o último fator de especial importância para frutos de citros.

De acordo com MULLA et alii (1981), as propriedades físico-químicas dos pesticidas, como hidro ou lipossolubilidade, coeficientes de partição, adsorção ou quimiosorção, pressão de vapor e volatilização determinam o destino final dos pesticidas nas porções vivas e não-vivas dos sistemas.

Segundo SPENCER et alii (1973), a volatilização e o transporte da fase de vapor são importantes na dissipação e movimento de muitos pesticidas no solo, planta e sistemas de áqua. A pressão de vapor é o parâmetro chave 
que controla o comportamento de volatilização do pesticida, e sua interação com outras propriedades físicas bāsicas, tais como, solubilidade em āgua, adsorção e persistēncia podem ser usadas para estimar a taxa de vaporização relativa de pesticidas em condicões ambientais.

SPENCER \& CLIATH (1983) citam que a propensão de um resíduo de pesticida em volatizar-se é diretamente dependente de sua solubilidade em água e pressão de vapor. Compostos com alta pressão de vapor são mais difíceis de serem retidos. A pressão de vapor de muitos produtos aumenta 3 a 4 vezes a cada $109 \mathrm{C}$ de acréscimo na temperatura. Já o aumento na solubilidade em água intensifica a sua translocação dentro da planta. Neste sentido, ROUCHAUD \& MEYER (1982) citam tambëm as perdas por volatilização em compostos que apresentam baixa ação sistēmica e EBELING (1963) diz que aumentos de umidade causam aumento nas taxas de volatilização dos produtos em seus vários substratos.

A quantidade de pesticida depositada e a uniformidade de sua distribuição depende em grande parte do tipo de equipamento utilizado para a aplicação (EBELING, 1963).

IWATA (1980) verificou a grande influência do método de aplicação nos níveis de resíduos em folhas de laranjeira, quando era utilizada a mesma dosagem por área. Assim, a aplicação de $5,6 \mathrm{~kg}$ i.a./ha de dioxation a baixo e alto volumes resultou em quantidade de residuos 2,5 vezes superior para a aplicação a baixo volume. O autor ci- 
ta tambēm que as curvas de degradação tendem a ser paralelas mesmo que diferentes métodos de aplicação ou dosagens forem utilizados.

WESTLAKE et alie (1973) trabalhando com dioxation em laranjas 'Valência', aplicado em dosagem de 5,6 kg i.a./ha diluídos em $935,2.335$ e 11.684 litros de água, mostraram que, quanto menor a diluição do produto maior ēo depósito deste na planta.

A influência da formulação sobre o depósito inicial dos defensivos é discutida por GUNTHER (1969) que exemplifica a ocorrência de depósitos maiores na formulação concentrado emulsionável para alguns produtos e na formulação pó-molhável para outros.

Segundo DUPUIS (1975), a formulação pode afetar a taxa e o grau de penetração do produto ou a tenacidade do depósito superficial, sendo que a penetração pode aumentar a degradação se o composto atingir o tecido sub-cuticular com alta atividade metabólica. Porēm, se o mesmo permanece em cuticula mais ou menos inerte da folha ou fruto, pode persistir por um longo periodo, protegido de influēncias externas.

A variação no desaparecimento de pesticidas em função de condições climáticas tem sido observada por vários anos (EBELING, 1963).

$$
\text { NIGG et alii (1979) citam que os resultados }
$$
por eles obtidos suportam a suposição que a diferença dos 
níveis de residuos de paraoxon em citros entre flórida e Califórnia são devidas às condições úmidas na Flórida e secas na Califórnia, jā que as correlações das variāveis ambientais com os residuos de paraoxon indicaram a influência da precipitação acumulada $(r=-0,71)$. Estes pesquisadores também avaliaram o desaparecimento dos resíduos de paration e paraoxon em agroecossistema de pomar de laranjeiras 'Valência', concluindo que a radiação solar foi a variável ambiental mais correlacionada com o paration e a precipitação atmosférica foi a mais correlacionada com o paraoxon.

GUNTHER et alii (1977) observaram aumento na dissipação de inseticidas organofosforados em condições quentes e ūmidas.

Também IWATA (1980), comparando resíduos de metidation e fentoato em folhas e frutos de citros, cita que a persistência nos frutos em níveis ligeiramente superiores, provavelmente seja devida a proteção destes pelas folhas em relação a radiação solar e ao movimento de ar.

A temperatura aparentemente influencia a taxa de migração de resíduos na casca dos citros, sendo que as temperaturas altas de verão diminuem a persistência dos residuos de Neotran, bem como de outros acaricidas que migram para os "sacos" de óleo (JEPPSON \& GUNTHER, 1970).

A morfologia e fisiologia das plantas variam entre as diversas espécies e também entre os diferentes órgãos de uma mesma planta. EBELING (1963) cita que a depo- 
sição de pesticidas é influenciada pela estrutura e fisiologia da planta. Por outro lado, segundo BARTSCH (1974), em frutos de crescimento rápido como cereja e uva, os resíduos diminuem rapidamente, citando que para o diazinon foram observados periodos de meia-vida de 2 e 3 dias, respectivamente.

Assim, JEPPSON \& GUNTHER (1970), comparando resíduos de carbofenotion em laranjas e limões concluiram que a diminuição nos níveis de residuos foi maior nos limões devido ao seu crescimento durante o periodo de degradação.

GUNTHER (1969) demonstra que o efeito das variedades de citros na degradação de residuos de inseticidas depende do produto utilizado.

Após a deposição do defensivo agrícola na superficie de uma planta, parte deste material perde-se rapidamente, sendo que a porção remanescente pode apresentar penetração no substrato. A Figura 1 ilustra este comportamento; de acordo com GUNTHER \& BLINN (1956), a parte da curva designada como $\underline{x}$ representa fisicamente o produto deslocado pelo desprendimento das camadas superiores fracamente ligadas do depósito inicial, principalmente pela ação dos

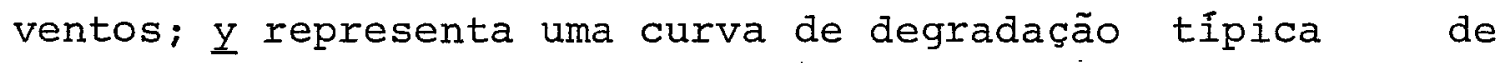
ações combinadas de desprendimento, codestilação associada com o processo de respiração da planta, volatilização, fotodecomposição, hidrólise, oxidação e penetração; $\underline{z}$ repre- 
senta uma curva de persistēncia do produto penetrado, o qual permanece suscetível somente ao ataque metabólico e hidrolítico. Estas curvas representam somas desses e talvez outros processos atuando simultaneamente com transições graduais de um estágio para outro.

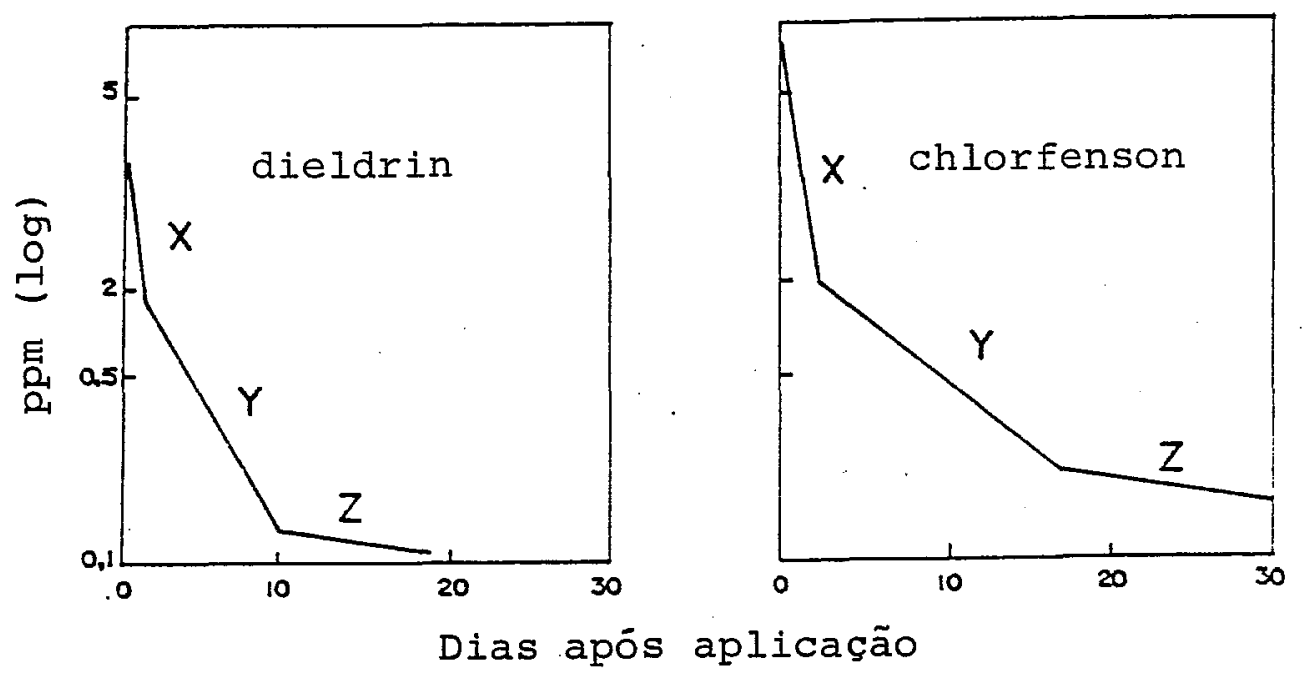

Figura 1: Residuos de dieldrin e chlorfenson em frutas cítricas (GUNTHER \& BLINN, 1956).

Os residuos representados pelo segmento $\underline{y}$ da Figura 1 tendem a desaparecer ou degradar em diferentes niveis para cada composto e cada variedade, os quais são, aproximadamente, funções diretas das concentrações aplicadas (GUNTHER \& BLINN, 1956). Porém, de acordo com GUNTHER (1969), a porcentagem ou decréscimo fracionais dos resíduos com o tempo são independentes tanto da concentração 
inicial como das grandezas do depósito. Semelhantemente, os residuos persistentes ( $z$ na Figura 1), desaparecem ou são degradados a taxas constantes, porém menores, variando entre substâncias e algumas vezes entre variedades.

De acordo com GUNTHER \&. BLINN (1955) parecem existir dois tipos principais de residuos em plantas e em solos. Estes são designados de degradantes e persistentes. Os dois tipos de comportamento são ilustrados graficamente na Figura 2. A curva $\underline{\text { A }}$ ilustra a degradação onde a quantidade de inseticida presente numa determinada época depende do depósito sobre a folha, mas a porcentagem remanescente do produto numa determinada época após a aplicação é indiferente à quantidade aplicada, sob condições ambientais constantes e em mesma cultivar de planta. A curva B é tambēm essencialmente uma curva de degradação desde que esta representa o total dos residuos cuticulares migrantes. Com relação à persistência, como representado pela curva Ć, uma nova e menor inclinação é estabelecida duas a quatro semanas após a aplicação do inseticida na fruta. Esta nova reta representa o desaparecimento lento do inseticida na planta; contrastando com o comportamento tipido de degradação rāpida das principais perdas em tecidos cuticulares. Estes autores citam que esses tipos de comportamento são designados de comportamento de desaparecimento, sendo mais pronunciado em partes de plantas cobertas por ceras como frutos de citros ou partes de plantas com óleo como o abacate. 


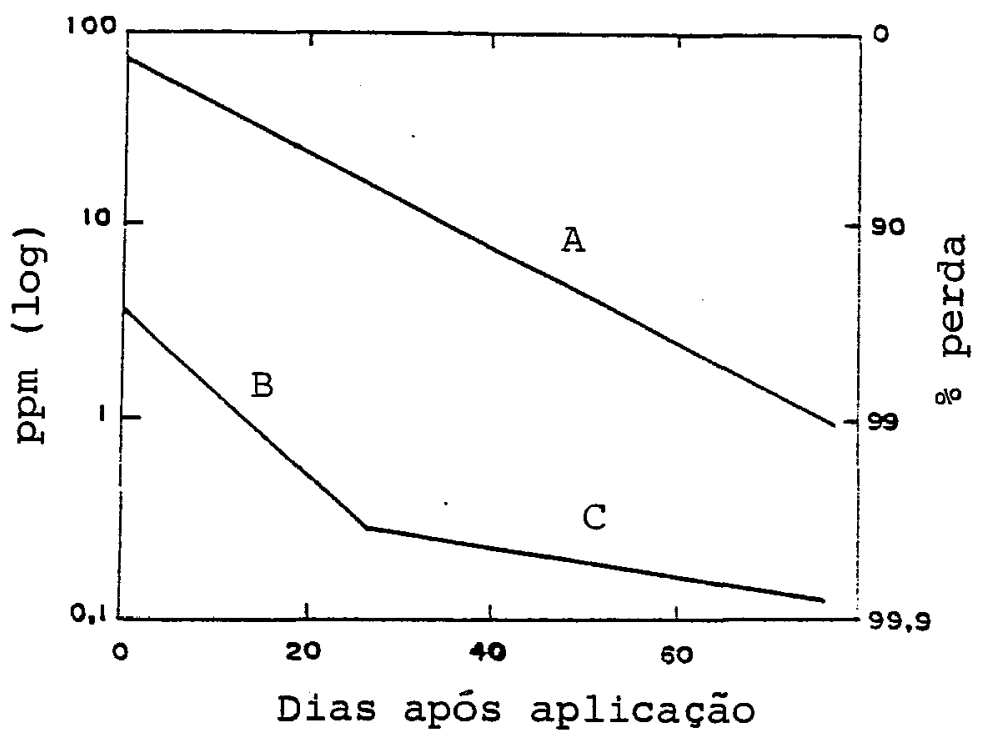

Figura 2: Curvas de degradação ( $A$ e $B$ ) e persistência (C) de inseticidas em folhas e frutos de laranjeiras. A, DDT em folhas; BeC, p-clorofenil-p-clorobenzenesulfonato em frutos. (GUNTHER \& BLINN, 1955).

GUNTHER (1969) cita que os processos de degradação e de persistência geralmente seguem uma reação cinética de primeira ordem, permitindo desta maneira, que suas respectivas curvas sejam plotadas semilogaritmicamente como Iinhas retas do logaritmo do valor do residuo (em ppm) contra intervalos de tempo decorridos desde o tratamento, como apresentado nas Figuras 1 e 2. Por outro lado, os resíduos na casca de frutas citricas, geralmente mostram um comportamento curvilíneo não simétrico em escala aritmética e duas linhas retas que se intersectam em escala semilogarit- 
mica (Figura 3). A curva $\underline{B}$ refere-se a degradação e a $\underline{C}$, a persistência. A curva B representa o desaparecimento inicial do produto aplicado, ainda parcialmente na superfície, pelos processos de perda do depósito, ação de fatores atmosféricos e ataque metabólico; enquanto a curvá $\underline{C}$ representa o produto que penetrou nas camadas cuticulares, tornando-se persistente apesar de ainda vagarosamente degradado através de ataque metabólico por agentes no interior dos tecidos da casca.

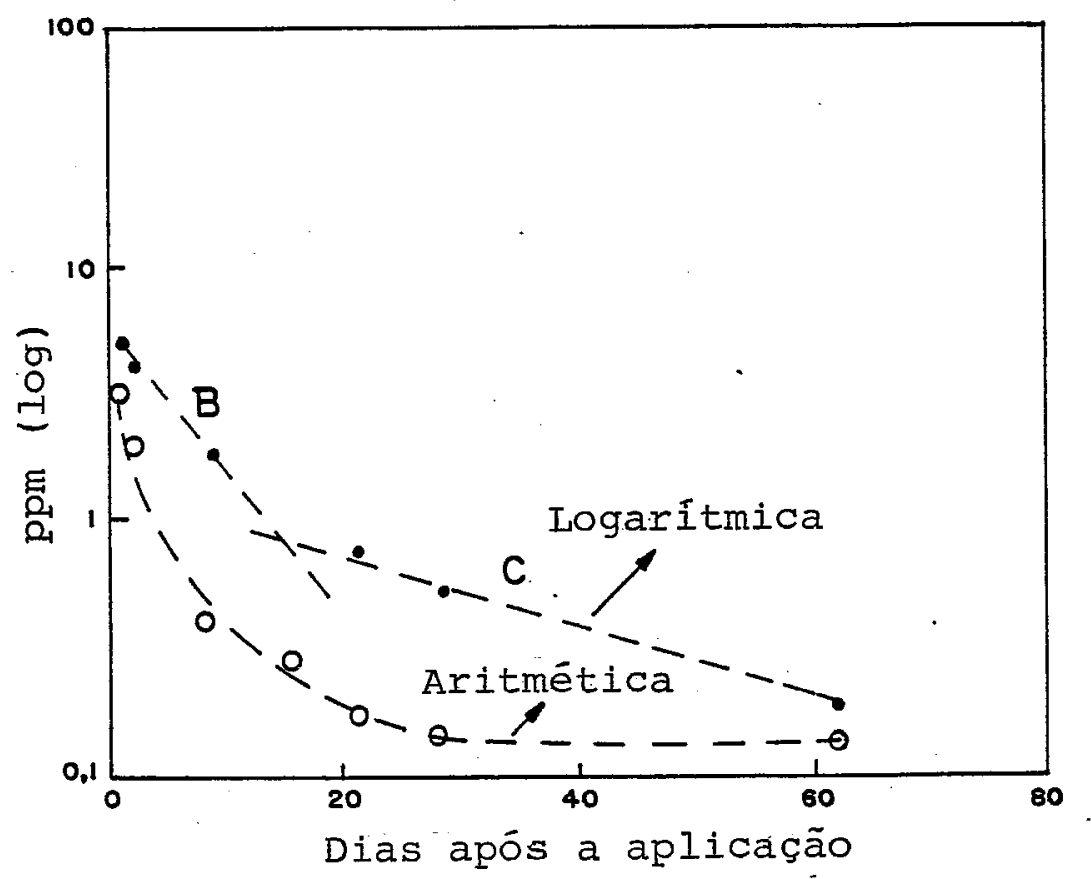

Figura 3: Curvas de degradação (B) e persistēncia (C) do Malation $(1,4 \mathrm{~kg}$ PM 25\%/380 litros) sobre e no interior de cascas de laranjas 'Valēncia! (GUNTHER \& WESTLAKE, 1968 citado por GUNTHER, 1969). 
EBELING (1963) divide os fatores envolvidos no desaparecimento dos residuos, em dois grupos. No primeiro, encontram-se aqueles comuns a todos os produtos: a planta tratada, a formulação do pesticida e os fatores que causam o desaparecimento rápido dos depósitos superficiais como chuva, umidade, vento, temperatura e luminosidade. No segundo grupo estão os fatores que dependem da natureza do produto, incluindo volatilização e decomposição “química, sendo que muitos pesticidas podem penetrar nos tecidos da planta e serem metabolizados ou quimicamente alterados, afetando a quantidade e persistência dos resíduos.

Quanto a penetração dos produtos, GUNTHER \& JEPPSON (1954) e GUNTHER \& BLINN (1955) distinguem três categorias de resíduos: extra-cuticulares, cuticulares e subcuticulares. Os primeiros são os residuos aderentes à camada de cera (depósito superficial); os segundos são os resíduos incrustados ou dissolvidos nela e os ūltimos são aqueles presentes abaixo desta camada. Já KHAN (1982) cita que os resíduos de pesticidas absorvidos e translocados nos tecidos de plantas podem estar presentes em três possiveis formas: residuos facilmente extraíveis, conjugados à componentes naturais das plantas e não extraíveis, ou residuos incorporados aos constituintes das plantas.

No estudo de resíduos de defensivos agrícolas, uma das determinações importantes é o valor da "meia-vida", definido por GUNTHER \& BLINN (1955) como o tempo 
requerido para que a metade de uma dada quantidade de material reaja (ou dissipe). Segundo GUNTḦER (1969), para um determinado produto e cultura, o valor de meia-vida de persistência é uma característica constante e utilizada em comparações de persistência (longevidade) de vārios pesticidas em um substrato como frutos de citros. No entanto, este mesmo autor cita que "meias-vidas" baseadas nas curvas de persistência (C nas Figuras 2 e 3 ) são satisfatoriamente constantes, enquanto aquelas baseadas nas curvas de degradação (B nas Figuras 2 e 3) são notadamente afetadas pelas variações das condições climāticas; assim, uma chuva no período de degradação irá deslocar para baixo tanto a curva $\underline{B}$ como a $\underline{C}$, podendo alterar a inclinação de $\underline{B}$ mas não a de $\underline{C}$. Na Tabela 1 são apresentados os valores de meia-vida de persistência de alguns produtos em cascas de frutas citricas.

Outros conceitos toxicológicos importantes do ponto de vista de resíduos são: tolerāncia e intervalo de segurança.

A tolerância ou limite máximo de residuo é a quantidade máxima de resíduo de um defensivo agrícola tolerada no alimento, como decorrēncia de sua aplicação adequada, numa fase especifica desde a sua produção até o consumo, expressa em partes (em peso) do defensivo e/ou seus derivados por um milhão de partes (em peso) do alimento (ppm). Como intervalo de segurança ou período de carên- 
17.

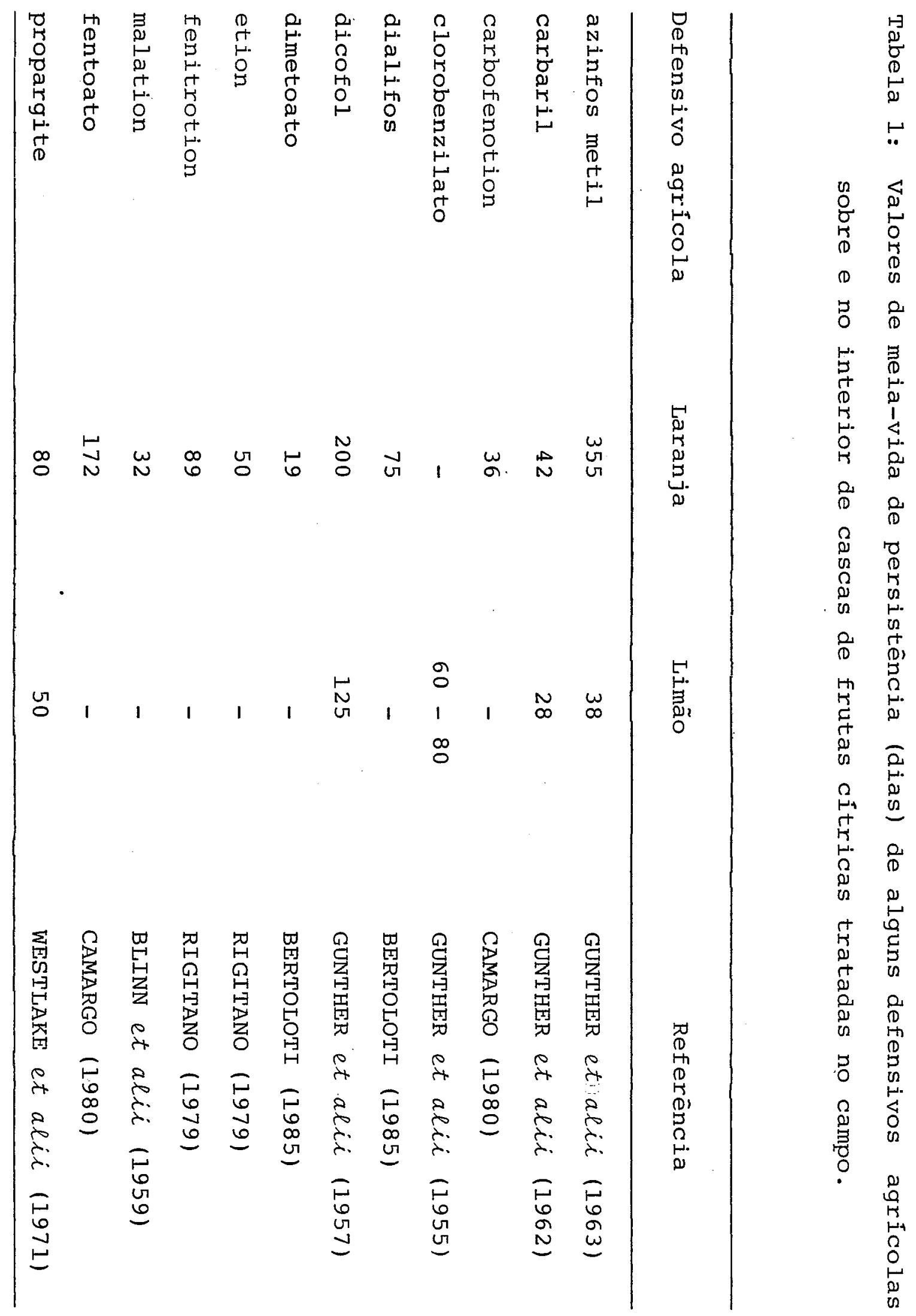


cia, entende-se "o intervalo de tempo, expresso em dias entre a última aplicação do defensivo e a colheita ou comercialização do vegetal, abate ou ordenha do animal, conforme o caso, a fim de que os resíduos estejam de acordo com os limites máximos permitidos" (Associação Nacional de Defensivos Agrícolas - ANDEF, 1984). Segundo DUPUIS (1975), - estabelecimento do período de carência é benéfico para o agricultor, pois se este seguir as recomendações, seus produtos não apresentarão problemas de resíduos.

\section{2, DETERMINAÇÃO DOS RESÍDUOS DE DEFENSIVOS AGRÍCOLAS EM FRUTAS CITRICAS}

Quanto a origem de possiveis residuos em citros, DUPUIS (1975) cita que a morfologia e fisiologia do fruto é um aspecto de especial importância. Este mesmo autor considera que a morfologia particular do fruto e as diferentes formas de utilização são as principais características que influenciam a presença de residuos. A Figura 4 mostra as estruturas comumente encontradas nos frutos de citros. Com relação à utilização dos frutos, deve-se considerar além do consumo "in natura", também os produtos do seu processamento, como: sucos (vários tipos), polpa (ração para gado e melaço) e óleo essencial. 


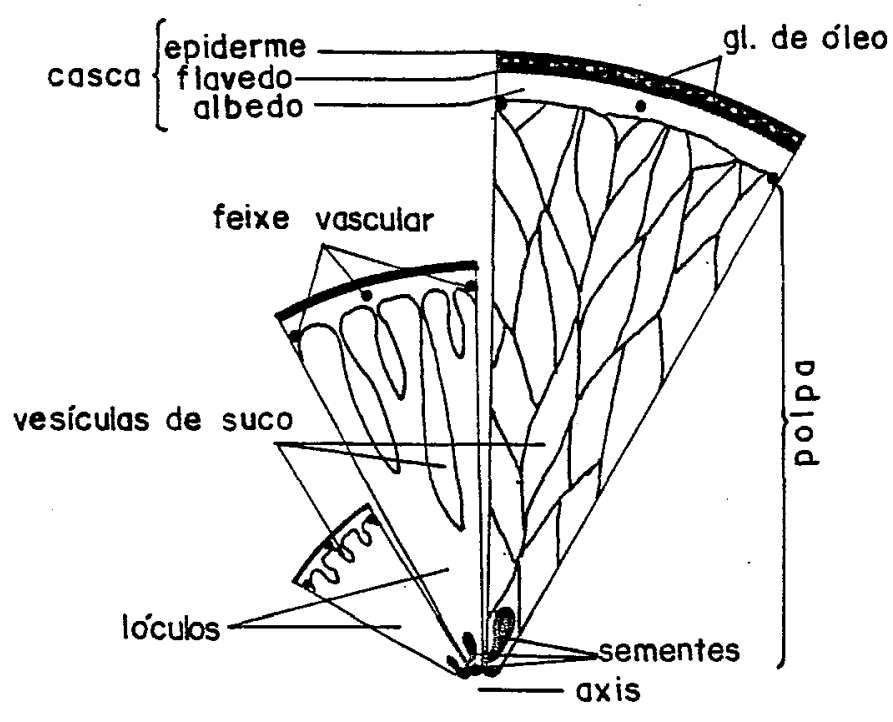

Figura 4: Desenvolvimento esquemático de fruto de citros em três estágios de crescimento (DUPUIS, 1975).

A pesquisa de residuos de defensivos agrícolas em frutas cítricas è relativamente antiga em outros paises. GUNTHER (1969) cita que os primeiros estudos de desaparecimento do depósito e resíduos de defensivos, foram desenvolvidos com avaliações dos residuos de DDT em folhas e cascas de frutas citricas, em 1946.

Considerando a importância econômica e social da produção de cítricos para o Brasil, associada a utilização de defensivos agrícolas no seu processo produtivo e ao destino internacional de seus produtos, pode-se inferir que - comportamento dos residuos neles existentes é assunto que só recentemente passou a ser estudado, já que o estudo pioneiro foi realizado por RIGITANO (1979). 
As tolerâncias para defensivos agrícolas em frutas cítricas, são baseadas na fruta toda, ou seja, considera-se a quantidade de resíduos presentes em função de uma quantidade conhecida da fruta toda, sem especificar suas partes. Por exemplo, miligrama do defensivo ou seu produto de degradação, por kilograma de fruta (mg/kg = ppm), incluindo casca, polpa (suco + bagaço) e sementes. Entretanto, em pesquisas mais completas, a casca e a polpa são analisadas separadamente, visando a avaliação da penetração dos produtos nas frutas (GUNTHER, 1969).

Na Tabela 2 são apresentados dados de tolerâncias e períodos de carência para vārios produtos utilizados na citricultura, estabelecidos em diferentes países. Considerando estes dados, DUPUIS (1975) argumenta que a variação dos períodos de carência de um país para outro è compreensivel, desde que condições meteorológicas diferentes e diferenças nas práticas culturais influenciam a taxa de desaparecimento de um defensivo. Quanto às variações em tolerāncias, estas refletem a tendēncia das autoridades em estabelecer valores mínimos, admitindo que a proteção da cultura é garantida sob condições locais. Isto ilustra o fato que resíduos excedendo uma dada tolerância, transgride a lei, mas não são necessariamente tóxicos ao consumidor. o autor cita também que em alguns casos, estas diferenças poderão criar problemas em relação a exportação. GUNTHER et alii (1957) determinaram os resí- 


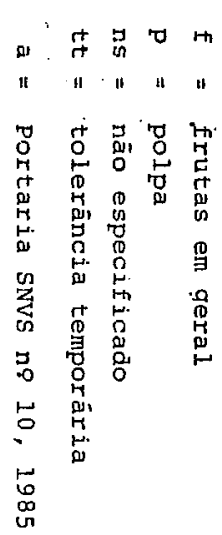

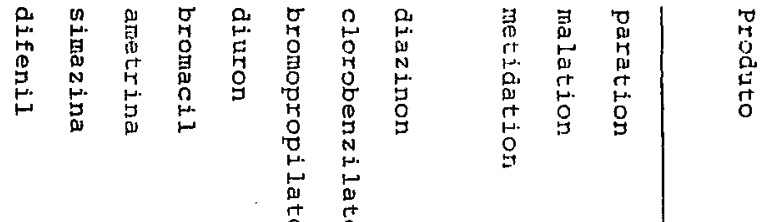

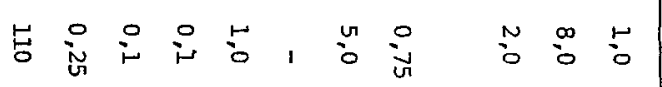

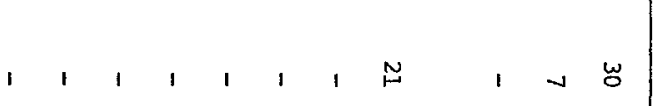

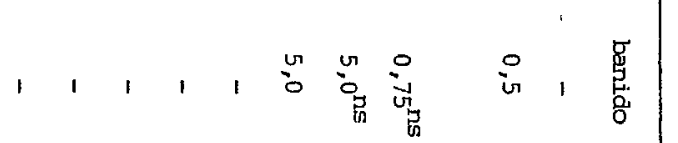

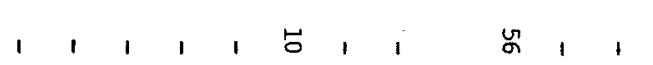

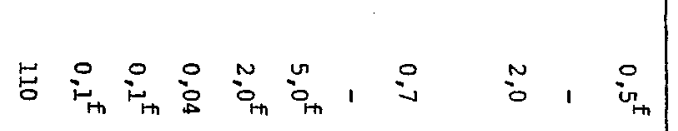

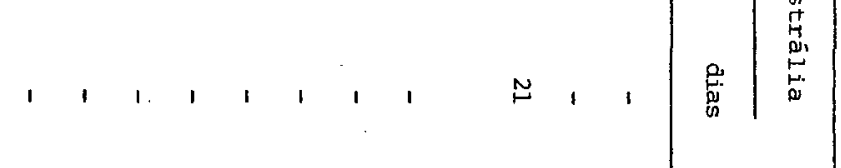

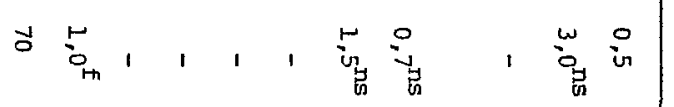

$$
\begin{aligned}
& \text { 喟| }
\end{aligned}
$$

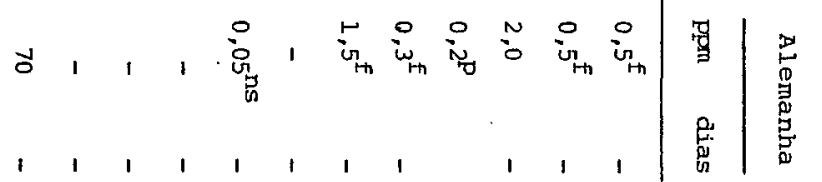

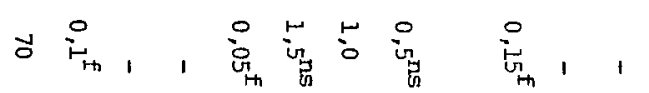

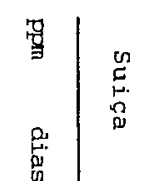

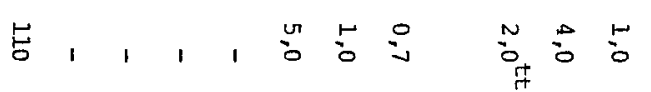

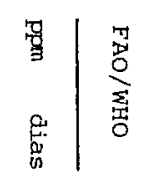

$$
\begin{aligned}
& \text {, 年 }
\end{aligned}
$$$$
\begin{aligned}
& \stackrel{-1}{0} \\
& 0 \\
& 0 \\
& 0 \\
& 0 \\
&
\end{aligned}
$$$$
\begin{array}{ll} 
& \\
0 & 1 \\
0 & 0 \\
0 & 0 \\
0 & 0 \\
0 & 0 \\
0 & 0
\end{array}
$$$$
\text { @ }
$$$$
\text { (0) }
$$$$
\text { 今. }
$$$$
\text { 可 }
$$$$
\text { م. }
$$$$
\text { on }
$$

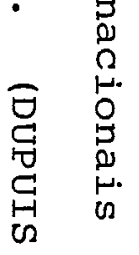

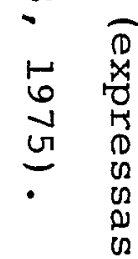$$
\text { 号 }
$$$$
\text { 兽 }
$$$$
\text { 号 }
$$$$
\text { 党 }
$$

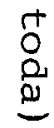$$
10
$$$$
\begin{aligned}
& 8 \\
& 8 \\
& 0 \\
& 5 \\
& 0 \\
& 1
\end{aligned}
$$ 
duos de dicofol em laranjas 'Valência' e limões, provenientes da aplicação no campo, de $0,73 \mathrm{~kg}$ (PM 25\%) por 380 litros de āgua, gastando-se 1.400 litros por hectare. Para quantificação dos resíduos foram utilizados os métodos colorimétrico e cloro total. Os valores de meia-vida do dicofol em cascas foram de 200 e 170 dias, respectivamente para o método colorimétrico e cloro total em laranjas 'Valência' e de 120 e 140 dias, respectivamente, em limões. Tambēm foram feitas determinações de resíduos em laranjas lavadas com detergente e não lavadas, verificando-se que este produto penetra vagarosamente nas porções oleosas e cerosas da casca e que, os residuos presentes nas frutas colhidas até 40 dias após aplicação podem ser reduzidos através de lavagem. Na polpa dos frutos foram encontradas quantidades despreziveis de dicofol.

Os residuos de dioxation em laranjas 'Navel' e limões, resultantes da aplicação de $0,68 \mathrm{~kg}$ da formulação concentrado emulsionável $(0,48 \mathrm{~kg} / \ell)$ por 380 litros, foram avaliados por GUNTHER et alii (1958a). Foram aplicados 23.400 e 14.000 litros/ha, respectivamente para laranjeiras e limoeiros. Os valores de meia-vida de persistência em casca de laranja e limão foram de 94 e 82 dias, respectivamente. Na polpa, os níveis de residuos encontrados não excederam a 0,03 ppm. Comparando a formulação mencionada com a pó molhável, em relação ao comportamento dos resíduos, mencionam que a rápida penetração da formulação emulsioná- 
vel resultou unicamente em resíduos do tipo persistentes, enquanto a formulação pó molhável apresentou resíauos degradantes e persistentes.

A determinação dos resíauos de diazinon em limões foi realizada por GUNTHER et alii (1958). As plantas receberam aplicação de $0,9 \mathrm{~kg} / 380$ litros das formulações pō-molhāvel (PM 25\%) e concentrado emulsionāvel (CE 25\%), gastando-se 10.500 litros por hectare. Os valores de meia-vida de degradação na casca, foram de 2,5 e 6,5 dias, respectivamente para $\mathrm{PM} 25 \%$ e CE 25\%, sendo que para persistência esses valores foram de 12 e 13 dias, respectivamente.

A degradação e persistência de resíduos de malation em cascas e polpas de laranjas 'Valência' foram estudadas por BLINN et alii (1959) em aplicação de 1,36 kg da formulação PM 25\% por 380 litros de ägua e aplicados a alto volume. As análises dos residuos, realizadas pelo método colorimétrico, determinaram valores de meia-vida na casca, de 7 e 32 dias para degradação e persistência, respectivamente. Na polpa, os níveis de resíduos não ultrapassaram a 0,04 ppm, durante os 62 dias de amostragens. GUNTHER et alii (1962) determinaram os residuos de carbaril em cascas e polpas de limões e laranjas 'Valência', resultantes da aplicação de 0,45 e 0,9 kg de Sevin PM 50\%/380 litros, utilizando-se 14.000 litros/ha nos limoeiros e 23.400 litros/ha nas laranjeiras. Para quanti- 
ficação dos resíduos utilizaram o método colorimētrico. Foram encontrados valores de meia-vida de 28 e 42 dias, para limões e laranjas 'Valência', respectivamente. Na polpa dos frutos não foram detectados residuos de carbaril, sendo verificado também que a penetração do inseticida nas porções oleosas e cerosas da laranja, é vagarosa e que até 30 dias apōs a aplicação, ocorre uma remoção dos resíduos presentes, pela simples lavagem dos frutos.

ANDERSON et alii (1963), estudando os residuos de azinfós metílico (Guthion), presentes em frutos de laranja, cujas plantas receberam 2 aplicações de 0,23 kg de ingrediente ativo (Guthion 25\% PM)/380 litros, espaçadas de 26 dias, citam que o processo de lavagem removeu 30\% dos resịduos em frutos colhidos 14 dias após a segunda aplicação. Estes aucores verificaram também que a polpa não apresentava resíduos detectáveis nesta ocasião.

Ainda com relação aos resíduos de:azinfós metilico (Guthion), GUNTHER et alii (1963) observaram que os valores de meia-vida deste inseticida em limões e laranjas 'Valência', foram respectivamente de 30 a 38 dias e de 340 a 400 dias, sendo que, segundo os autores não houve explicação evidente para esta discrepāncia de valores entre as duas variedades de citros. No entanto, a chuva ou a simples lavagem dos frutos podem ocasionar reduções significativas nos residuos existentes em laranjas tratadas com Guthion. Em laranjas provenientes de plantas tratadas com 
$1,8 \mathrm{~kg}$ de Guthion 25\% PM, foram observadas reduções nos resíduos que variaram de 96\% ( 1 dia após aplicação) até 71\%, aos 120 dias apōs.

WESTLAKE et alii (1970) estudaram a persistência de resíduos de monocrotofos em laranjas 'Valência', cujas plantas receberam aplicação de Azodrin a alto e a baixo volumes, respectivamente com $11,0 \mathrm{~kg}$ de princípio ativo/ 18.700 litros/ha e $1,1 \mathrm{~kg} / 935$ litros/ha. Para determinação dos resíduos, foi utilizado cromatógrafo a gás, equipado com detector de ionização de chama alcalina. Os valores de meia-vida encontrados foram de 16 a 13 dias, respectivamente para alto e baixo volumes. A lavagem dos frutos, 12 dias após a aplicação, teve pouco efeito nos níveis de residuos, indicando rápica penetração deste produto no interior da casca. Aos 38, 66 e 108 dias após tratamento foram analisados os residuos na polpa dos frutos e somente a aplicação a alto volume resultou em traços do defensivo.

A persistência de propargite em laranjas 'Navel' e Iimões 'Eureka', que receberam aplicação de campo na dosagem de $0,27 \mathrm{~kg}$ i.a./380 litros foi determinada por WESTLAKE et alii (1971). Observaram que os valores de meia-vida para laranjas e limões foram respectivamente de 80 e 50 dias, sendo que a lavagem das laranjas colhidas aos 7 e 28 dias após aplicação, reduziu os níveis de resíduos em 12 e 20\%, respectivamente, enquanto que na amostra de laranjas colhidas aos 75 dias após aplicação e nos limões, não houve 
redução através da lavagem. Estes autores não detectaram penetração de proporgite na polpa dos frutos.

WESTLAKE et alii (1972) encontraram uma meia-vida de persistência de 40-45 dias, para fosalone em laranjas 'Valência'. o produto foi aplicado nas dosagens de 0,22 e 0,44 litros de fosalone CE $0,36 \mathrm{~kg} / \mathrm{litro,} \mathrm{o} \mathrm{que} \mathrm{cor-}$ respondeu a 0,085 e $0,17 \mathrm{~kg}$ de fosalone técnico, em 380 litros, gastando-se 95 litros de calda por árvore. Estes autores constataram que cerca da metade dos resíduos da casca foram removidos por lavagem, indicando baixa penetração do defensivo, mesmo após 35 dias da aplicação.

VAN DYR (1975) estudou o comportamento de residuos de paration; dimetoato, endossulfan e metidation, na Âfrica do Sul. A aplicação destes produtos no início do crescimento dos frutos, resultou em valores de meia-vida de 1,$4 ; 2,3 ; 3,9$ e 7,3 dias, respectivamente, enquanto a aplicação no final do desenvolvimento dos frutos (final de verãol, apresentou valores de 5,$1 ; 8,1 ; 54,5$ e 52,2 dias.

o autor explicou que a diferença entre as duas épocas foi devida a diluição dos residuos em função do crescimento dos frutos.

IWATA et alii (1979) avaliaram os residuos de metidation (Supracide), aplicado em laranjeiras na Califórnia. Os valores de meia-vida de degradação e persistência foram respectivamente, de 4 e 9 dias.

RIGITANO (1979) estudou os residuos de etion 
e fenitrotion em cascas e polpas de laranjas 'Hamlin'. 0 autor utilizou $400 \mathrm{ml}$ de Ethiol 100 (40 ml de i.a.) e $150 \mathrm{ml}$ de Folithion $50 \mathrm{CE}(75 \mathrm{ml}$ de i.a.) por 100 litros de água, gastando-se 1,7 litros de calda por planta, no início da maturação dos frutos. A amostragem e análise dos frutos foram realizadas aos $3,10,17,24,34,45,60$ e 104 dias após a aplicação. Os resíduos foram determinados por cromatografia gás-líquido, utilizando-se detector de ionização de chama alcalina (DICA). Os valores de meia-vida de persistência nas cascas, para etion e fenitrotion, foram respectivamente de 50 e 89 dias. Nas polpas não foram detectados residuos desses produtos acima dos limites de detecção do mētodo, os quais foram de 0,01 e 0,02 ppm para etion e fenitrotion, respectivamente.

CAMARgo (1980) estudou a degradação e persistência dos resíduos de carbofenotion (Trithion 4E) e fentoato (Cidial 50E) em cascas e polpas de laranjas 'Ham lin', cujas plantas receberam aplicação de $120 \mathrm{ml}$ de Trithion $4 \mathrm{E}$ e $200 \mathrm{ml}$ de Cidial $50 \mathrm{E}$ por 100 litros de água, no início da maturação dos frutos, o que correspondeu a 1,17 ml i.a. de carbofenotion e $1,7 \mathrm{ml}$ i.a. de fentoato. A amostragem dos frutos deu-se aos $3,10,17,24,34,45,60$ e 104 dias para carbofenotion e ainda aos 147 dias para fentoato, após a aplicação dos produtos. A determinação dos resíduos foi feita por cromatografia gasosa, utilizando-se detector de ionização de chama alcalina (DICA). Os valores 
de meia-vida de degradação e persistência nas casdas de laranjas, foram respectivamente de 13 e 36 dias para carbofenotion e 9 e 172 dias para fentoato. Nas polpas dos frutos não foram detectados resíduos acima dos limites do método analitico utilizado $(0,02 \mathrm{ppm}$ para carbofenotion e $0,01 \mathrm{ppm}$ para fentoato). Carbofenotion apresentou residuos, com base na fruta toda, em níveis abaixo do limite de tolerância (2 ppm), em todas as amostragens, enquanto os níveis de residuos do fentoato estiveram sempre acima da tolerância $(0,01 \mathrm{ppm})$, durante todo o período estudado.

A avaliação dos resíduos de dialifos (Torak E 48) e dimetoato (Rogor $\mathrm{E} 50$ ) em cascas e polpas de laranja 'Hamlin' foi realizada por BERTOLOTI (1985), através da aplicação de $1.500 \mathrm{~g}$ i.a./ha de dialifos e $1.400 \mathrm{~g}$ i.a./ha de dimetoato, no início da maturação dos frutos. Estes foram amostrados aos 3, 7, 14, 25, 40,66 e 105 dias após a aplicação. Para determinação dos residuos foi utilizado cromatógrafo a gás, equipado com detector de ionização de chama alcalina (DICA). Nas cascas, os valores de meia-vida de degradação e de persistēncia foram, respectivamente, de 28 e 75 dias para dialifos e de 7 e 19 dias para dimetoato. Foram detectados residuos de ambos os inseticidas nas polpas dos frutos, porém em níveis muito baixos. Entretanto, os resíduos de dialifos e dimetoato, com base na fruta toda, estiveram abaixo da tolerância desde a primeira amostragem ( 3 dias após a aplicação). 
VASCONCELLOS et alii (1983) avaliaram os niveis de residuos deixados em polpa de frutos de laranja 'Natal!, cujas plantas receberam 400 gramas de dissulfoton $2,5 \%$; 200 gramas de forato 5\%, 200 gramas de carbofuran 5\% e 100 gramas de aldicarb 10\% por planta, aplicados aos solo quando os frutos tinham cerca de 7 meses de desenvolvimento. As amostragens foram realizadas aos $30,45,60,75$ e 90 dias após a aplicação. Dentre os inseticidas testados, apenas o carbofuran apresentou resíduos na polpa dos frutos, decrescendo de 0,13 ppm no 30 dia a $<0,05$ ppm no 75 ? dia, sendo que os outros produtos, apresentaram frutos sem resíduos detectáveis de acordo com o limite de sensibilidade de cada método, desde o 30 Q dia após a aplicação.

BATISTA et alii (1985) estudaram a distribuição de resíduos de aldicarb em casca, bagaço e suco de limão siciliano, atravēs da aplicação de 20 e $40 \mathrm{~g}$ i.a./ planta. As amostras foram colhidas 45 dias após a aplicação, sendo os residuos totais analisados na forma do metabólito sulfona, mediante o uso de cromatōgrafo a gās equipado com detector fotométrico de chama. Foram detectados residuos em todas as amostras provenientes de plantas tratadas, variando de (dosagens 20 e 40 g p.a./planta, respectivamente): casca, 0,14-0,37 ppm e 0,54-1,0 ppm; bagaço, $0,07-0,10$ ppm e 0,16 - 0,21 ppm e suco, 0,04-0,05 ppm e 0,08-0,18 ppm. Estes autores fizeram a composição dos residuos na fruta toda, considerando a participação per- 
centual em peso das diversas partes, e observaram que a dosagem recomendada (20 g p.a./planta) conduziu a obtenção de niveis residuais dentro do limite estabelecido pela legislação $(0,2 \mathrm{ppm})$, sendo mencionado também que a observação do periodo de carência (60 dias) deveria, provavelmente, reduzir mais esses niveis.

Os resíduos de aldicarb também foram avaliados em frutos de laranja 'Valēncia' e 'Natal', por BATISTA et alii (1986). O defensivo foi aplicado nas dosagens de 20 e $40 \mathrm{~g}$ i.a./planta. As amostragens foram realizadas aos $11,21,30,34,60$ e 79 dias após a aplicação, para laranja 'Valência', e aos 10, 20, 31 e 42 dias para laranja 'Natal'. Os residuos de aldicarb foram analisados da mesma forma que mencionada no trabalho anterior (BATISTA et alii, 1985). Foram detectados resíduos em laranjas 'Valência?, apenas na amostragem de 60 dias, em teores de 0,03 ppm (uma amostra) e variāveis de 0,024 - 0,044 ppm para as dosagens de 20 e $40 \mathrm{~g}$ i.a./planta, respectivamente. Em Iaranja 'Natal' foram encontrados residuos em todas as amostragens, variando de $0,029-0,062 \mathrm{ppm}$ e de 0,042 - 0,159 ppm, para as dosagens de 20 e $40 \mathrm{~g}$ i.a./planta. Os autores citam que em nenhuma amostra os resíduos atingiram a tolerância estabelecida pela legislação $(0,2 \mathrm{ppm})$.

BATISTA et alii (1987) determinaram os residuos de bifentrin em laranja, empregando as dosagens de $25 ; 37,5 ; 50 ; 75$ e $100 \mathrm{~g}$ i.a./ha. Foram observados 4 in- 
tervalos de colheitas das amostras $(1,3,7$ e 10 dias após a aplicação), sendo utilizado cromatógrafo a gās equipado com detector de captura de elétrons para quantificação dos resíduos.

Estes foram detectados até o final do período de colheita das amostras, nos tratamentos com 75 e $100 \mathrm{~g}$ p.a./ha, com valores máximos de 0,08 e 0,15 ppm, respectivamente. Nos demais tratamentos os resultados indicaram níveis não detectáveis $(<0,01$ ppm), antes do final do periodo de colheita.

\subsection{RESÍDUOS DE DEFENSIVOS AGRÍCOLAS EM PRODUTOS CÍ- TRICOS}

Segundo GUNTHER (1969) tolerâncias especificas para produtos cítricos, como ração seca para gado,óleos de limão e laranja, suco congelado, etc., não eram usualmente estabelecidas nos Estados Unidos. As tolerâncias eqüivalentes para esses produtos, se necessárias, são aparentemente extrapoladas da fruta toda, sendo que o suco fresco representa metade a trēs-quartos do peso da fruta, - óleo recuperável da prensa representa de 0,1 a $0,8 \%$ e a ração seca para gado, de um-quarto a metade do peso da fruta, com um eventual fator de dessecação em torno de 8, ou de $85 \%$ de umidade para $10 \%$. No entanto, para muitos defensivos usados na citricultura, são exigidos os dados refe-· 
rentes aos residuos presentes em ração para gado.

Na Figura 5 são mostrados os diferentes produtos resultantes do processamento de frutos de citros, e de quais partes dos frutos eles derivam. As características desses produtos e os aspectos gerais para sua obtenção são discutidos em KESTERSON \& BRADDOCK (1975), enquanto DUPUIS (1975) aborda estes produtos sob o enfoque de residuos.

No Brasil, os principais produtos da indūstria cítrica são: suco concentrado, "pellets" (ração para gado), óleo essencial e d-limoneno.

\subsubsection{SUCOS DE FRUTAS CITRICAS}

o suco é o principal produto explorado na industrialização de frutas cittricas no Brasil. De acordo com a FUNDAÇÃO GETÚLIO VARGAS (1988), na safra 1987/88 foram produzidas $765 \mathrm{mil}$ toneladas.

Naturalmente, as frutas citricas possuem uma barreira muito eficiente no controle da contaminação de seus sucos. Esta é representada pela casca, que funciona como um impedimento físico, através da cobertura total da polpa e um impedimento químico pelas substāncias que nela se encontram. Exemplos destes componentes químicos são as ceras e os óleos. Segundo DUPUIS (1975) os defensivos são geralmente não-polares e assim, são preferencialmente reti- 


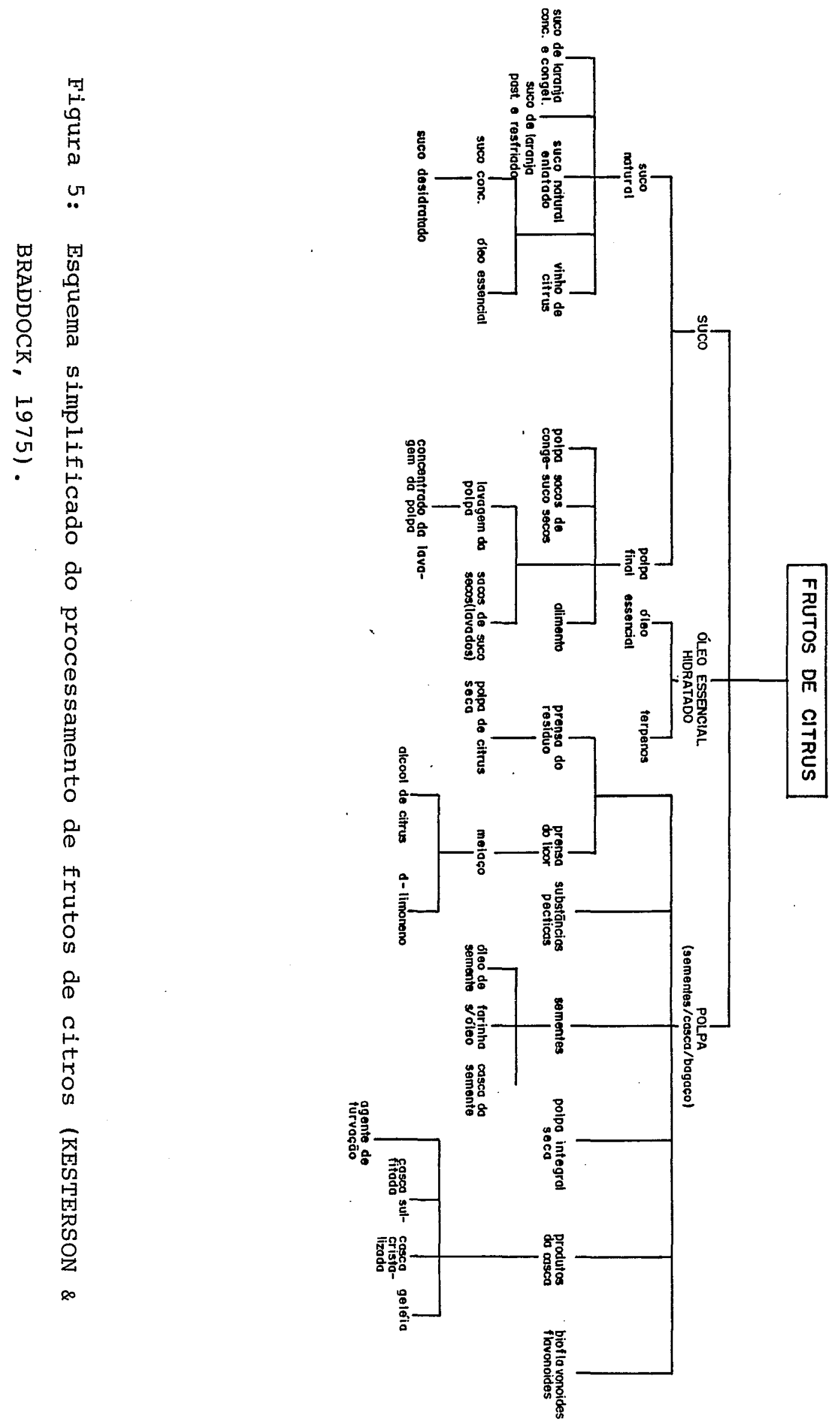


dos na camada lipofilica da epiderme ou em "sacos" de óleo. Esse mesmo autor apresenta dados de residuos em citros, referentes a diversos inseticidas, e enfatiza a ausência de residuos detectáveis na polpa dos frutos.

De acordo com GUNTHER (1969) o inseticida encontrado na fruta lavada, descascada e livre do albedo, pode ser considerado como penetrado no suco, enquanto a fruta estava intacta. Considerando que muitos inseticidas são solüveis em óleos cítricos e que os residuos penetrados desses produtos são amplamente encontrados nos "sacos" de óleos da casca, este autor cita que sucos preparados em laboratório, apenas separando-se a polpa da casca, devem apresentar menores níveis de residuos que aqueles preparados por meio de prensas mecânicas (sucos comerciais), pois estes ültimos apresentam um pouco de óleo cítrico. DUPUIS (1975) comenta que o processo de extração de suco de frutas citricas, tem um efeito decisivo na quantidade e qualidade do suco obtido e consequlentemente, no teor de possíveis residuos de defensivos. Segundo o autor os equipamentos modernos de extração possibilitam o controle quantitativo dos componentes incluídos no suco, e entre eles se incluem os öleos essenciais. Desde que seja mantida uma quantidade muito baixa de óleo nos sucos (limite máximo de 0,02\%), não se espera quantidades significativas de residuos nos mesmos.

De acordo com GUNTHER (1969) não são conhe- 
cidos os efeitos da concentração a vácuo (acima de $72 \%$ Brix) sobre residuos de defensivos que podem estar presentes em sucos comerciais, exceto para paration. No entanto, pode ser presumido que esse processo de destilação, essencialmente a vapor, possa remover parte dos residuos presentes. ANDERSON et alii (1963) estudaram os residuos de azinfós metílico (Guthion) presentes em produtos originados da industrialização de laranja. Os frutos lavados apresentavam residuos de 0,7 ppm, antes de serem processados. No suco obtido não foram detectados residuos de azinfós metílico $(<0,3$ ppm), apesar do óleo essencial apresentar $30,3 \mathrm{ppm}$.

GUNTHER (1969) mostra os resultados de análises de residuos em sucos, provenientes de frutas contendo altas concentrações de vários defensivos na casca. Verifica-se que, na maioria dos casos, não se detectou resíduos nos sucos, sendo que quando presentes se apresentavam em baixos niveis $(<0,2 \mathrm{ppm})$.

A distribuição dos resíduos de metidation em diferentes frações de laranjas, obtidas por processamentos comerciais é mostrada em DUPUIS (1975). Partindo-se de frutos que apresentavam 4,0 ppm de residuos na casca e 0,61 ppm na fruta toda, obteve-se suco com niveis de residuo $<0,05 \mathrm{ppm}$. 


\subsubsection{RACÕES PARA GADO}

Como sub-produto da industrialização de frutas citricas, o "pellets" ou bagaço seco e prensado, tem recebido especial atenção devido a sua fácil comercialização e bons preços alcançados no mercado externo. Segundo

JORGE $^{1}$ na safra $1987 / 88$ foram produzidas cerca de 900 mil toneladas de "pellets", sendo a totalidade destinada a exportação.

DUPUIS (1975) cita que para cada tonelada de frutas processadas permanecem de 500 a $600 \mathrm{~kg}$ de bagaço. Uma pequena parte é usada na manufatura de pectinas e flavonoides, sendo sua principal utilização, a conversão em ração para gado. Segundo este autor as condições usadas para a preparação são favorāveis à diminuição nos níveis de resíduos existentes.

Quanto ao fator potencial de concentração de resíduos, desde a extração da casca até a ração pronta, GUNTHER (1969) menciona o valor de 8 vezes, enquanto DUPUIS (1975) apresenta o valor de 6 vezes. O segundo autor parece mais se aproximar da realidade, quando se parte de cascas com $85 \%$ de umidade e obtêm-se "pellets" com 10\% de umidade, sem se considerar perdas durante o processamento.

1 JORGE, B.F. (Citrosuco Paulista S.A., Limeira) Comunicação pessoal, 1988 . 
Uma fórmula simples é apresentada a seguir, para se calcular o fator de concentração, pela perda de umidade:

$$
F C=\frac{100-Y^{\circ}}{100-x \%}, \text { onde: }
$$

FC = Fator de concentração;

$y \%$ = a umidade final da ração e

$\mathrm{x} \%$ = $\mathrm{a}$ umidade da casca fresca.

Entretanto, a previsão da quantidade de resíduos na ração para gado, considerando apenas o fator potencial de concentração, conduz a valores superestimados, pois ocorrem comumente grandes perdas no processamento desse produto, durante as operações de tratamento com cal e secagem, pois a substāncia descartada na prensagem é uma emulsão diluída de óleos cítricos em água, os quais são excelentes solventes para muitos inseticidas orgānicos (GUNTHER, 1969). Este mesmo autor mostra uma lista de produtos que apresentaram diminuição de resíduos em função do processamento das cascas em ração para gado, sendo o malation um exemplo extremo, já que foi totalmente perdido durante a operação de tratamento com cal. Outros produtos que não toleraram este tratamento, foram: azinfós metílico, carbaril, dicofol e quinometionato.

Os resultados de alguns estudos referentes 
a determinação de resíduos em ração para gado, proveniente de frutas tratadas no campo com defensivos agrícolas, são apresentados na Tabela 3, onde observa-se uma suscetibilidade variável dos produtos em relação ao processamento adotado, sendo que os resultados mais discrepantes ocorreram com o monocrotofos e dioxation, com este ūltimo não sofrendo diminuição de resíduos em função do processamento em ração para gado, enquanto o outro foi grandemente eliminado.

\subsection{BROMOPROPILATO}

O bromopropilato foi testado primeiramente para controle de ácaros, sob condições de campo, em 1966 (World Health Organization - WHO, 1974). Segundo a Portaria SNVS no 10 de 08 de março de 1985 (BRASIL. Leis, decretos, etc., 1985), este produto é classificado como acaricida do grupo químico dos benzilatos. Sua $\mathrm{DL}_{50}$ oral é de $5000 \mathrm{mg} / \mathrm{kg}$ e a $\mathrm{DL}_{50}$ dérmica $10.200 \mathrm{mg} / \mathrm{kg}$ para coelho, de acordo com NAKANO et alii (1977).

Propriedades e caracteristicas

Nome químico: isopropil 4,4'-dibromobenzilato

Fōrmula empirica: $\quad \mathrm{C}_{17} \mathrm{H}_{16} \mathrm{Br}_{2} \mathrm{O}_{3}$ 


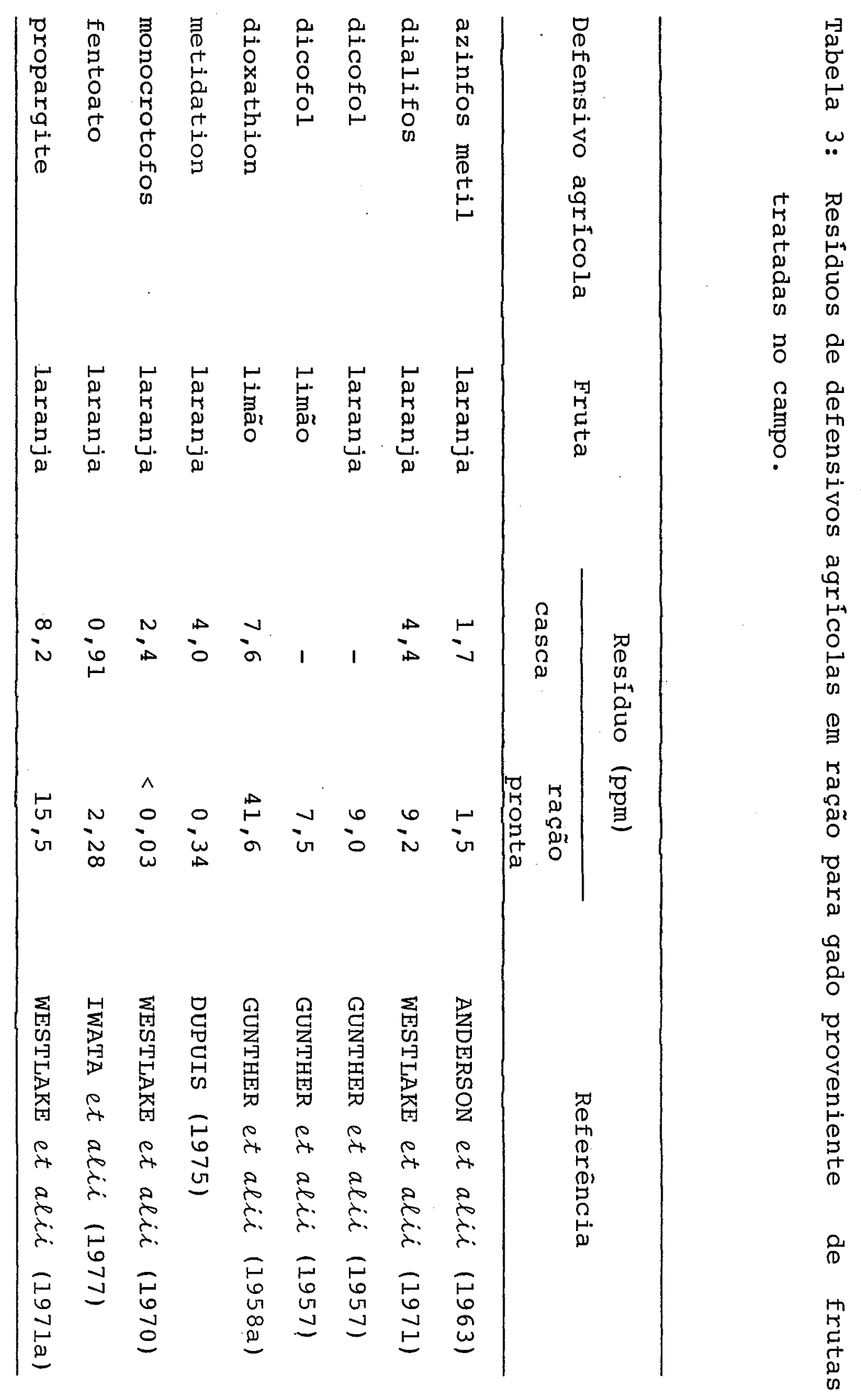


Fórmula estrutural:

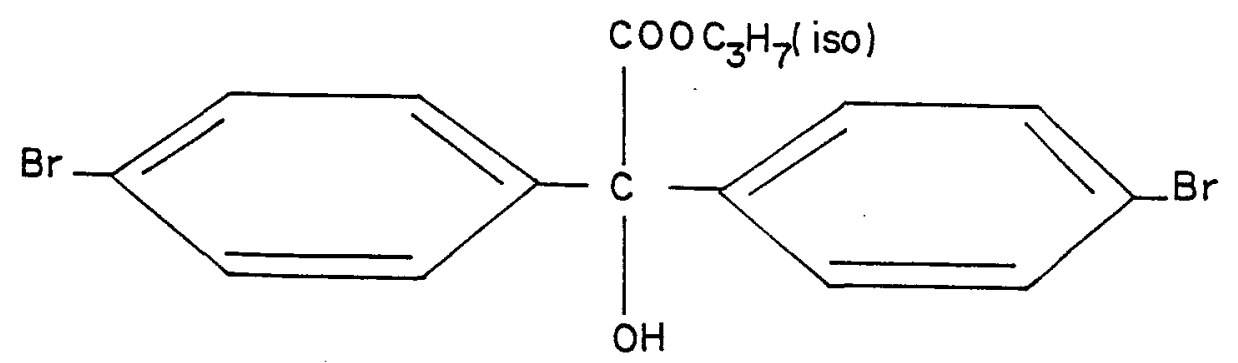

Propriedades físicas: (WHO, 1974)

o composto é um pó branco cristalino, com ponto de ebulição de 779C. A pressão de vapor é $.5,5 \mathrm{x}$ $10^{-7} \mathrm{~mm} \mathrm{Hg}$ a $20 \% \mathrm{C}$ e $5,25 \times 10^{-3} \mathrm{~mm} \mathrm{Hg}$ a $100 \% \mathrm{C}$. Sua estabilidade é razoável em meio neutro ou ligeiramente ácido (em pH 6-7, em água, é > 3 anos). O produto técnico possui no minimo 88\% de isópropil-4,4' dibromobenzilato, sendo os outros $12 \%$ representados por sub-produtos da fabricação. o bromopropilato é um acaricida de contato, tendo como principais culturas para aplicação, a fruta-pomo, citros, uva, lúpulo e algodão (WHO, 1974). Sua utilização em citros apresenta-se como uma alternativa no controle integrado de pragas (DUPUIS, 1975). Este autor comenta que a vantagem dos acaricidas carbinois, nos quais o bromopropilato se inclui, sobre os fosfatos orgânicos é que eles 
controlam a população de ácaros por um período de tempo maior e não são tóxicos a insetos úteis.

A eficiência de bromopropilato no controle dos ácaros, da falsa ferrugem, Phylloroptruta oleivora ou da leprose, Brevipalpus phoenicis é citada em SWIRSH et alii (1969), ROSSETO et alii (1981), RODRIGUES et alii (1981), CAETANO \& PRATES (1981), MYAZAKI et alii (1982), OLIVEIRA (1986), MARICONI et alii (1986) e EZAWA \& OLIVEIRA (1987).

\subsubsection{RESÍDUOS DE BROMOPROPILATO EM CITROS}

o bromopropilato é um acaricida não sistêmico e não penetrante. Ele permanece na casca dos frutos, migrando, talvez, em pequenas quantidades para a polpa. Vários experimentos em maçãs, citros e banana, mostraram claramente que a polpa de frutas tratadas continham no máximo traços de residuos do produto. (WHO, 1974). Neste mesmo trabalho è citado que, altas dosagens ou múltiplas aplicações geralmente produzem altos níveis de resíduos, istoé, a quantidade de resíduos logo após a aplicação é proporcional a quantidade de ingrediente ativo aplicada. Além disso, o nível e grau de desaparecimento dos resíduos de bromopropilato em frutas diferentes são excepcionalmente uniformes. 
Segundo Cassidy ${ }^{1}$, citado pela WHO (1974), a dissipação dos resíduos deste produto é devida principalmente aos fatores atmosféricos e diluição por crescimento.

A análise dos resíduos de bromopropilato, incluindo possíveis produtos de sua degradação (ácido 4,4' -dibromobenzilico; 4,4'-dibromobenzofenona; . 4,4'-dibromobenzhydroly e ácido 4-bromobenzóicol foi estudada por CULLEN et alii (1968), utilizando cromatógrafode gás, equipado com detector de captura de elétrons. O limite de deteção do método analítico foi de 0,01 ppm para leite e de 0,1 ppm para maçãs e laranjas.

Os residuos de bromopropilato podem ser determinados por métodos específicos utilizando cromatografia gasosa e cromatografia de camada delgada. Os detectores de captura de elétrons, microcoulomētrico e ionização de chama tēm sido usados com sucesso $\left(\mathrm{Geigy}^{2}\right.$ e Cannizzaro et alii ${ }^{3}$ ),

1 CASSIDY, J.E. Progress report. Fate of $14 \mathrm{C}$ GS 19851 on apples. Unpublished report from Geigy Chemical Corporation, New York, 1967.

2 GEYGY CHEMICAL CORPORATION. Ardsley, New York. Unpublished Reports filed with FATO, 1973.

3 CANNIZZARO, R.; CULLEN, T.; KAHRS, R.A.; MALLSEN, A.M. Specificity of gas-chromatographic determination of Acarol residues. Unpublished from Geigy Chemical Corporation, New York, 1968. 
citados por WHO (1974).

De acordo com WHO (1974) os residuos encontrados na colheita de maçãs tratadas são principalmente do composto original, sendo que o ácido 4,4'-dibromobenzilico representa aproximadamente 7\% destes. ₹. mencionado também que o ácido bromobenzóico, 4,4' dibromobenzofenona e 4,4' dibromobenzohidrol não puderam ser detectados.

Os dados de residuos de bromopropilato e os valores estimados de meia-vida em vārias culturas são apresentados em WHO (1974), sendo que citros apresentou 1,8 ppm imediatamente após a aplicação e meia-vida de 3 semanas.

Na TABELA 4 são apresentados os dados de residuos de bromopropilato em algumas culturas, onde observa-se um aumento no depósito inicial em função da utilização de dosagens crescentes. No entanto, a diminuição dos níveis de residuos ocorreu diferentemente para cada caso. Também é evidente a baixa penetração dos resíduos na polpa de laranja.

o efeito do cozimento nos residuos de bromopropilato foi estudado por BLASS (1973) citado pela WHO (1974). O. cozimento de maçãs, que apresentaram 5,0;0,67 e 0,41 ppm de bromopropilato, por 14 e 30 minutos, indicaram ređução de 50 e $80 \%$ dos resíduos iniciais.

Devido ao fato dos resíduos de bromopropilato se acumularem na casca dos frutos de citros e ao grande interesse na utilização deste substrato como ração para ga- 
44.

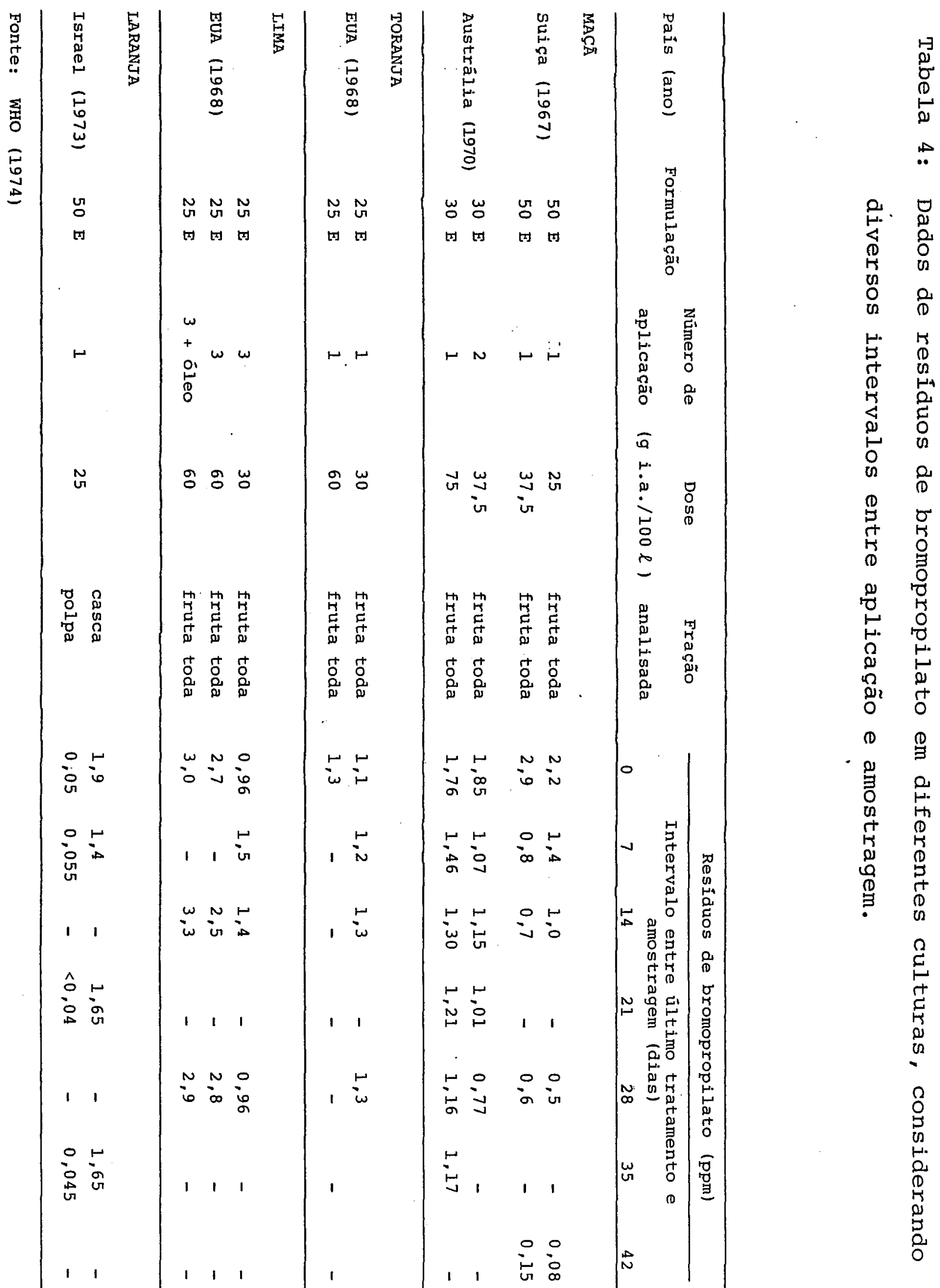


do, torna-se interessante o conhecimento do comportamento desses residuos nos referidos animais. Assim, a WHO (1974) cita que, a adição de bromopropilato à alimentação de gado leiteiro, em doses de 5 - $55 \mathrm{ppm}$, indicaram niveis de residuos que não ultrapassaram 1 ppm no leite por ele produzido. Com a retirada do produto da alimentação dos animais houve uma diminuição dos resíduos para niveis abaixo do limite de deteç̧ão, em sete dias. Também, bezerros alimentados com ração contendo este composto, acumularam quantidades significantes na gordura, mas somente pequenas quantidades nos músculos, rins e fígado.

Com relação ao limite de tolerância e período de carência de bromopropilato em citros, no Brasil, a Portaria SNVS no 10 de 08 de março de 1985 (BRASIL, Leis, decretos, etc., 1985), estabelece os valores de 5,0 ppm e 21 dias, respectivamente.

\subsection{CLOROBENZILATO}

o clorobenzilato foi introduzido como acaricida específico em 1952 (BARTSCH et alii, 1971). De acordo com a Portaria SNVS no 10 de 08 de março de 1985 (BRASIL. Leis, decretos, etc., 1985), este produto é classificado como acaricida fitossanitário do grupo dos benzilatos. Segundo NAKANO et alii (1977) sua $\mathrm{DI}_{50}$ oral é de $700-3200 \mathrm{mg} / \mathrm{kg}$ e a $\mathrm{DL}_{50}$ dérmica de 1000 - $3000 \mathrm{mg} / \mathrm{kg}$ para o coelho. 
46.

Propriedades e características

Nomes químicos: etil 4,4'-diclorobenzilato

etil 2-hidroxi - 2,2 -di(p-chorofenil) acetato (IUPAC)

Fórmula empírica: $\quad \mathrm{C}_{16} \mathrm{H}_{14} \mathrm{Cl}_{2} \mathrm{O}_{3}$

Förmula estrutural:

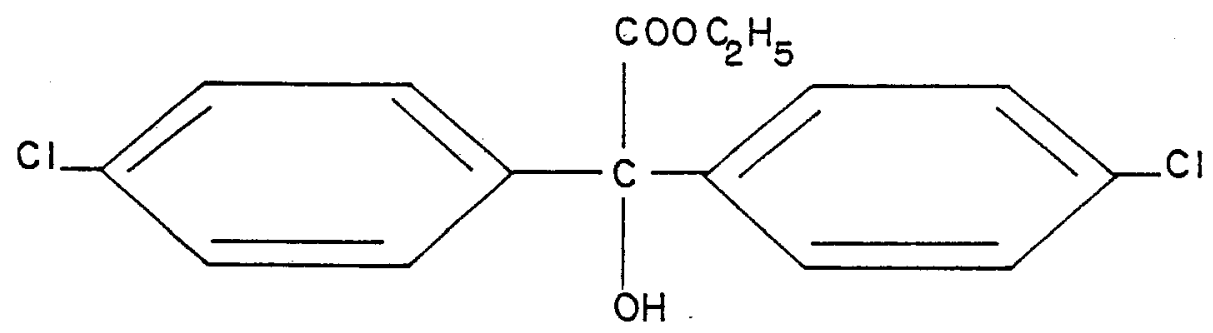

Propriedades fisicas: (BARTSCH et alii, 1971)

o composto puro é um líquido amarelado e viscoso, com ponto de ebulição de 141 a $1429 \mathrm{C}$ a $0,06 \mathrm{~mm}$ de $\mathrm{Hg}$. A pressão de vapor é $2,2 \times 10^{-6} \mathrm{~mm}$ de $\mathrm{Hg}$ a $209 \mathrm{C}$ e $1,4 \mathrm{x}$ $10^{-4} \mathrm{~mm}$ de $\mathrm{Hg}$ a $609 \mathrm{C}$. O produto técnico contēm aproximadamente $93 \%$ do composto acima, è um liquido pardacento com gravidade especifica de 1,2816 a 209/40 e pesa 1,283 kg/1i- 
tro. Clorobenzilato é virtualmente insolúvel em água, mas è muito solúvel em benzeno, acetona, álcool metílico, xileno e querosene desodorizada.

BARTSCH et alii (1971) citam que o clorobenzilato é um produto apropriado para controle de ácaros em frutas, uvas, plantas em crescimento como algodão, chā e particularmente em plantações de citros. Neste sentido, DUPUIS (1975) comenta que sua utilização é interessante para um programa de controle integrado de pragas, pois não é tóxico para insetos ūteis.

São diversas as referências que comprovam a eficiência de clorobenzilato no controle do ácaro-da falsa ferrugem, Phyllocoptruta oleivora lOLIVEIRA \& FERNANDES, 1983). Tambēm JEPPSON \& GUNTHER (1970) e FRENCH \& DUBE (1978) citam a eficiência deste produto no controle do referido ácaro.

\subsubsection{RESÍdUOS DE CLOROBENZILATO EM CITROS}

Os residuos de clorobenzilato em frutos de citros têm sido encontrados somente na casca (BARTSCH et alii, 1971). Segundo JEPPSON \& GUNTHER (1970) os resíduos localizam-se na camada de cera dos frutos e apresentam longos períodos de atuação, mostrando movimentação lenta para āreas subcuticulares da casca.

Quanto à anālise dos resíduos de clorobenzi- 
lato, BIINN et alii (1954) apresentam dois métodos analíticos: ultravioleta e colorimétrico. Os dois são baseados na hidrólise do clorobenzilato, presente no extrato de casca de citros, a ácido p,p'-diclorobenzilico, o qual é posteriormente oxidado a p,p'-diclorobenzofenona. Pelo método ultravioleta conseguiram recuperação de 87 a $103 \%$ de clorobenzilato, enquanto pelo método colorimétrico foram obtidos valores de 80 a $94 \%$, sendo os dois métodos sensíveis a $15 \mu \mathrm{g}$ de clorobenzilato em 3 gramas de extratos de citros (5 ppm). Os autores citam que o método ultravioleta é mais simples e rápido, além de apresentar melhor recuperação e sensibilidade em relação ao colorimétrico.

BARTSCH et alì (1971) apresentam várias alternativas de extração, limpeza e determinação dos resíduos, sendo que o método recomendado inclui a extração por meio de uma mistura de acetona e hexano, limpeza do extrato em coluna de alumina e determinação quantitativa em cromatógrafo a gás equipado com célula de titulação microcoulométrica sensível a cloro.

BLINN et alii (1954) analisando resíduos de clorobenzilato em frutos de limão coletados em área comercial pulverizada com $0,45 \mathrm{~kg}$ da formulação pó molhável a $25 \% / 380$ litros, encontraram valores que variaram de 8,6 a 5,7 ppm no 19 e 60 \% dias após a aplicação, respectivamente, pelo método ultravioleta e de 7,1 a 5,6 ppm pelo método colorimétrico. Na polpa dos frutos não foram detectados re- 
síduos em nenhuma das amostragens $11,15,30$ e 60 dias após a aplicação).

GUNTHER et alii (1955), trabalhando com dois métodos de análise química (ultravioleta e colorimétrico) e auxiliados pelo método biológico com o ácaro vermelho, demonstraram que o acaricida clorobenzilato possui uma meia-vida de 60-80 dias em cascas de limões pulverizados, sob condições de campo. Também concluiram que o clorobenzilato não penetrou em quantidades significativas na polpa. dos frutos.

Os dois trabalhos anteriores foram utilizados por GUNTHER (1969) para traçar a curva de persistência de clorobenzilato em cascas de limão Eureka, utilizando como métodos quantitativos o colorimétrico e o ultravioleta (FIGURA 5).

O estudo dos residuos de clorobenzilato, resultantes da aplicação de $0,11 \mathrm{~kg} / 380$ litros de solução, mostrou que o depósito inicial em cascas de limão foi de 9,5 ppm e que os resíduos persistiram por mais de 160 dias, enquanto a aplicação de $0,34 \mathrm{~kg} / 380$ litros (dosagem superior a utilizada na prática), resultou em depósito inicial de 19 ppm (JEPPSON \& GUNTHER, 1970). 
50.

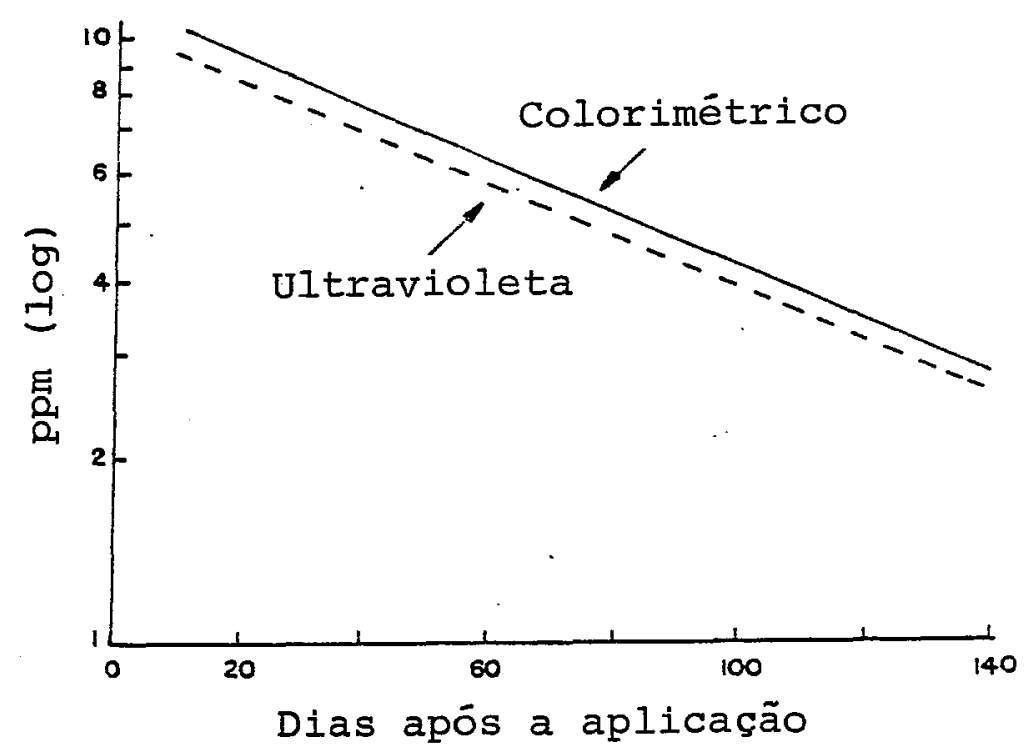

Figura 6: Curvas de persistência dos residuos de clorobenzilato, determinados pelos métodos colorimétrico e ultravioleta, em cascas de limões Eureka, após a aplicação de uma formulação pó molhável a 25\% na dosagem de $1,8 \mathrm{~kg} / 380$ litros (GUNTHER, 1969).

BARTSCH (1971) cita que a meia-vida de clorobenzilato em cascas de lima, determinada por cromatografia gasosa é de 20 dias. Este autor apresenta dados de residuos de clorobenzilato em laranjas 'Valência', cujas plantas receberam aplicação de $30 \mathrm{~g}$ i.a./100 litros, da formulação pó molhāvel 25\%. O método analítico empregado foi o ultravioleta, sendo que os resultados indicaram níveis de resíduos na casca de 1,38; 1,78; 2,80;1,43 e 1,99 ppm aos 0 , 3, 7, 14 e 21 dias após a aplicação. Na polpa não foram 
detectados residuos.

o estudo da redução de resíduos de clorobenzilato em laranja (Citrus sinensis (L.) osbeck), atravēs da lavagem do fruto e preparo do purê da fruta toda, foi reaIizado por ALBACH \& LIME (1976). Para determinação quantitativa dos residuos foi utilizado cromatógrafo de gás equipado com detector de captura de elétrons. Estes autores observaram que a lavagem eliminou 15\% dos resíduos, enquanto o processo de fabricação do purê mais a lavagem reduziram 81\% destes. É citado também que, mesmo um dia apōs a aplicação, os resíduos não excederam a tolerância estabelecida $(5,0 \mathrm{ppm})$.

IWATA (1979) avaliou os residuos de clorobenzilato em polpa de laranja e limão, cujas plantas foram tratadas com dosagem excessiva $(3,4 \mathrm{~kg} / \mathrm{ha})$. A coleta das amostras se deu aos 52 e 59 dias após aplicação, sendo que a determinação dos resíduos foi realizada através de cromatógrafo de gás, equipado com detector de captura de elétrons. Não foi verificada presença de residuos na polpa, nem para laranja, nem para limão, acima do limite de detecção $(0,01 \mathrm{ppm})$.

No Brasil, o limite de tolerância de clorobenzilato em citros é de 1,0 ppm e o período de carência, de 5 dias (Portaria SNVS no 10 de 08 de março de 1985, BRASIL. Leis, decretos, etc., 1985). 


\section{MATERIAIS E MÉTODOS}

\subsection{EXPERIMENTO DE CAMPO}

Os dois experimentos foram instalados na Estação Experimental de Citricultura do Instituto Agronômico de Campinas, localizada no município de Cordeirópolis-SP. Utilizou-se a variedade 'Valência' em pomar de 10 anos de idade, com espaçamento de $7 \times 6 \mathrm{~m}$, sendo a parcela experimental constituída de 3 plantas adjacentes.

\subsubsection{EXPERIMENTO 1 - BROMOPROPILATO}

A instalação deu-se em junho de 1982, ocasião em que os frutos da referida variedade estavam em fase inicial de maturação, constando o experimento com 2 tratamentos e 3 repetições em delineamento inteiramente casualizado. As dosagens de bromopropilato (Neoron $50 \mathrm{CE}$ ), utilizadas foram: $1000 \mathrm{~g} \mathrm{p.a./ha} \mathrm{(tratamento} \mathrm{A)} \mathrm{e} 2000 \mathrm{gp.a.} / \mathrm{ha}$ (tratamento B). As diluições feitas foram: $250 \mathrm{ml}$ e $500 \mathrm{ml}$ de Neoron $50 \mathrm{CE}$, respectivamente, por 100 litros de água. Para aplicação do produto, foi utilizado um 
pulverizador costal motorizado marca JACTO, procurando-se molhar uniformemente as plantas, até o início do escorrimento, sendo gastos em média 3,4 litros de calda por planta. Na preparação da calda utilizou-se o espalhante adesivo Colombina na quantidade de $40 \mathrm{ml} / 100$ litros de água. As amostragens de frutos foram realizadas aos $3,7,15,24,38,59$ e 100 dias após a aplicação, através da colheita de 24 frutos de cada parcela $(8$ frutos por árvore, ao acaso). Paralelamente às amostras de parcelas tratadas foram também colhidas amostras testemunhas de ārvores sabidamente não pulverizadas, a fim de se estudar a possível interferência das impurezas no cromatograma final. Os frutos foram acondicionados em sacos de papel e enviados para o laboratório, onde foram, basicamente, preparados de acordo com GUNTHER (1969). Dessa maneira, as cascas foram separadas das polpas com auxilio de um descascador de alumínio, conforme Figura 7. Com auxilio de um vazador de metal de $2 \mathrm{~cm}$ de diâmetro e $12 \mathrm{~cm}$ de comprimento, foi retirado um cilindro de polpa de cada laranja.

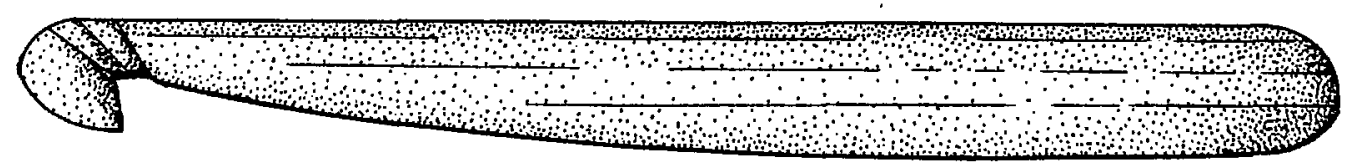

Figura 7: Descascador de frutos de citros, construido com alumínio. Escala $1: 1$. 
As cascas foram moîdas em moedor marca Lico e o material obtido foi homogeneizado. Após, pesou-se $20 \mathrm{~g}$ de cascas e $20 \mathrm{~g}$ de polpas, em duplicata. As amostras foram, então, envoltas por papel alumínio e acondicionadas em congelador a $-209 \mathrm{C}$, até o momento de serem analisadas.

\subsubsection{EXPERIMENTO 2 - CLOROBENZILATO}

Este experimento foi instalado em julho de 1983, com 2 tratamentos e 4 repetições em delineamento inteiramente casualizado. As dosagens de clorobenzilato (Akar $500 \mathrm{EC}$ ) utilizadas foram: $500 \mathrm{~g} \mathrm{p.a./ha} \mathrm{(tratamento}$ A) e $1000 \mathrm{~g} \mathrm{p.a./ha} \mathrm{(tratamento} \mathrm{B).} \mathrm{As} \mathrm{diluições} \mathrm{feitas} \mathrm{fo-}$ ram: $84 \mathrm{ml}$ e $168 \mathrm{ml}$ de Akar $500 \mathrm{EC}$, respectivamente, por 100 litros de água.

o equipamento utilizado para aplicação, bem como o espalhante adesivo e sua dosagem, são os mesmos referidos no experimento anterior. A calda necessária por árvore, foi de 5 litros, sendo aplicada até o início do escorrimento.

Os frutos foram amostrados aos 3, 7, 15, 25, 42,60 e 100 dias após a aplicação. A metodologia de amostragem e preparação das amostras foram as mesmas referidas para o experimento 1 , sendo neste caso, também colhidas amostras testemunhas de árvores não tratadas. 


\subsection{LiMITES DE DETECCÃO; PORCENTAGENS DE RECUPERACÃO E DESCRICÃ̃ DO MÉTODO DE ANÁLISE DE RESÍDUOS DE BROMOPROPILATO E CLOROBENZILATO EM CASCA E POLPA DE LARANJAS}

Realizou-se o estudo dos limites de detecção e das porcentagens de recuperação de bromopropilato e clorobenzilato em casca e polpa de laranjas 'Valência', através de amostras preparadas identicamente àquelas provenientes de plantas tratadas. A seguir, foram fortificadas no sentido de se obter concentrações de $1 ; 0,1 ; 0,05 ; 0,02 ; 0,01$; 0,005 e 0,002 ppm para bromopropilato e $2 ; 1,0,5 ; 0,2 ; 0,1$ e 0,05 ppm para clorobenzilato em ambos os substratos, sendo que as determinações foram feitas em duplicata para cada nível de fortificação.

o método de análise de resíduo foi basicamente aquele de RIBAS (1974). As amostras, no caso de casca, são submetidas à extração com uma mistura de acetonitrilo e água e, no caso de polpa, usando-se apenas acetonitrilo; em seguida é feita partição em ēter de petróleo e água. A limpeza do extrato é efetuada em coluna de florisil, sendo a eluição procedida com uma mistura de éter de petróleo e éter etílico. Segue-se a determinação quantitativa feita em cromatógrafo de gás equipado com detector de captura de elétrons (DCE). 


\subsubsection{REAGENTES}

- acetonitrilo - para análise de pesticidas;

- āgua destilada;

- éter etílico - PA - livre de peróxidos, destilado em destilador de vidro;

- éter de petróleo $(30$ - 609C) - PA - ACS - redestilado em destilador de vidro;

- n-hexano - PA - ACS - redestilado em destilador de vidro;

- florisil - 60 - 100 mesh, mantido em estufa a 1309C, desativado com 5\% de água destilada, no dia anterior ao da anālise;

- sulfato de sódio, anidro, granulado;

- padrões analíticos de bromopropilato e clorobenzilato.

\subsubsection{APARELHOS, VIDRARIA E OUTROS MATERIAIS}

- cromatógrafo de gás, marca CG, modelo 3700, equipado com detector de captura de elétrons (niquel $-\mathrm{Ni}^{63}$ ) e coluna cromatográfica de vidro, diâmetro de 1/8", comprimento 1,2 m, empacotada com 2,5\% de SE-30/Chromosorb WHP ;

- liquidificador de alta rotação - marca Walita;

- bomba pneumática, marca GE, motor de 1/4 HP;

- capela com ventilação forçada por exaustor; 
- banho-maria elétrico, com suporte para Kuderna-Danish;

- balança analitica, marca Metler, modelo Hlo;

- microseringa de $10 \mu 1$, marca Terumo;

- quitassato, $500 \mathrm{ml}$;

- funil de separação, $500 \mathrm{ml}$;

- funil de vidro comum;

- provetas graduadas, 10, 50, 100 e $250 \mathrm{ml}$;

- tubos de centrifuga graduados, $15 \mathrm{ml}$;

- coluna cromatográfica, vidro 10 x $300 \mathrm{~mm}$, com placa porosa de porosidade grosseira;

- concentrador Kuderna-Danish, $500 \mathrm{ml}$;

- coluna de reflexo de Snyder, com 3 bolas;

- tubos coletores de Mills, graduados, $10 \mathrm{ml}$;

- pipetas graduadas de $1,2,5$ e $10 \mathrm{ml}$;

- papel de filtro Whatman ne 5;

- rolha de borracha revestida com folha de aluminio, para tubo de centrifuga de $15 \mathrm{ml}$;

- régua de madeira 
58 .

\subsubsection{DESCRICÃ̃ DO MÉTODO DE ANÁLISE DE RESIDUOS DE BROMOPROPILATO E DE CLOROBENZILATO EM CASCA E POLPA DE LARANJAS}

\section{A - Extração}

A1. Pesar $20 \mathrm{~g}$ de amostra (casca ou polpa), transferir para o copo do liquidificador, adicionar $100 \mathrm{ml}$ de uma solução de acetonitrilo + água destilada (65+ 35) no caso de extração de casca, ou $100 \mathrm{ml}$ de acetonitri1o, apenas, no caso de polpa, e homogeneizar por 3 minutos.

A2. Filtrar em funil de Büchner, através de papel de filtro, com auxílio de vácuo, recolhendo o filtrado em um quitassato.

A3: Transferir uma alíquota de $40 \mathrm{ml}$ do quitassato para um funil de separação, adicionar $40 \mathrm{ml}$ de éter de petróleo e agitar vigorosamente por 30 segundos; juntar $5 \mathrm{ml}$ de uma solução saturada de $\mathrm{Na}_{2} \mathrm{SO}_{4}$ e $200 \mathrm{ml}$ de água destilada. Agitar novamente durante 30 segundos, esperar a separação das fases e eliminar a camada aquosa inferior.

A4. Filtrar o extrato de éter de petróleo em um pouco de $\mathrm{Na}_{2} \mathrm{SO}_{4}$ suspenso num funil de vidro, retendo $30 \mathrm{ml}$ em uma proveta graduada. 


\section{B - Limpeza}

B1. Preparar uma coluna cromatográfica de florisil de 10 x $300 \mathrm{~mm}$, adicionando-se florisil desativado no dia anterior com 5\% de água destilada, até uma altura de $14 \mathrm{~cm}$; com auxílio de uma régua de madeira fazer a acomodação do florisil. Adicionar $\mathrm{Na}_{2} \mathrm{SO}_{4}$ anidro, suficiente para formar uma camada de $1 \mathrm{~cm}$ sobre o florisil e eluir a coluna com éter de petrōleo, quando este estiver quase atingindo a camada de $\mathrm{Na}_{2} \mathrm{SO}_{4}$, introduzir os $30 \mathrm{ml}$ de extrato contido na proveta, eluindo com velocidade de 60-80 gotas por minuto, passando a coletar o eluente em um concentrador Kuderna-Danish.

B2. Eluir a coluna com $50 \mathrm{ml}$ de uma solução de éter-etílico + éter de petróleo $(6+94)$, na mesma velocidade citada, continuando a recolher o eluente no concentrador.

B3. Concentrar em banho-maria em capela com ventilação forçada atē $1 \mathrm{ml}$ no tubo coletor de Mills, do concentrador Kuderna-Danish.

B4. Completar, no tubo de Mills, o volume para $5 \mathrm{ml}$ com $\mathrm{n}$-hexano. Transferir o extrato final para um tubo de centrifuga graduado de $5 \mathrm{ml}$ e fechar bem, com rolha de borracha revestida com folha de aluminio. 


\section{C - Determinação quantitativa por croma- tografia de gás}

Cl. Injetar aliquotas de 3-8 $\mu l$ do extrato final no cromatógrafo.

C2. Se necessário, em função do nível de contaminação, concentrar o extrato até obter picos mensuráveis ou diluílo até obter picos com menos de $70 \%$ de deflexão na escalà.

C3. Diluir o padrão analitico de forma a se obter picos de alturas semelhantes aos da amostra.

C4. Injetar aliquotas de 3-8 $\mu 1$ no cromatógrafo, na sequência: padrão, amostra, amostra padrão.

C5. Condições de operação do cromatógrafo:

\begin{tabular}{lll}
\hline \multirow{2}{*}{ Parâmetros } & \multicolumn{2}{c}{ Produto } \\
\cline { 2 - 3 } Fluxo de nitrogênio $\left(\mathrm{N}_{2}\right)$ & $35 \mathrm{ml} / \mathrm{min}$. & $35 \mathrm{ml} / \mathrm{min}$. \\
Temperatura da coluna & $2159 \mathrm{C}$ & $1909 \mathrm{C}$ \\
Temperatura do vaporizador & $2209 \mathrm{C}$ & $2109 \mathrm{C}$ \\
Temperatura do detector & $2609 \mathrm{C}$ & $2609 \mathrm{C}$ \\
Atenuação & $1 \mathrm{x}$ & $1 \times \mathrm{x}$ \\
Compensador de corrente & $10^{-9} \mathrm{~A}$ & $10^{-8} \mathrm{~A}$ \\
Velocidade de registro & $0,25 \mathrm{pol} / \mathrm{min}$. & $0,25 \mathrm{pol} / \mathrm{min}$. \\
Tempo de retenção & $3 \mathrm{~min} . \mathrm{e} 40 \mathrm{seg}$. & $5 \mathrm{~min} . \mathrm{e} 15 \mathrm{seg}$. \\
\hline
\end{tabular}


C6. Cálculo dos resíduos: Os residuos foram calculados por comparação direta com os padrões, baseados nas alturas dos picos dos padrões e das amostras, levando-se em consideração o conteúdo de āgua dos dois substratos (BARRY et alii, 1968).

$$
\begin{aligned}
& \text { Residuos em cascas } \\
& \text { ppm }=\frac{m p \times \text { ha }}{1,05 \times \mathrm{V} \times \mathrm{Hp}} \\
& \text { Residuos em polpas } \\
& \text { ppm }=\frac{\mathrm{mp} \times \mathrm{ha}}{1,03 \times \mathrm{V} \times \mathrm{Hp}}
\end{aligned}
$$

onde:

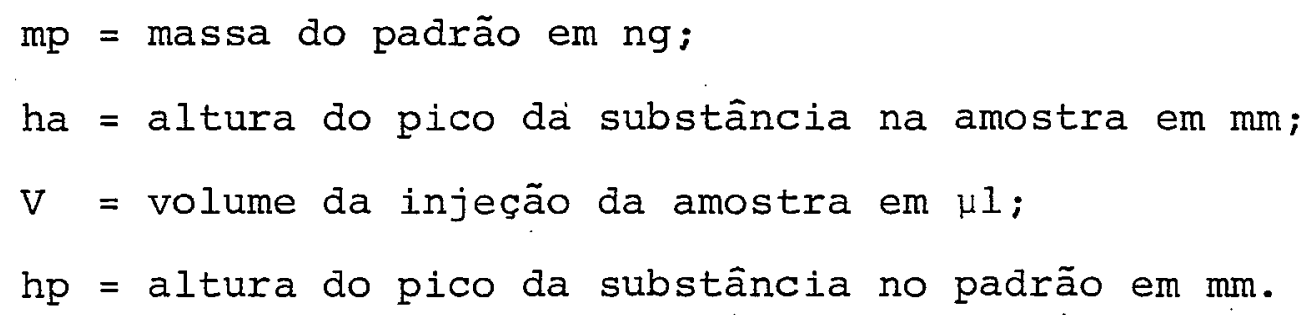




\section{RESULTADOS E DISCUSSÃO}

\subsection{LiMITES DE DETECCÃO E PORCENTAGENS DE RECUPERAÇÃO DO MÉTODO}

Na Tabela 5 são apresentados os dados dás porcentagens de recuperação de bromopropilato e de clorobenzilato em cascas e polpas fortificadas. Os cromatogramas obtidos nas fortificações de $0,01 \mathrm{ppm}$ de bromopropilato e de $0,5 \mathrm{ppm}$ de clorobenzilato em amostras de cascas e polpas, bem como aqueles de amostras testemunhas, são mostrados nas Figuras 8, 9, 10, 11, 12 e 13.

As análises das amostras fortificadas com bromopropilato revelaram porcentagens de recuperação variāvel de 79-108\% em casca e de 79-113\% em polpa. o limite de deteç̧ão desse produto nesses substratos ficou estabelecido em $0,005 \mathrm{ppm}$, porque abaixo deste valor as impurezas interferentes, nas condições das análises executadas, dificultaram a quantificação dos picos nos cromatogramas.

Quanto ao clorobenzilato, foi detectada variação nas porcentagens de recuperação de 71-98\% em casca e de 71-93\% em polpa. O limite de deteç̧ão desse acaricida 
nos referidos substratos ficou estabelecido em 0,1 ppm, pois abaixo deste valor a quantificação dos picos nos cromatogramas foi dificultada por impurezas interferentes.

Pelos resultados obtidos com a utilização do método de RIBAS (1974), para recuperação de bromopropilato e clorobenzilato em amostras de cascas e polpas de laranjas, pode-se considerar este método altamente satisfatório para análise desses dois acaricidas nesses substratos. Em polpa de laranja, IWATA (1979) conseguiu recuperação de 0,01 ppm de clorobenzilato, sendo que o autor explica este baixo limite de deteção devido a limpeza adicional da amostra e uso de cromatógrafo de gás equipado com detector de captura de elétrons.

TABELA 5: Porcentagens de recuperação de bromopropilato e clorobenzilato, pelo método de RIBAS (1974) em casca e polpa de laranjas fortificadas.

\begin{tabular}{|c|c|c|c|c|c|c|c|c|c|c|}
\hline \multirow{2}{*}{ bromopropilato } & \multicolumn{10}{|c|}{ Nivel de fortificaçāo (ppm) } \\
\hline & 2 & 1 & 0,5 & 0,2 & 0,1 & 0,05 & 0,02 & 0,01 & 0,005 & 0,002 \\
\hline \multirow{2}{*}{ casca } & - & 101 & - & - & 95 & 94 & 94 & 92 & 97 & $<I D^{a}$ \\
\hline & - & 108 & - & - & 98 & 94 & 93 & 80 & 79 & $<\tau D$ \\
\hline \multirow{2}{*}{ polpa } & - & 82 & - & - & 84 & 91 & 96 & 95 & 113 & $<$ ID \\
\hline & - & 82 & - & - & 89 & 97 & 79 & 92 & 105 & $<I D$ \\
\hline \multicolumn{11}{|l|}{ clorobenzilato } \\
\hline \multirow{2}{*}{ casca } & 85 & 76 & 77 & 75 & 90 & $<\mathrm{LD}$ & - & - & - & - \\
\hline & 78 & 98 & 76 & 71 & 75 & $<\mathrm{LD}$ & - & - & - & - \\
\hline \multirow{2}{*}{ polpa } & 79 & 75 & 89 & 71 & 93 & $<\mathrm{LD}$ & - & - & - & - \\
\hline & 81 & 85 & 86 & 73 & 91 & $<L D$ & - & - & - & - \\
\hline
\end{tabular}

(a) ID = Limite de Detecção 


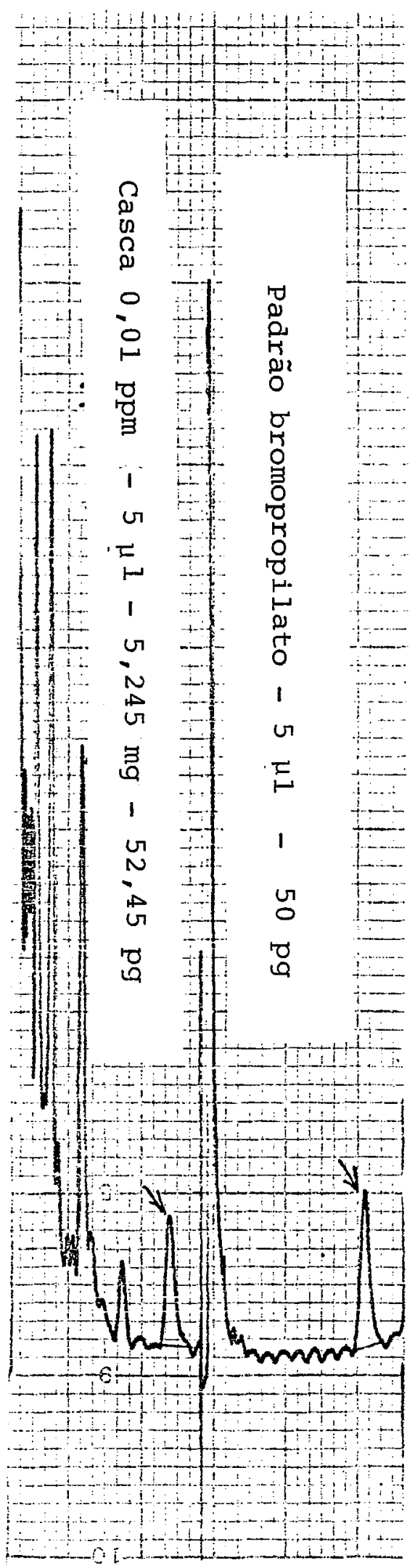

Condições de operação Atn $=1 \mathrm{x}$

$\mathrm{z}=0,25 \mathrm{pol} / \mathrm{minuto}$

$\mathrm{CC}=10^{-9} \mathrm{~A}$

Figura 8: Cromatogramas do padrão e da amostra de casca fortificada com $0,01 \mathrm{ppm}$ de bromopropilato. 


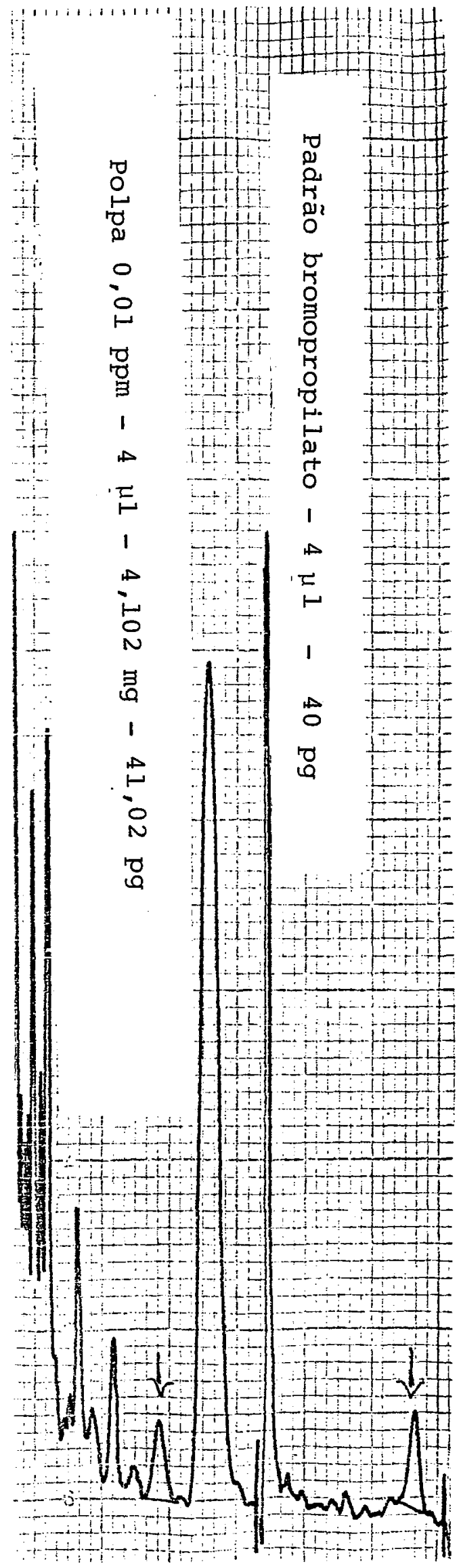

65.

Condições de operação

$$
\begin{aligned}
& \text { Atn }=1 \mathrm{x} \\
& \mathrm{z}=0,25 \text { pol/minuto } \\
& \mathrm{CC}=10^{-9} \mathrm{~A}
\end{aligned}
$$

Figura 9: Cromatogramas do padrão e da amostra de polpa fortificada com $0,01 \mathrm{ppm}$ de bromopropilato. 


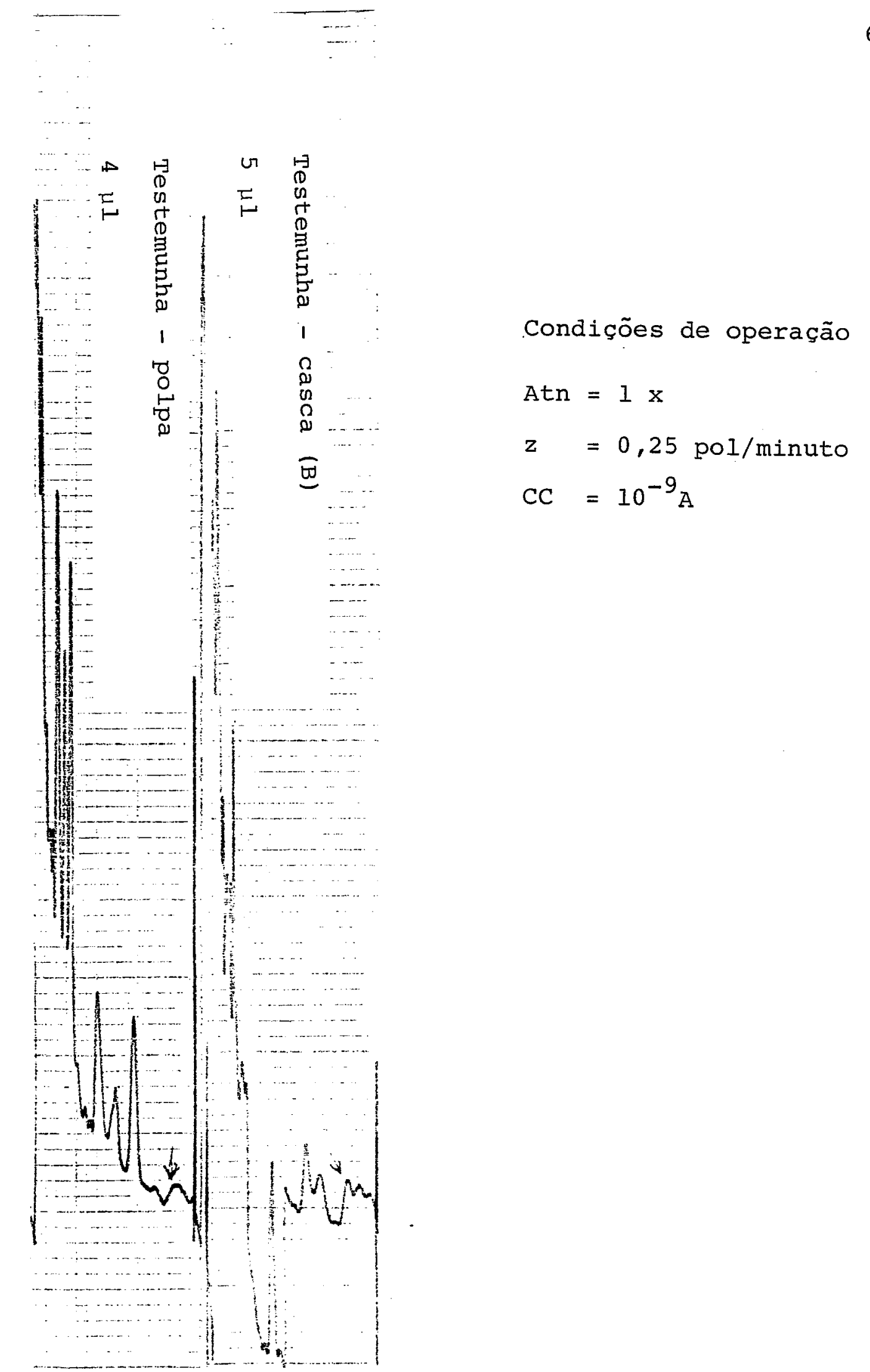

66.

Figura 10: Cromatogramas de amostras testemunhas de cascas e polpas (2159C - "bromopropilato".) . 


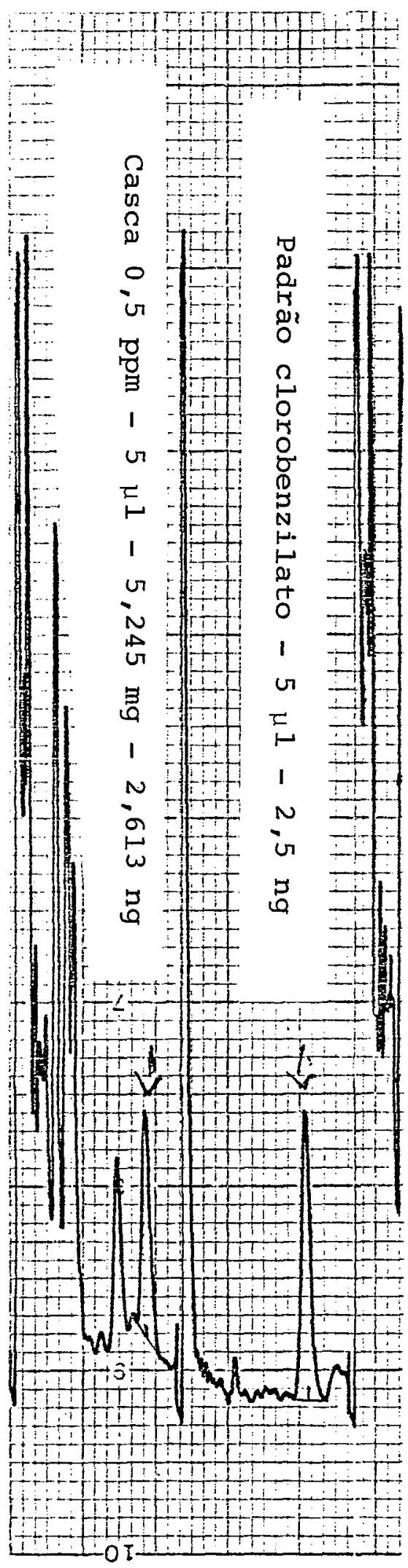

Condições de operação

$$
\begin{aligned}
& \text { Atn }=1 \mathrm{x} \\
& \mathrm{z}=0,25 \text { pol/minuto } \\
& \mathrm{CC}=10^{-8} \mathrm{~A}
\end{aligned}
$$

Figura 11: Cromatogramas do padrão e da amostra de casca fortificada com $0,5 \mathrm{ppm}$ de clorobenzilato. 


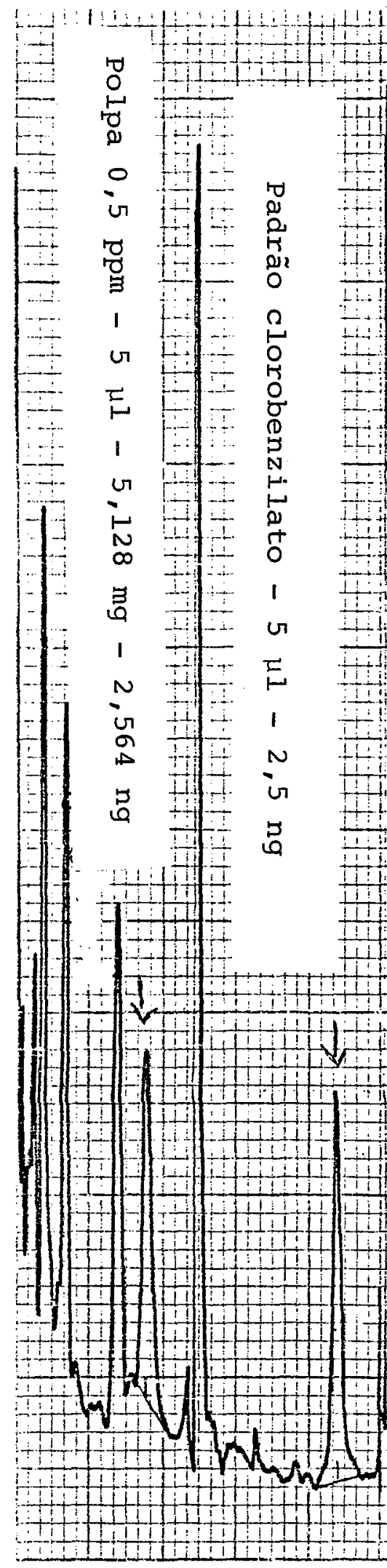

68.

Condições de operação

$$
\begin{aligned}
& \text { Atn }=1 \mathrm{x} \\
& \mathrm{z}=0,25 \text { pol/minuto } \\
& \mathrm{CC}=10^{-8} \mathrm{~A}
\end{aligned}
$$

Figura 12: Cromatogramas do padrão e da amostra de polpa fortificada com $0,5 \mathrm{ppm}$ de clorobenzilato. 
69.

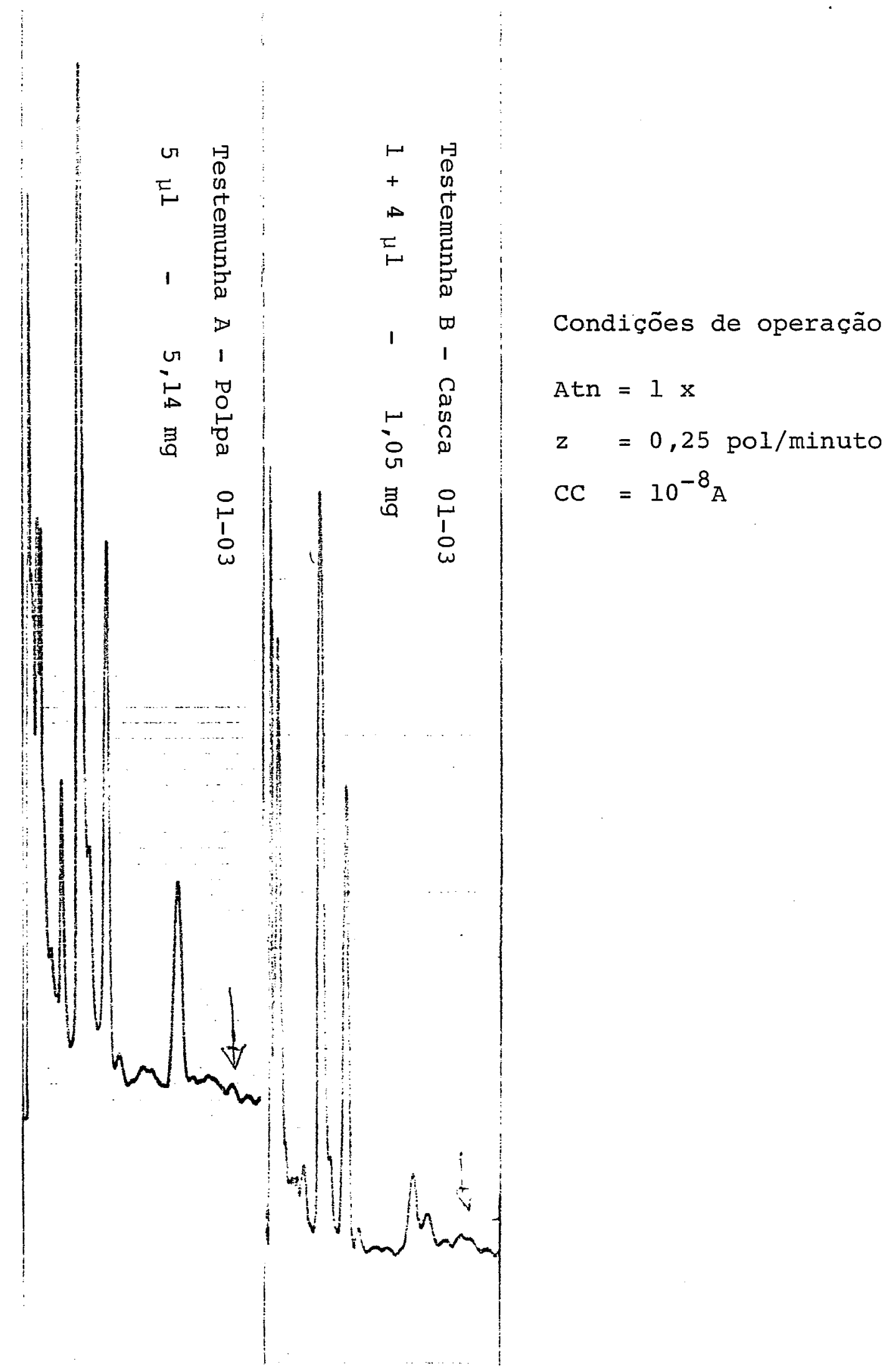

Figura 13: Cromatogramas de amostras testemunhas de cascas e polpas (1909C - "clorobenzilato"). 


\subsection{RESIDUOS DE BROMOPROPILATO EM CASCAS E POLPAS DE LARANJAS 'VALÊNCIA'}

Na Tabela 6 são apresentados os resultados obtidos nas análises de frutos provenientes de plantas tratadas com bromopropilato, sendo que nas Figuras 14 e 15 são mostradas as ilustrações gráficas destes resultados para cascas. Observa-se que as quantidades de residuos presentes na casca de laranjas 'Valēncia' seguiram a poporção de aproximadamente 2:3 para os tratamentos A e B, indicando desta maneira uma degradação inicial (antes da primeira coleta) mais rápida para a dosagem de $2000 \mathrm{~g}$ i.a./ha quando comparada a $1000 \mathrm{~g}$ i.a./ha, pois logo apōs a aplicação, a quantidade de residuos esperada é proporcional a quantidade de ingrediente ativo aplicada (WHO, 1974).

Com os valores obtidos no presente estudo aos 2 dias após a aplicação, pode-se visualizar a grande diminuição inicial dos resíduos de bromopropilato presentes nos frutos. Assim, a quantidade de residuos na fruta toda, considerando que a variedade 'Valência' apresenta 19\% de casca e, obviamente 81\% de polpa (IWATA, 1977), determina valores da ordem de 1,1 ppm para a dosagem de $1000 \mathrm{gi.a./ha,}$ - que é significativamente inferior a 1,8 ppm citado pela WHO (1974) para resíduos determinados imediatamente após a aplicação, considerando-se a dosagem "média . recomendada (650 g i.a./ha). 
Tabela 6: Residuos de bromopropilato em cascas e polpas de laranjas 'Valência' provenientes de plantas pulverizadas com $1000 \mathrm{~g}$ i.a./ha (tratamento A) e $2000 \mathrm{~g}$ i.a./ha (tratamento B).

\begin{tabular}{|c|c|c|c|c|c|c|}
\hline \multirow{2}{*}{$\begin{array}{l}\text { Dias após a } \\
\text { aplicação }\end{array}$} & \multirow{2}{*}{ Tratamento } & & \multicolumn{3}{|c|}{ Repetição (ppm) } & \multirow{2}{*}{$\begin{array}{c}\text { Média (ppm) } \\
(m \pm d p)\end{array}$} \\
\hline & & & 1 & 2 & 3 & \\
\hline \multirow{9}{*}{3} & \multirow{5}{*}{ A } & \multirow{2}{*}{ Casca } & 5,83 & 5,20 & 5,19 & \multirow{2}{*}{$5,40 \pm 0,29$} \\
\hline & & & 5,44 & 5,66 & 5,10 & \\
\hline & & \multirow{2}{*}{ Polpa } & 0,029 & 0,023 & 0,030 & \multirow{2}{*}{$0,03 \pm 0,003$} \\
\hline & & & 0,027 & 0,029 & 0,022 & \\
\hline & & & & & & \\
\hline & \multirow{4}{*}{ B } & \multirow{2}{*}{ - Casca } & 8,81 & 6,89 & 7,72 & \multirow{2}{*}{$7,67 \pm 0,97$} \\
\hline & & & 8,87 & 6,64 & 7,10 & \\
\hline & & \multirow{2}{*}{ Polpa } & 0,082 & 0,060 & 0,084 & \multirow{2}{*}{$0,07 \pm 0,01$} \\
\hline & & & 0,079 & 0,063 & 0,077 & \\
\hline \multirow{8}{*}{7} & \multirow{4}{*}{$\mathrm{A}$} & \multirow{2}{*}{ Casca } & 4,02 & 4,78 & 4,20 & \multirow{2}{*}{$\begin{array}{c}4,38 \pm 0,36 \\
(1,23)^{\mathrm{a}}\end{array}$} \\
\hline & & & 4,18 & 4,20 & 4,90 & \\
\hline & & \multirow{2}{*}{ Polpa } & 0,052 & 0,047 & 0,048 & \multirow{2}{*}{$\begin{array}{c}0,05 \pm 0,008 \\
(0,59)\end{array}$} \\
\hline & & & 0,056 & 0,035 & 0,040 & \\
\hline & \multirow{4}{*}{ B } & \multirow{2}{*}{ Casca } & 7,93 & 5,77 & 6,56 & \multirow{2}{*}{$\begin{array}{c}6,65 \pm 1,16 \\
(1,15)\end{array}$} \\
\hline & & & 8,01 & 5,07 & 6,53 & \\
\hline & & \multirow{2}{*}{ Polpa } & 0,40 & 0,34 & 0,54 & \multirow{2}{*}{$\begin{array}{c}0,43 \pm 0,091 \\
(0,17)\end{array}$} \\
\hline & & & 0,32 & 0,49 & 0,50 & \\
\hline \multirow{9}{*}{15} & \multirow{4}{*}{ A } & \multirow{2}{*}{ Casca } & 3,67 & 3,50 & 3,42 & \multirow{2}{*}{$\begin{array}{c}3,49 \pm 0,21 \\
(1,25) .\end{array}$} \\
\hline & & & 3,24 & 3,80 & 3,31 & \\
\hline & & \multirow{2}{*}{ Polpa } & 0,10 & 0,11 & 0,12 & $0,11 \pm 0,013$ \\
\hline & & & 0,095 & 0,12 & 0,13 & $(0,42)$ \\
\hline & & & & & & \\
\hline & & Casca & 5,76 & 4,19 & 5,55 & $2,22-0,62$ \\
\hline & D & & 5,80 & 4,70 & 5,33 & $(1,27)$ \\
\hline & 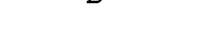 & Polpa & 0,41 & 0,42 & 0,45 & $0,41 \pm 0,033$ \\
\hline & & & 0,41 & 0,40 & 0,35 & $(1,05)$ \\
\hline
\end{tabular}

(a) Os números entre parēnteses indicam os quocientes de redução entre duas coletas consecutivas 
Tabela 6: Continuação

\begin{tabular}{|c|c|c|c|c|c|c|}
\hline \multirow{2}{*}{$\begin{array}{l}\text { Dias após a } \\
\text { aplicação }\end{array}$} & \multirow{2}{*}{ Tratamento } & & \multicolumn{3}{|c|}{ Repetição (ppm) } & \multirow{2}{*}{$\begin{array}{c}\text { Média (ppm) } \\
(m \pm d p)\end{array}$} \\
\hline & & & 1 & 2 & 3 & \\
\hline \multirow{8}{*}{24} & \multirow{4}{*}{ A } & \multirow[t]{2}{*}{ Casca } & 2,86 & 2,40 & 2,84 & $2,63 \pm 0,30$ \\
\hline & & & 2,93 & 2,19 & 2,57 & $(1,33)$ \\
\hline & & \multirow{2}{*}{ Polpa } & 0,13 & 0,12 & 0,11 & $0,12 \pm 0,019$ \\
\hline & & & 0,081 & 0,13 & 0,13 & $(0,92)$ \\
\hline & \multirow{4}{*}{ B } & \multirow{2}{*}{ Casca } & 3,41 & 4,13 & 4,44 & $4,04 \pm 0,37$ \\
\hline & & & 3,81 & 4,17 & 4,25 & $(1,29)$ \\
\hline & & \multirow{2}{*}{ Polpa } & 0,38 & 0,30 & 0,21 & $0,30 \pm 0,055$ \\
\hline & & & 0,30 & 0,31 & 0,28 & $(1,37)$ \\
\hline \multirow{8}{*}{38} & \multirow{4}{*}{ A } & \multirow[t]{2}{*}{ Casca } & 2,32 & 1,86 & 2,25 & $2,07 \pm 0,31$ \\
\hline & & & 2,46 & 1,81 & 1,73 & $(1,27)$ \\
\hline & & \multirow{2}{*}{ Polpa } & 0,077 & 0,067 & 0,087 & $0,08 \pm 0,012$ \\
\hline & & & 0,075 & 0,075 & 0,10 & $(1,50)$ \\
\hline & \multirow{4}{*}{ B } & \multirow{2}{*}{ Casca } & 3,13 & 3,70 & 3,90 & $3,64 \pm 0,32$ \\
\hline & & & 3,73 & 3,97 & 3,38 & $(1,11)$ \\
\hline & & \multirow{2}{*}{ Polpa } & 0,12 & 0,11 & 0,099 & $0,11 \pm 0,010$ \\
\hline & & & 0,11 & 0,091 & 0,11 & $(2,73)$ \\
\hline \multirow{8}{*}{59} & \multirow{4}{*}{ A } & \multirow[t]{2}{*}{ Casca } & 1,86 & 1,61 & 2,05 & $1,73 \pm 0,30$ \\
\hline & & & 2,01 & 1,51 & 1,31 & $(1,20)$ \\
\hline & & \multirow{2}{*}{ Polpa } & 0,065 & 0,041 & 0,035 & $0,04 \pm 0,014$ \\
\hline & & & 0,047 & 0,041 & 0,023 & $(1,90)$ \\
\hline & \multirow{4}{*}{ B } & \multirow{2}{*}{ Casca } & 2,35 & 2,77 & 2,53 & $2,56 \pm 0,14$ \\
\hline & & & 2,54 & 2,62 & 2,53 & $(1,42)$ \\
\hline & & \multirow{2}{*}{ Polpa } & 0,055 & 0,070 & 0,045 & $0,06 \pm 0,009$ \\
\hline & & & 0,057 & 0,065 & 0,053 & $(1,90)$ \\
\hline \multirow{9}{*}{100} & \multirow{4}{*}{ A } & \multirow{2}{*}{ Casca } & 1,73 & 0,93 & 1,92 & $1,49 \pm 0,43$ \\
\hline & & & 1,89 & 1,45 & 1,03 & $(1,16)$ \\
\hline & & Polpa & 0,064 & 0,060 & 0,064 & $0,05 \pm 0,014$ \\
\hline & & & 0,034 & 0,041 & 0,039 & $(0,84)$ \\
\hline & & & & & & \\
\hline & & Casca & 1,89 & 2,11 & 2,09 & $2,04-0,12$ \\
\hline & B & & 1,89 & 2,17 & 2,08 & $(1,25)$ \\
\hline & & Polpa & 0,081 & 0,062 & 0,042 & $0,07 \pm 0,022$ \\
\hline & & & 0,046 & 0,070 & 0,10 & $(0,87)$ \\
\hline
\end{tabular}


Ambos os tratamentos tiveram quocientes de redução semelhantes entre dois levantamentos consecutivos, em todos os casos, o que indica não ser importante em cascas a quantidade inicial depositada como determinante da velocidade de desaparecimento dos resíduos de bromopropilato, concordando com GUNTHER (1969) no tocante ao desaparecimento dos resíduos seguirem uma reação cinética de primeira ordem.

o comportamento dos resíduos de bromopropilato em cascas (Figuras 14 e 15) evidenciou uma diminuição substancial do nível de depōsito deste produto durante as trēs primeiras semanas após a aplicação. Após este periodo, notou-se menores taxas de degradação dos residuos. De acordo com GUNTHER \& BLINN (1955) a curva representativa do comportamento inicial dos residuos de bromopropilato é a. curva de degradação, enquanto a referente a diminuição mais lenta é a curva de persistência. Segundo GUNTHER (1969) as Figuras 14 e 15 representam o comportamento básico de resíduos de inseticidas não-sistêmicos em cascas de citros.

Com base nos resultados obtidos, os valores de meia-vida de degradação foram de 19 e 21 dias e os de persistência foram de 83 e 89 dias, respectivamente para as dosagens de 1000 e $2000 \mathrm{~g}$ i.a./ha. Estes valores mostram que o bromopropilato persiste por um periodo de tempo maior que os estéres fosforados (GUNTHER, 1969). Os valores ob- 


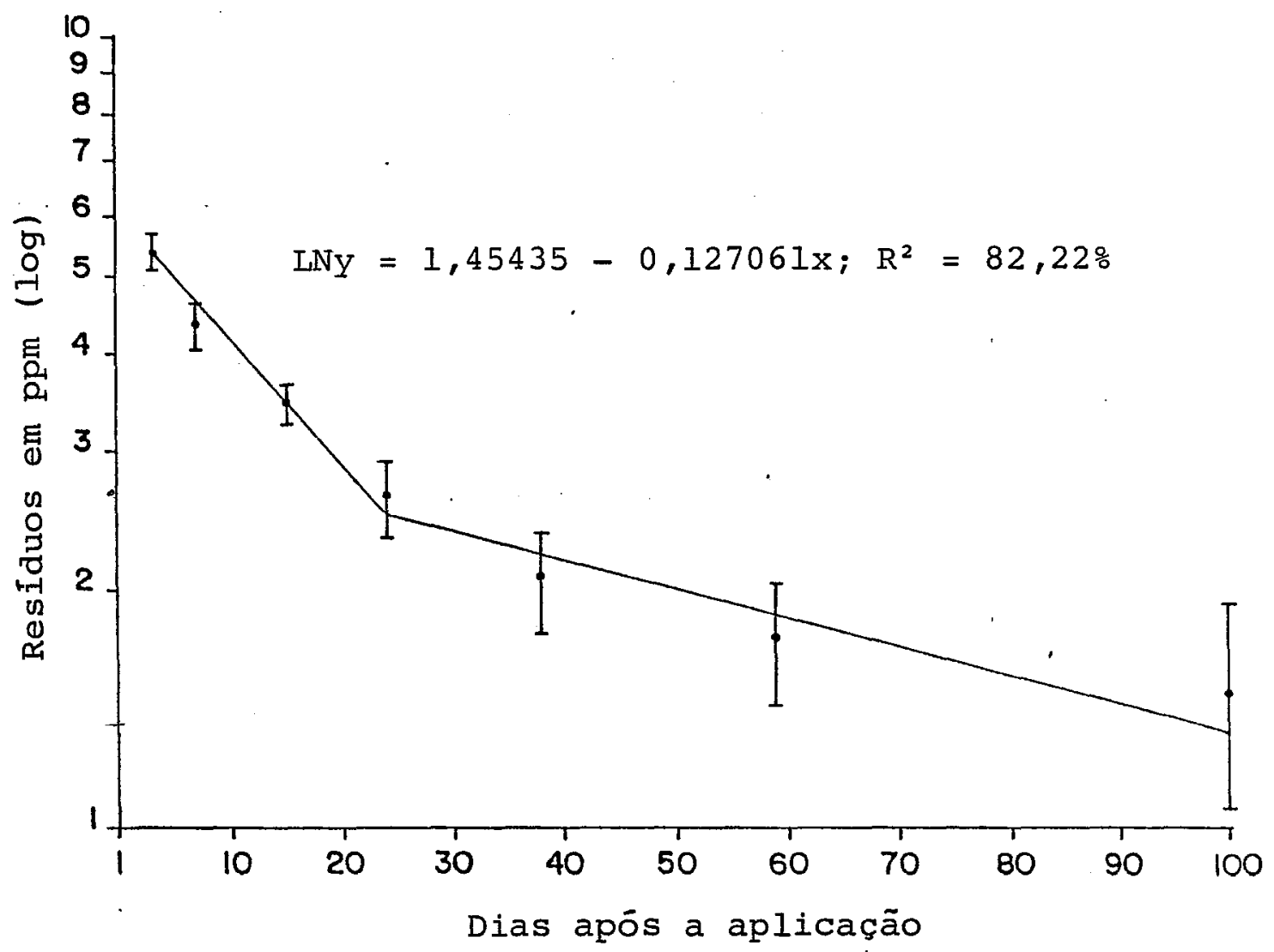

Figura 14: Curvas de degradação e persistência de resíduos de bromopropilato sobre e no interior de cascas de laranjas 'Valência', provenientes de plantas pulverizadas com $1000 \mathrm{~g}$ i.a./ha. 
75 .

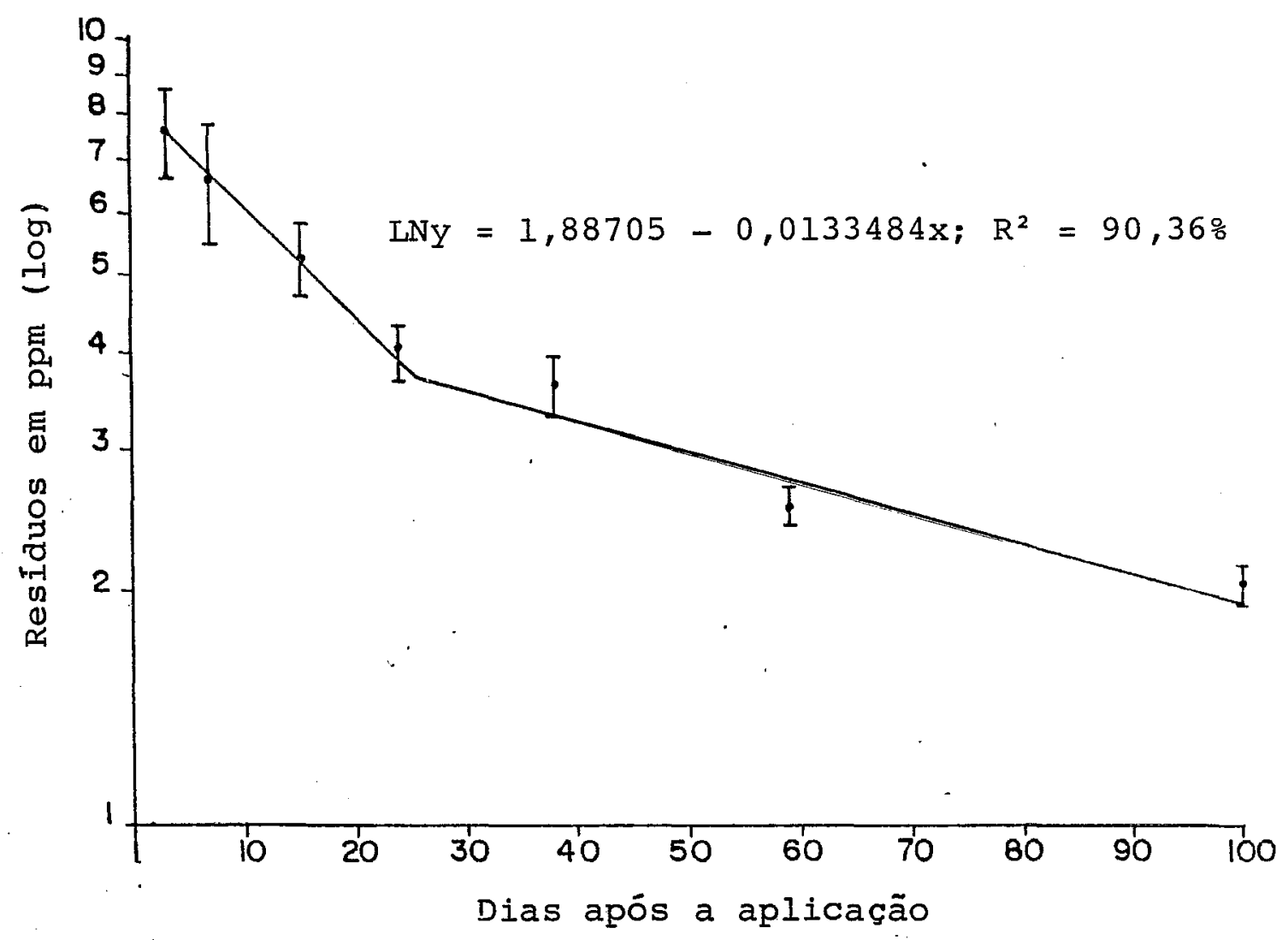

Figura 15: Curvas de degradação e persistēncia de resíduos de bromopropilato sobre e no interior de cascas de laranjas 'Valência', provenientes de plantas pulverizadas com $2000 \mathrm{~g}$ i.a./ha. 
tidos para a meia-vida de degradação se aproximam dos apresentados em WHO (1974), que é de 3 semanas (21 dias).

Baseando-se nas informações de cassidy ${ }^{1}$ citado pela WHO (1974), pode-se dizer que a diminuição nos níveis de residuos, verificada no presente trabalho, deveu-se principalmente aos fatores atmosfēricos, já que a diluição por crescimento não deve ser considerada, uma vez que o produto foi aplicado no início da maturação dos frutos.

Na polpa dos frutos detectou-se resíduos de bromopropilato durante todo o periodo estudado, sendo que suas variações foram de 0,03-0,12 ppm e 0,06 - 0,43 ppm para as dosagens de 1000 e 2000 g i.a./ha, respectivamente. Os niveis de residuos neste substrato aumentaram durante as sucessivas amostragens até atingirem valores máximos para o tratamento A (24 dias após a aplicação) e tratamento B (7 dias após a aplicação). Apōs estes períodos, os resíduos de ambas as dosagens apresentaram uma diminuição gradativa até o final do periodo estudado, quando atingiram valores semelhantes aos iniciais. Desta maneira, observa-se que houve penetração dos residuos de bromopropilato na polpa dos frutos, porém em níveis muito baixos, concordan-

1 CASSIDY, J.E. Progress report. Fate of 14C GS 19851 on apples. Unpublished report from Geigy Chemical Corporation, New York, 1967. 
do com wHo (1974) que menciona a ausência ou ocorrência de apenas traços de residuos neste substrato. Verifica-se assim que a casca exerce uma eficiente barreira contra a penetração dos resíauos de bromopropilato, fato este já constatado para outros produtos, GUNTHER et alii (1957), BLINN et alii (1959), GUNTHER et alii (1962), ANDERSON et alii (1963), GUNTHER (1969), WESTLAKE et alii (1971), DUPUIS (1975), RIGITANO (1979), CAMARGO (1980) e BERTOLOTI (1985). Como as tolerāncias para defensivos agrícolas em frutas citricas são estabelecidas com base na fruta toda (GUNTHER, 1969), os resíduos na variedade 'Valência' podem ser obtidos compondo-se-lhes a partir dos valores citados em IWATA (1977), para a participação porcentual de cascas e polpas. Desta maneira, verifica-se que as duas dosagens estudadas (1000 e $2000 \mathrm{~g}$ i.a./ha) apresentaram niveis de residuos inferiores a tolerância estabelecida pela legislação, que é de 5 ppm (BRASIL. Leis, decretos, etc., 1985), mesmo aos 2 dias após a aplicação. Certamente, a observação do período de carência $(21$ dias de acordo com BRASII. Leis, decretos, etc., 1985) resultará a ocorrência de niveis de residuos que torna o produto ainda mais seguro, desde que obedecida a boa prática agrícola. 
4.3. RESÍdUOS DE CLOROBENZILATO EM CASCAS E POLPAS DE LARANJAS. 'VALÊNCIA'

Os resultados obtidos nas anälises de frutos provenientes de plantas tratadas com clorobenzilato são apresentados na Tabela 7 e nas Figuras 16 e 17.

Observando-se os resultados apresentados na

Tabela 7, verifica-se que os níveis de residuos deste produto nas cascas dos frutos do tratamento B (1000 g i.a./ha) foram próximos aos dobro daqueles do tratamento A $\quad(500 \mathrm{~g}$ i.a./ha), em todas as amostragens.

Os quocientes de redução entre dois levantamentos consecutivos foram semelhantes em ambos os tratamentos, indicando desta maneira, que a quantidade inicialmente depositada não é importante na determinação da velocidade de desaparecimento dos residuos de clorobenzilato em cascas de laranja. Como já relatado para o bromopropilato, este comportamento segue uma reação cinética de primeira ordem (GUNTHER, 1969).

A diminuição dos níveis de residuos em função do tempo decorrido após a aplicação (Figuras 16 e 17) mostra que não é possível a distinção dos dois tipos de curvas, conforme verificado para o bromopropilato e sim a presença ūnica de uma curva de degradação (GUNTHER \& BLINN, 1955). Por outro Iado, GUNTHER (1969) encontrou comportamento semelhante ao encontrado no' presente trabalho, quando 
Tabela 7: Resíduos de clorobenzilato em cascas e polpas de laranjas 'Valência' provenientes de plantas pulverizadas com $500 \mathrm{~g}$ i.a./ha (tratamento A) e $1000 \mathrm{gi.a.} / \mathrm{ha}$ (tratamento B).

\begin{tabular}{|c|c|c|c|c|c|c|c|}
\hline \multirow{2}{*}{$\begin{array}{l}\text { Dias apōs a } \\
\text { aplicação }\end{array}$} & \multirow{2}{*}{ Tratamento } & & \multicolumn{4}{|c|}{ Repetição (ppm) } & \multirow{2}{*}{$\begin{array}{c}\text { Média (pprn) } \\
(m \pm d p)\end{array}$} \\
\hline & & & 1 & 2 & 3 & 4 & \\
\hline \multirow{7}{*}{3} & \multirow{4}{*}{ A } & \multirow[t]{2}{*}{ Casca } & 2,1 & 2,2 & 2,9 & 2,5 & \multirow[t]{2}{*}{$2,49 \pm 0,30$} \\
\hline & & & 2,2 & 2,5 & 2,8 & 2,7 & \\
\hline & & \multirow{2}{*}{ Polpa } & n.d. ${ }^{a}$ & $\mathrm{n} . \mathrm{d}$ & n.d. & n.d. & \multirow{5}{*}{$5,00 \pm 1,06$} \\
\hline & & & n.a. & n.d. & n.d. & n.d. & \\
\hline & \multirow{3}{*}{ B } & \multirow{2}{*}{ Casca } & 4,0 & 6,0 & 5,0 & 6,6 & \\
\hline & & & 3,5 & 4,2 & 5,1 & 5,6 & \\
\hline & & Polpa & $\begin{array}{l}\text { n.d. } \\
\text { n.d. }\end{array}$ & $\begin{array}{l}\text { n.d: } \\
\text { n.d. }\end{array}$ & $\begin{array}{l}\text { n.d. } \\
\text { n.d. }\end{array}$ & $\begin{array}{l}\text { n.d. } \\
\text { n.d. }\end{array}$ & \\
\hline \multirow{8}{*}{7} & \multirow{4}{*}{ A } & \multirow{2}{*}{ Casca } & 1,9 & 2,3 & 3,0 & 2,1 & \multirow{4}{*}{$\begin{array}{c}2,31 \pm 0,42 \\
(1,08)^{b}\end{array}$} \\
\hline & & & 2,0 & 2,3 & 2,9 & 2,0 & \\
\hline & & \multirow[t]{2}{*}{ Polpa } & n.d. & n.d. & n.d. & n.d. & \\
\hline & & & n.d. & n.d. & n.d. & n.d. & \\
\hline & \multirow{4}{*}{ в } & \multirow{2}{*}{ Casca } & 4,0 & 5,4 & 5,8 & 6,7 & \multirow{4}{*}{$\begin{array}{c}5,42 \pm 0,95 \\
(0,92)\end{array}$} \\
\hline & & & 4,5 & 4,7 & 6,3 & 6,0 & \\
\hline & & \multirow[t]{2}{*}{ Polpa } & n.d. & n.d. & n.d. & n.d. & \\
\hline & & & n.d. & n.d. & n.d. & n.d. & \\
\hline \multirow{9}{*}{15} & \multirow{4}{*}{ A } & \multirow{2}{*}{ Casca } & 2,2 & 2,4 & 2,3 & 2,0 & \multirow{4}{*}{$\begin{array}{c}2,22 \pm 0,20 \\
(1,04)\end{array}$} \\
\hline & & & 2,2 & 2,6 & 2,1 & 2,0 & \\
\hline & & \multirow{2}{*}{ Polpa } & n.d. & n.d. & n.d. & n.d. & \\
\hline & & & n.d. & n.d. & n.d. & n.d. & \\
\hline & \multirow{5}{*}{ B } & \multirow{3}{*}{ Casca } & 4.5 & 5,6 & 6,5 & 5,3 & \multirow{5}{*}{$\begin{array}{c}5,11 \pm 0,94 \\
(1,06)\end{array}$} \\
\hline & & & 3.6 & 5.8 & 4,2 & 5,4 & \\
\hline & & & & & & & \\
\hline & & \multirow{2}{*}{ Polpa } & n.d. & n.d. & n.d. & n.d. & \\
\hline & & & n.d. & n.d. & n.d. & n.d. & \\
\hline
\end{tabular}

(a) $\mathrm{n}$. d. = não detectável $(<0,1 \mathrm{ppm})$

(b) os números entre parēnteses indicam os quocientes de reduçäo entre duas coletas consecutivas 
Tabela 7: Continuação

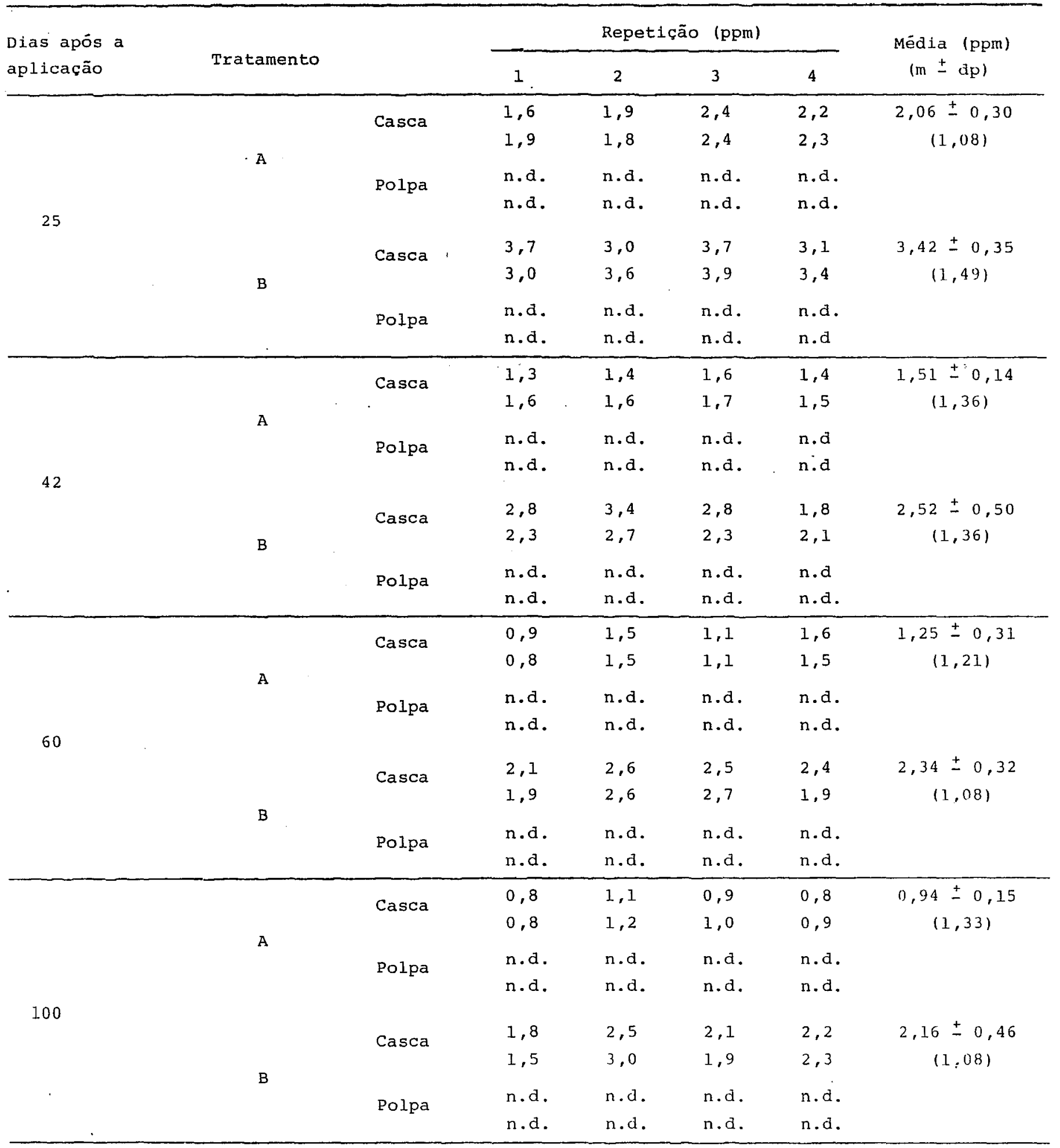


81.

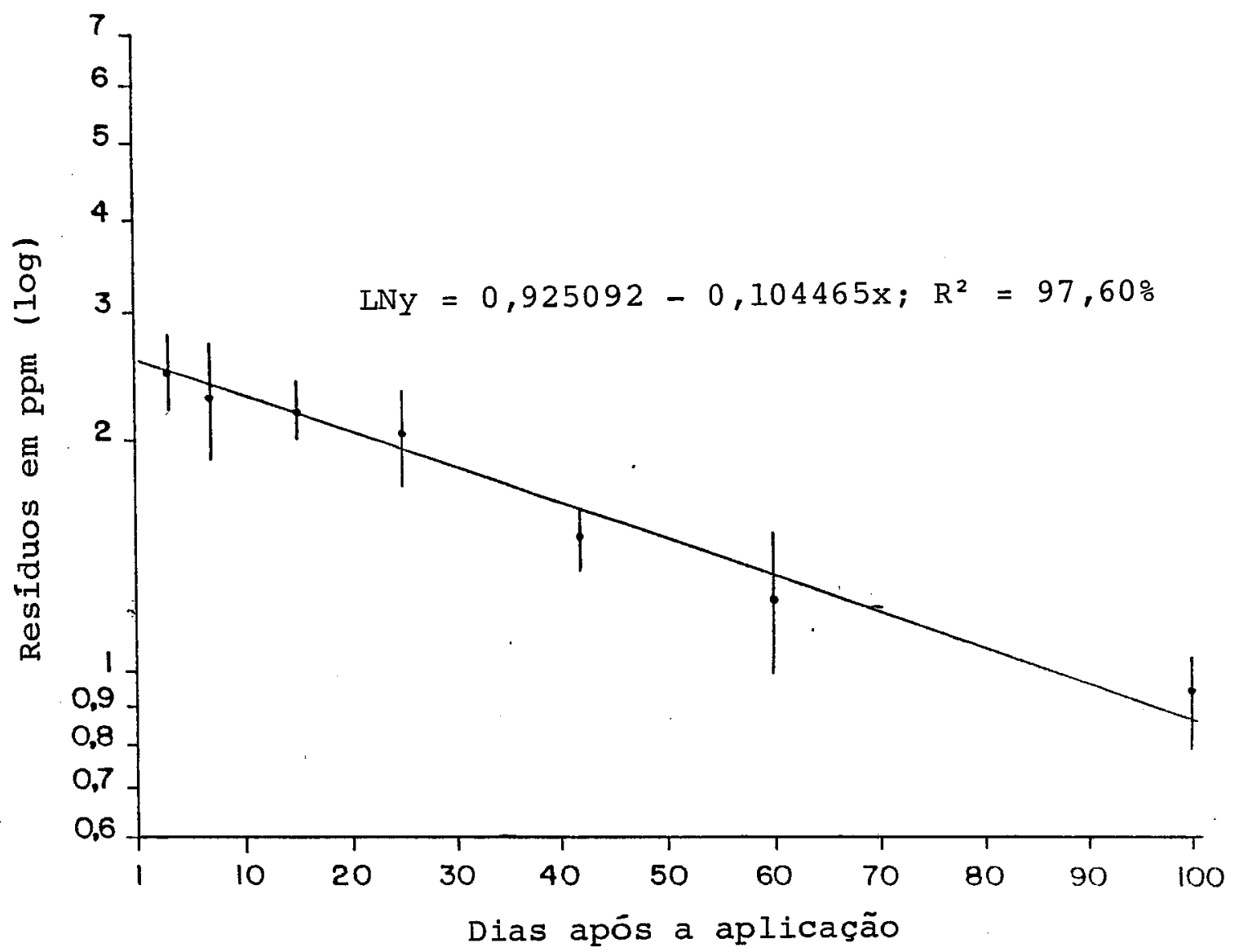

Figura 16: Curva de persistência de resíduos de clorobenzilato sobre e no interior de cascas de laranjas 'Valência', provenientes de plantas pulverizadas com $500 \mathrm{~g}$ i.a./ha. 


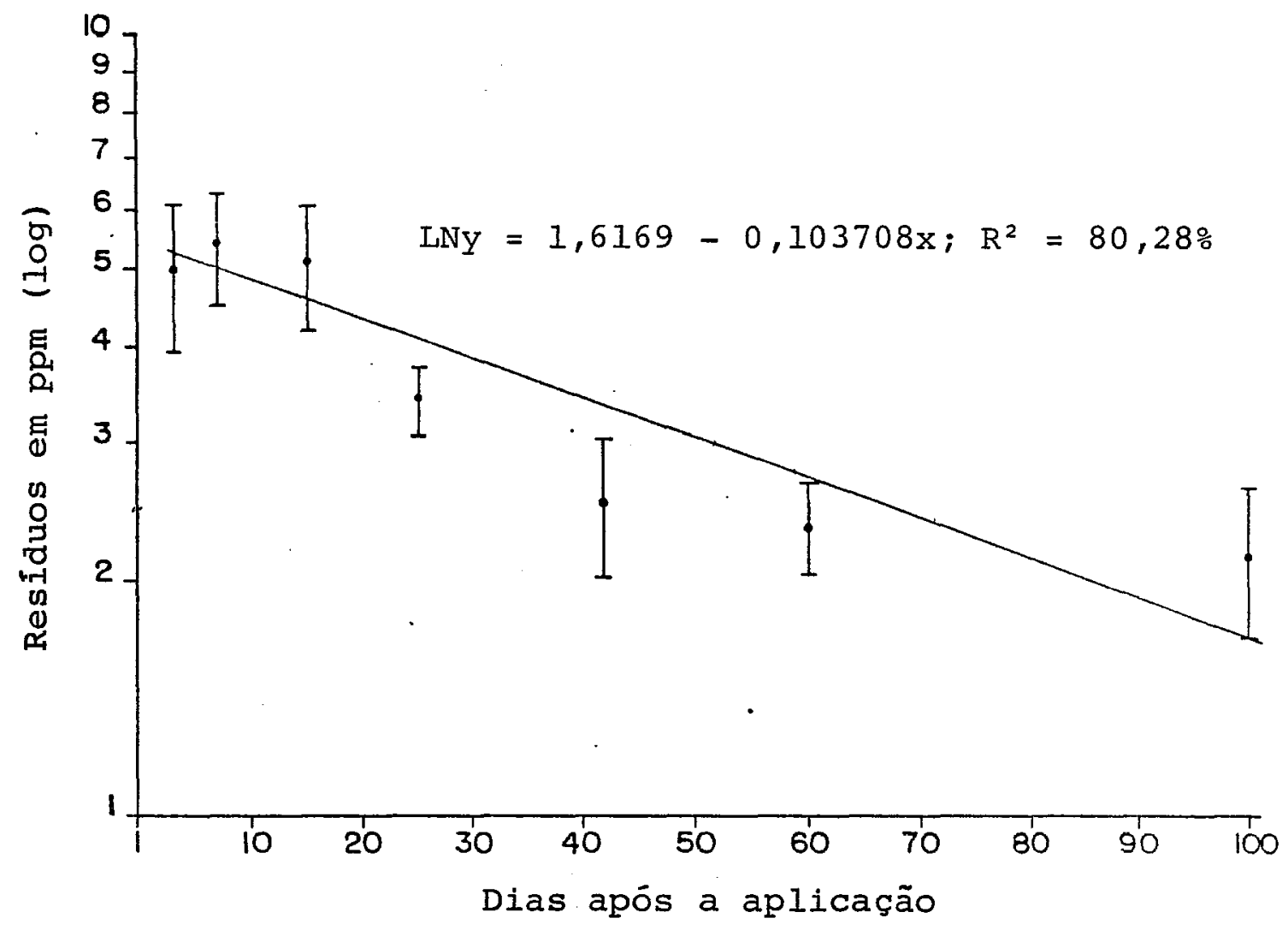

Figura 17: Curva de persistência de resíduos de clorobenzilato sobre e no interior de cascas de laranjas 'Valência', provenientes de plantas pulverizadas com $1000 \mathrm{~g}$ i.a./ha. 
analisou residuos de clorobenzilato em casca de limões 'Eureka', chamando esta curva de "curva de persistência".

Com base nas Figuras 16 e 17 , os valores determinados de meia-vida de persistência em cascas foram de 63 e 59 dias, respectivamente para 500 e 1000 g i.a./ha, confirmando a independência da velocidade de desaparecimento em relação a quantidade inicial depositada, pois aqueles valores revelaram-se muito próximos. Neste sentido, os valores obtidos na presente pesquisa estão praticamente dentro do intervalo estabelecido por GUNTHER et alii (1955) em cascas de limões (60 - 80 dias) e muito acima daquele citado por BARTSCH (1971) em cascas de lima (20 dias).

Na parte comestivel dos frutos (polpa) não houve deteção de resíduos $(0,1$ ppm) em quaisquer dos dias após a aplicação, indicando nenhuma ou talvez muito pouca (não detectável, abaixo de $0,1 \mathrm{ppm}$ ) penetração dos resíduos na polpa e que a casca funciona como barreira contra a penetração dos resíduos deste produto, fato este tambëm citado por BLINN et alii (1954), GUNTHER et alii (1955), BARTSCH et alii (I97I) e IWATA (1979).

Considerando que os limites de tolerância para defensivos agricolas em frutas cítricas são estabelecidas com base na fruta toda e que a variedade 'Valência' apresenta 19\% de casca e 81\% de polpa (IWATA, 1977), os residuos da fruta toda para fins de comparação com as tolerāncias oficiais, podem ser obtidos ponderando-se os valo- 
res de residuos encontrados nas cascas e nas polpas em função da participação porcentual de cada substrato. A secretaria Nacional de Vigilância Sanitária do Ministério da Saúde estabeleceu tolerāncia de 1 ppm de clorobenzilato na fruta toda e periodo de carência de 5 dias após a ültima aplicação (BRASIL. Leis, decretos, etc., 1985). Assim, pois, com base nos resultados obtidos na presente pesquisa, verifica-se que a boa prática agrícola, aliada a observação do período de carência conduz a níveis de resíduos satisfatórios e dentro dos limites estabelecidos pela legislação, pois para a dosagem de $500 \mathrm{~g}$ i.a./ha os níveis de residuos na fruta toda estiveram abaixo da tolerância desde a primeira avaliação ( 3 dias após a aplicação). No entanto, para a dosagem de $1000 \mathrm{~g}$ i.a./ha estes níveis estiveram próximos a tolerância nas três primeiras avaliações (3, 7 e 15 dias após a aplicação), apresentando em seguida uma diminuição significativa. Apesar de ser encontrado níveis de resíduos pouco acima da tolerância oficial até 7 dias após a aplicação, estes resíduos se restringiram às cascas e portanto, fora da parte comestivel dos frutos. No caso da utilização de cascas para a fabricação de ração para gado, deve-se considerar que ocorrem grandes perdas no processamento desse produto (GUNTHER, 1969). Além disso, ALBACH et alii (1976) observaram redução de 15\% nos resíduos de clorobenzilato presentes em frutos, que foram lavados, e de $81 \%$ em frutos lavados e processados em purê, 
mostrando assim a importância de se conhecer a localização dos residuos nas diversas partes dos frutos. 


\section{CONCLUSÕES}

A partir dos resultados obtidos na presente pesquisa, concluiu-se que:

A. o método de análise de resíduos, desenvolvido por RIBAS (1974), originalmente descrito para café, é altamente satisfatório para a análise de resíduos de bromopropilato e de clorobenzilato em cascas e polpas de laranjas, permitindo a deteç̧ão de 0,005 ppm de resíduos de bromopropilato e de 0,1 ppm de resíduos de clorobenzilato em ambos os substratos;

B. Os residuos de bromopropilato apresentam penetração na polpa dos frutos, porēm em níveis muito baixos, sendo que os de clorobenzilato não penetram ou penetram em quantidades inferiores ao limite de detecção do método analitico empregado, mostrando assim que a casca exerce um papel fundamental contra a penetração dos resíduos;

C. Os valores de meia-vida de degradação e de persistência de bromopropilato em cascas de laranjas 'Valência' são, respectivamente, de 19 e 83 dias para a dosagem de $1000 \mathrm{~g}$ i.a./ha e de 21 e 89 dias para a dosagem de $2000 \mathrm{~g}$ 
i.a./ha. Para o clorobenzilato a meia-vida de persistência em cascas é de 63 a 59 dias, respectivamente, para as dosagens de 500 e $1000 \mathrm{~g} \mathrm{i.a./ha;}$

D. Os residuos de bromopropilato foram inferiores a tolerância oficial (5 ppm) desde os três dias após a aplicação, para ambas as dosagens $(1000$ e $2000 \mathrm{~g}$ i.a./ha):

E. Os resíduos de clorobenzilato aos três dias após a aplicação foram inferiores a tolerāncia oficial (1 ppm) para a dosagem de $500 \mathrm{~g}$ i.a./ha e praticamente iguais a esta tolerāncia para dosagem de $1000 \mathrm{~g}$ i.a./ha. 
88.

\section{REFERÊNCIAS BIBLIOGRÁFICAS}

ALBACH, R.F. \& LIME, B.J. Pesticide residue reduction by the process of preparing whole oranges puree. Journal of Agricultural and Food Chemistry, Washington, 24 (6):1217$-20,1976$.

ANDERSON, C.A.; MAC DOUGALL, C.; KESTERSON, J.E.; HENDRICSON, T.; BROOKS, R.F. The effect of processing on Guthion residues in orange and orange products. Journal of Agricultural and Food Chemistry, Washington, 11 (5) :422-4, 1963 .

ASSOCIAÇÃO NACIONAL DE DEFENSIVOS AGRICOLAS - ANDEF. Residuos de defensivos em alimento/Avaliação toxicológica/ Estabelecimento de limites máximos permitidos de residuos (tolerâncias); Aditivos alimentares. In: CURSO SOBRE TOXICOLOGIA DE DEFENSIVOS AGRICỌLAS, 3, São Paulo, 1984. São Paulo. p.83-103. 
BARRY, H.C.; BURKE, J.A.; DUGGAN, R.E.; GAUL, J.A.; HUNDLEY, J.G.; JOHNSON, L.Y., Eds. Extraction and cleanup. In: - Pesticide analytical manual; methods which detect multiple residues. U.S. Department of Health, Education, and Welfare, 1968. v.1, chap. 2.

BARTSCH, E. Diazinon. II. Residues in plants, soil and water. Residue Reviews, New York, 51:37-68, 1974.

BARTSCH, E.; EBERLE, D.; RAMSTEINER, K.; TOMANN, A.; SPINLER, M. The carbinol acaricides: chlorobenzilate and chloropropilate. Residue Reviews, New York, 39:1-93, 1971 .

BATISTA, G.C. de; BOSCARIOL, I.R.; MACIEL, E.; CHIAVEGATO, L.G.; ZAMBOM, S. Distribuição de resíduos de aldicarb em limão siciliano determinados por cromatografia de gās. Anais da Sociedade Entomológica do Brasil, Jaboticabal, $14(2): 261-7,1985$.

BATISTA, G.C. de; BOSCARIOL, L.R.; RAETANO, C.G.; PAULO, A.D. Residuos de bifenthrin em laranja determinados por cromatografia gasosa. In: CONGRESSO BRASILEIRO DE ENTOMOLOGIA, 11, Campinas, 1987. Resumo. p.3. 
BATISTA, G.C. de; DORIZOTTO, P.H.; BOSCARIOL, L.R.; MARICONI, F.A.M.; FRANCO, J.F. Resíduos de aldicarb em laranjas Valência e Natal determinados por cromatografia de gās. Pesquisa Agropecuāria Brasileira, Brasilia, 2ll (6) :593-6, 1986 .

BERTOLOTI, L.M. Residuos de dialifos e dimetoato em cascas e polpas de laranjas Hamlin determinados por cromatografia gasosa. Piracicaba, 1985. 64p. (Mestrado-Escola Superior de Agricultura "Luiz de Queiroz"/USP).

BLINN, R.C.; CARMAN, G.E.; EWART, W.E.; GUNTHER, F.A. Residual behavior of various insecticides on and in lemons and oranges. Journal of Economic Encomology, College Park, $\underline{52}(1): 42-4,1959$.

BLINN, R.C.; GUNTHER, F.A.; KOLBEZEN, M.J. Microdetermination of the acaricide ethyl p,p'-dichlorobenzilate (Chlorobenzilate). Journal of Agricultural and Food Chemistry, Washington, $\underline{2}(21): 1080-3,1954$. 
BRASIL. Leis, decretos, etc. Portaria SNVS no 10 de 08 de março de 1985. Diărio Oficial, Brasilia, $14 \mathrm{mar} .1985$. Seção 1, p.4591-64l. Atribui à DINAL a compilação da relação de substâncias com ação tóxica sobre animais ou plantas, cujo registro pode ser autorizado no Brasil, em atividades agropecuárias e em produtos domissanitários e determina outras providências.

CAETANO, A.A. \& PRATES, H.S. Controle do ácaro da falsa ferrugem dos citros - Phyllocoptruta oleivora (Ashm, 1879) com novos acaricidas. In: CONGRESSO BRASILEIRO DE ENTOMOLOGIA, 7, Fortaleza, 1981. Resumo. p.176.

CAMARGO, J.L.G. de. Resíduos de carbophenotion e phenthoate em cascas e polpas de laranjas Hamlin determinados por cromatografia em fase gasosa. Piracicaba, 1980. 78p. (Mestrado - Escola Superior de Agricultura "Luiz de Queiroz"/USP) .

CULLEN, T.E.; KAHRS, R.A.; MATTSON, A.M.; MURPHY, R.T. The determination of residues of acarol (isopropyl 4,4'-dibromobenzilate) by gas chromatography. American ChemiCal Society, (156), 1968. (Abstracts paper AGFD). 
DUPUIS, G. Pesticide residues in citrus. In: CIBA GEIGY AGROCHEMICALS. Citrus - Technical Monography, Suiça, 1975. no $4, \mathrm{p} .81-8$.

EBELING, W. Analysis of the basic process involved in the deposition, degradation, persistance, and effectiveness of pesticides. Residue Reviews, New York, 3:35-163, 1963.

ELZAWA, J.Y. \& OLIVEIRA, C.A.L. de. Avaliação da ação acaricida de diversos produtos no controle do ácaro da leprose e B.phoenicis em citros. In: CONGRESSO BRASILEIRO DE ENTOMOLOGIA, 11, Campinas, 1987. Resumo. p.15.

FRENCH, J.V. \& DUBE, D.A. Aerial application for rust mite control on Texas citrus. Apud Horticultural Abstracts, Farnham Royal, $\underline{48}(6): 531,1978$. (Resumo).

FUNDAÇÃo GETÚLIO VARGAS. Laranja. Agroanalysis, Rio de Janeiro, $\underline{12}(2): 28-33,1988$.

GALLO, D. ; NAKANO, O.; SILVEIRA NETO, S.; CARVALHO, R.P.L.; BATISTA, G.C. de; BERTI FILHO, E.; PARRA, J.R.P.; ZUCCHI, R.A.; ALVES, S.B. Manual de Entomologia Agrícola. São Paulo, Agronômica Ceres, 1978. 531 p. 
GUNTHER, F.A. Insecticides residues in California citrus fruits and products. Residue Reviews, New York, 28 127,1969 .

GUNTHER, F.A. \& BLINN, R.C. Analysis of insecticides and acaricides. New York, Interscience, 1955. 696p.

GUNTHER, F.A. \& BLINN, R.C. Persisting residues in plant materials. Annals of Review Entomology, Stanford, 1 : 167-80, 1956 .

GUNTHER, F.A.; BLINN, R.C.; CARMAN, G.E. Residues of Sevin on and in lemons and oranges. Journal of Agricultural and Food Chemistry, Washington, 10:222-3, 1962 .

GUNTHER, F.A.; BLINN, R.C.; JEPPSON; L.R.; BARKLEY, J.H.; FRISONE, G.J.; GARMUS, R.D. Field persistence of the acaricide 4,4'-dichloro-alpha -(trichloromethyl) - benzhydrol (FW-293) on and in mature lemons and oranges. Journal of Agricultural and Food Chemistry, Washington, $\underline{5}(8): 595-8,1957$. 
GUNTHER, F.A.; CARMAN, G.E.; BLINN, R.C.; BARKLEY, J.H. Persistence of residues of Guthion on and in mature lemons and oranges and in laboratory processed citrus "pulp" cattle feed. Journal of Agricultural and Food Chemistry, Washington, 11:424-7, 1963.

GUNTHER, F.A.; EWART, W.H.; BLINN, R.C.; ELMER, H.S.; WACKER, G.B. Field persistence comparisons of residues of the insecticide, Diazinon, in lemons and Valēncia oranges and effects on juice flavor. Journal of Agricultural and Food Chemistry, Washington, $\underline{6}(7): 521-3,1958$.

GUNTHER, F.A.; IWATA, Y.; CARMAN, G.E.; SMITH, C.A. The citrus reentry problem: research on its causes and efects, and approaches to its minimization. Residue Reviews, New York, $67: 1,1977$.

GUNTHER, F.A. \& JEPPSON, L.R. Residues of p-chlorophenyl-p-chlorobenzene-sulfonate (Compound k-6451) on and in lemons and oranges. Journal of Economic Entomology, College Park, 47:1027-32, 1954. 
GUNTHER, F.A.; JEPPSON, L.R.; BARKLEY, J.H.; ELLIOTT, L.M. ; BLINN, R.C.; DUNN, C.L. Persistence of residues of 2,3-p-dioxane-dithiol S,S-bis $(0,0-$ diethyl) phosphorodithioate) as an acaricide on and in mature lemons and oranges. Journal of Agricultural and Food Chemistry, Washington, $6(3): 210-1,1958 a$.

GUNTHER, F.A.; JEPPSON, L.R.; WACKER, G.B. Persistence of chlorobenzilate residues in mature lemon fruits. Journal of Economic Entomology, College Park, $48(4): 372-4$, 1955 .

IWATA, Y. Minimizing occupational exposure to pesticides, Reentry field date - A recapitulation. Residue Reviews, New York, $\underline{75}: 127-47,1980$.

IWATA, Y.; CARMAN, G.E.; GUNTHER, F.A. Warker environment research: methidathion applied to orange trees. Journal of Agricultural and Food Chemistry, Washington, 27 (1) :119-29, 1979 .

IWATA, Y.; DUSCH, M.E.; CARMAN, G.E.; GUNTHER, F.A. Worker environment research: residues from carbaryl, chlorobenzilate, dimethoate and trichorfon applied to citrus trees. Journal of Agricultural and Food Chemistry, Washington, $27(6): 1141-5,1979$. 
IWATA, Y.; WESTLAKE, W.E.; BARKLEY, J.H.; CARMAN, G.E.; GUNTHER, F.A. Behavior of phenthoate (Cidial) deposits and residues on and in grape fruits, lemons and leaves, oranges and oranges leaves, and in the soil, beneath orange trees. Journal of Agricultural and Food Chemistry, washington, $\underline{25}(2): 362-8,1977$.

JEPPSON, L.R. \& GUNTHER, F.A. Acaricide residues on citrus foliage and fruits and their biological significance. Residue Reviews, New York, 33:101-36, 1970.

KESTERSON, J.W. \& BRADDOCK, R.J. Citrus fruit processing. In: CIBA GEIGY AGROCHEMICALS. Citrus - Technical Monography, Suiça, 1975. no 4, p.75-80.

KHAN, S.V. Bound pesticide residues in soil and plants. Residue Reviews, New York, 84:1-25, 1982.

MARICONI, F.A.M.; MOTTA, R.; SILVA, J.M.; TAKAOKA, M.; RAIZER, A.J.; SUGAHARA, C.A.; KATO, W.Y. Eficiēncia no combate ao äcaro da falsa ferrugem dos citros Phyllocoptruta oleivora (Ashmead, 1879). In: CONGRESSO BRASILEIRO DE ENTOMOLOGIA, 10, Rio de Janeiro, 1986. Resumo. p.318. 
MULLA, M.S.; MIAN, L.S.; KAWECKI, J.A. Distribution, transport, and fate of the insecticides malathion and parathion in the environment. Residue Reviews, New York, $81: 1-48,1981$.

MYAZAKY, I.; SUPLICY FILHO, N.; SAMPAIO, A.A. Comportamento do ácaro da leprose dos citros, Brevipalpus phoenicis (Geijskes, 1939), sob ação de acaricidas. o Biológico, São Paulo, $\underline{48}(1): 21-4,1982$.

NAKANO, O.; SILVEIRA NETO, S.; BATISTA, G.C. de; YOKOYAMA, M.; DEGASPARI, N.; MARCHINI, I.C.. Manual de inseticidas dicionário. São Paulo, Agronōmica Ceres, 1977. 272p.

NIGG, H.N.; ALLEN, J.C.; KING. R.W. Behavior of parathion residues in the Florida "Valência" orange agroecosystem. Journal of Agricultural and Food Chemistry, washington, $27(3): 578-82,1979$.

OLIVEIRA, C.A.L. de. Acaricidas no controle do ácaro da leprose Brevipalpus phoenicis (Geijskes, 1939) (Acari-Tenuipalpidae) na cultura de citros. In: CONGRESSO BRASILEIRO DE ENTOMOLOGIA, 10, Rio de Janeiro, 1986. Resumo. p. 338 . 
OLIVEIRA, C.A.L. de \& FERNANDES, M.A.F. Acaricidas no controle do Phyllocoptruta oleivara (Ashmead, 1879) e Brevipalpus phoenicis (Geijskes, 1939) na cultura de citros. Ecossistema, Espirito Santo do Pinhal, 8:120-7, 1983.

RIBAS, D. Método rápido para determinação de resíduos de inseticidas clorados em café. In: CONGRESSO BRASILEIRO SOBRE PESQUISAS CAFEEIRAS, 2, POços de Caldas, 1974. Resumo. p. 368-9.

RIGITANO, R.L. de O. Residuos de ethion e fenitrothion em cascas e polpas de laranjas Hamlin determinados por cromatografia em fase gasosa. Piracicaba, 1979. 64p. (Mestrado - Escola Superior de Agricultura "Luiz de Queiroz"/USP).

RODRIGUES, J.C.; TAVARES, S.; CARVALHO, J.C.; CORTE, C.R.; FEKETE, T.J.; MARICONI, F.A.M. Pulverização de laranjeiras, contra o "ácaro da falsa ferrugem" Phyllocoptruta (oleivora Cashm., 1879). In: CONGRESSO BRASILEIRO DE ENTOMOLOGIA, 7, Fortaleza, 1981. Resumo. p.186.

ROSSETO, J.; CAETANO, A.A.; PRATES, h.S. Controle do ácaro da leprose, Brevipalpus phoenicis (Geijskes, 1939) empomar citrico, com novos acaricidas. In: CONGRESSO BRASILEIRO DE ENTOMOLOGIA, 7, Fortaleza, 1981. Resumo. p.178. 
ROUCHAUD, J. \& MEYER, J.A. New trends in the studies about the metabolism of pesticides in plants. Residue Reviews, New York, $82: 1-35,1982$.

SPENCER, W.F. \& CLIATH, M.M. Measurement of pesticide vapor pressores: Residue Reviews, New York, 85:57-69, 1983.

SPENCER, W.F.; FARMER, W.J.; CLIATH, M.M. PEsticide volatilization. Residue Reviews, New York, 49:1-47, 1973.

SWIRSKI, E.; DORZIA, N.; AMITAI, S.; GREENBERG, S. Trials on the control of the citrus rust mite (Phyllocoptruta oleivora Ashm.) with four pesticides, and on their toxicity to predaceous mites (Acarina:Phytoseiidae). Israel Journal of Entomology, Tel Laviv, $\underline{4}: 145-55,1969$.

VAN DYK, I.P. The persistence of some pesticides on South African citrus. Apud Chemical Abstracts, Columbus, 85 (13): 156, 1975. (Resumo).

VASCONCELOS, H. de O.; FERREIRA, M.S.; CRUZ, C. de A. da; OLIVEIRA, A.M. de; UNGARO, M.T.S.; GUINDAN, C.M.A. Níveis residuais de inseticidas sistêmicos granulados de solo em frutos de laranja Natal (Citrus sinensis I. Osbeck). Anais da Sociedade Entomológica do Brasil, Jaboticabal, $12(1): 11-6,1983$. 
VIACAVA, C. Mercado interno e externo de suco citrico. Laranja, Cordeirópolis, $\underline{2}(8): 541-9,1987$.

WESTLAKE, W.E.; DUSCH, M.E.; GUNTHER, F.A.; JEPPSON, J.R. Persistence of 0,0-dietyl S-(2 chloro - 1 - phthalimidoethyl) - phosphoro dithiote (Torak) on and in lemons and dried citrus pulp cattle feed, and toxicity of the residues to mites. Journal of Agricultural and Food Chemistry, Washington, $19(6): 1191-5,1971$.

WESTLAKE, W.E.; GUNTHER, F.A.; CARMAN, G.E. Worker enviroment research: dioxathion (Delnav) residues on and in orange fruits and leaves, in dislodgable particulate matter, and in the soil beneath sprayed trees. Archives of Environmental Contamination and Toxicology, New York, $\underline{1}(1): 60-80,1973$.

WESTLAKE, W.E.; GUNTHER, F.A.; JEPPSON, L.R. Persistence of Azodrin residues on and in Valência oranges and in laboratory - processed citrus pulp cattle feed. Journal of Agricultural and Food Chemistry, Washington, 18 (5):864-5, 1970 . 
WESTLAKE, W.E.; GUNTHER, F.A.; JEPPSON, L.R. Persistence of omite residues on and in Navel oranges and lemons and in laboratory - processed citrus pulp cattle feed. Journal of Agricultural and Food Chemistry, Washington, 19 (5) : 894-6, 1971a.
WESTLAKE, W.E.; O'NEAL, J.R.; GUNTHER, F.A.; CARMAN, G.E. Persistence of the insecticide acaricide phosalone on and in oranges and in laboratory processed citrus pulp cattle feed. Journal of Agricultural and Food Che- mistry, Washington, $20(1): 161-5,1972$.

WORLD HEALTH ORGANIZATION - WHO. Bromopropylate. In: WHO. Evaluation of some pesticide residues in food, Geneva, 1974. p.62-91. (WHO Pesticide Residue Series, 3). 